University of Rhode Island

DigitalCommons@URI

Open Access Dissertations

2015

\title{
An Investigation of the Interactions Between Escherichia coli and the Intestinal Microbiota In Vivo and In Vitro
}

Matthew E. Mokszycki

University of Rhode Island, mattm413@gmail.com

Follow this and additional works at: https://digitalcommons.uri.edu/oa_diss

\section{Recommended Citation}

Mokszycki, Matthew E., "An Investigation of the Interactions Between Escherichia coli and the Intestinal Microbiota In Vivo and In Vitro" (2015). Open Access Dissertations. Paper 393.

https://digitalcommons.uri.edu/oa_diss/393

This Dissertation is brought to you for free and open access by DigitalCommons@URI. It has been accepted for inclusion in Open Access Dissertations by an authorized administrator of DigitalCommons@URI. For more information, please contact digitalcommons-group@uri.edu. 


\section{AN INVESTIGATION OF THE INTERACTIONS BETWEEN ESCHERICHIA COLI AND THE INTESTINAL MICROBIOTA IN VIVO AND IN VITRO \\ BY \\ MATTHEW E MOKSZYCKI}

A DISSERTATION SUBMITTED IN PARTIAL FULFILLMENT OF THE REQUIREMENTS FOR THE DEGREE OF

DOCTOR OF PHILOSOPHY

IN

CELL AND MOLECULAR BIOLOGY

UNIVERSITY OF RHODE ISLAND

2015 


\section{DOCTOR OF PHILOSOPHY DISSERTATION}

OF

MATTHEW E MOKSZYCKI

\section{APPROVED:}

Thesis Committee:

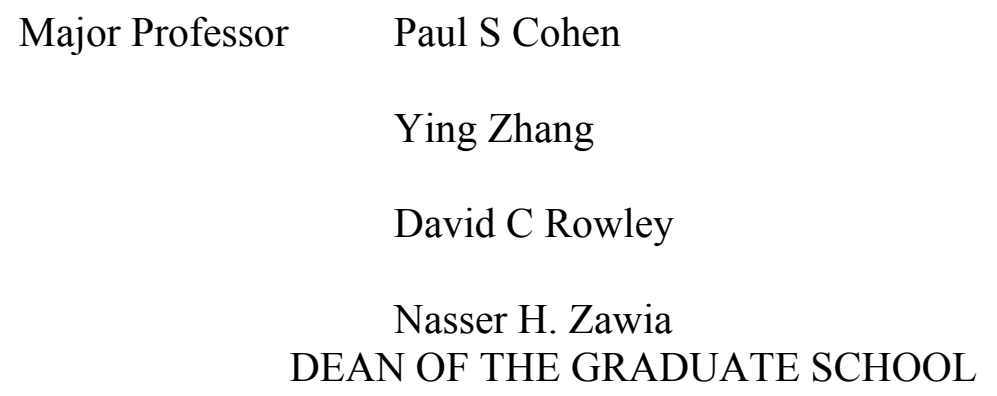

UNIVERSITY OF RHODE ISLAND

2015 


\begin{abstract}
We previously proposed that colonizing strains of E. coli likely occupy specific niches as minimal members of mixed biofilms formed primarily by anaerobic members of the gut flora. These "restaurants" formed by the different community members of the gut provide individual strains of $E$. coli with various unique binding pockets and locally provided mono- and disaccharides by breaking down polysaccharides which facultative anaerobes, such as E. coli, could not break down on their own. This allows strains of E. coli that cannot grow as efficiently on available sugars to colonize if they are able to occupy niches that other competing strains could not. For example, if the less efficient strain could bind better to specific anaerobic members or had a higher tolerance for bile salts it would be able to co-colonize with a strain that could grow better on available sugars as it would not be in direct competition to occupy the same niche. While the anaerobes in mixed biofilms provide a source of nutrients for minimal members such as $E$. coli through breakdown of large polysaccharides, the facultative anaerobes may improve the environment for strict anaerobes by reducing the concentration of oxygen within the biofilms. Oxygen diffuses from surrounding tissue into the intestines, oxygen from swallowed air is present in flatus, and at least one predominant anaerobe in the gut microbiome, Bacteroides fragilis, respires oxygen at low concentrations. As such, manuscript I looks at how colonization with specific strains of $E$. coli can affect the development of the intestinal microbiota. Five representative $E$. coli strains were used for this study: Nissle 1917, EDL933, MG1655, and two MG1655 mutants selected by the mouse gut $\left(e n v Z_{\mathrm{P} 41 \mathrm{~L}}\right.$ and $\left.f l h D C\right)$. While slight variances were observed between strains, these
\end{abstract}


were likely due to differences between hosts rather than the colonizing E. coli and no significant differences between the communities could be surmised.

In order to better understand the interactions between E. coli and the members of the intestinal microbiota, a novel in vitro method was developed. Manuscript II examines the development of the in vitro system as it was compared to the mouse model. This method was designed to be simple and inexpensive while providing an environment meant to replicate the natural habitat of these organisms: the mammalian gut. The current study examines the development of said in vitro model and its ability to mimic the mouse gut in terms of diversity of organisms, as well as its usefulness in examining the colonizing ability of competing $E$. coli strains. It is shown that, while still in development, this system is currently able to maintain diversity comparable to what is seen in mice. While the abundance of these diverse organisms is not necessarily at the levels seen in mice, the model is already an effective system for studying the microbial community of the gut in a controlled environment. Furthermore, the system is able to mimic certain colonization experiments of competing E. coli strains done in mice, and with improvements to bolster the growth of the diverse population could be used as a non-invasive method for studying gut microbes. 


\section{ACKNOWLEDGMENTS}

First and foremost I would like to thank Dr. Paul S Cohen, my mentor over the past 6 years. Not only did he provide me with support and guidance during my studies, but also believed in my abilities as a scientist throughout. I have learned so much from him, and am a better researcher because of it.

I would also like to thank Mrs. Mary P Leatham-Jenkins for teaching me so many skills in the laboratory, and constantly pushing me to do my best. She was always available to help if I needed it, and sometimes before I even realized I did. Thanks for everything Mary.

I would like to thank Dr. Ying Zhang for all of her guidance with the MiSeq data and Mothur pipeline. Thank you for convincing me that such a mountain of data could be made manageable.

I also thank Jimmy Adediran and Jon L Steffensen, both of whom helped tremendously with the work presented in this thesis. I would not have been able to test as many strains as I did were it not for Jimmy's help and without Jon's skills I could not have done so much work with the community analysis data. I sincerely appreciate the help both of you provided.

I wish also to thank all other members of the Cohen lab, past and present, who have conducted some of the experiments that appear in this thesis. Thank you for making this all possible.

I thank all of the faculty members who served on my committee, thank you for helping me get so far. I also thank the rest of the faculty members of the Department 
of Cell and Molecular Biology at the University of Rhode Island for teaching me so much and continuing to offer guidance outside of the classroom.

A special thanks to Janet Atoyan and Paul Johnson of the RI Genomics and Sequencing center for all of their help with sequencing and the scope.

Thanks to all the other students, graduate and undergraduate, that helped me during my time here.

Finally, I would like to express my gratitude to my parents and brothers (blood and fraternal) for always believing that I was capable of achieving this.

This research is based in part upon work conducted using the Rhode Island Genomics and Sequencing Center which is supported in part by the National Science Foundation under EPSCoR Grants Nos. 0554548 \& EPS-1004057. 


\section{PREFACE}

This dissertation has been prepared in the Manuscript Format according to the guidelines of the Graduate School of the University of Rhode Island with the style presented in the American Society for Microbiology journal, Infection and Immunity. The dissertation includes an introduction and the following two manuscripts:

The first manuscript: "Analysis of how Different Strains of Escherichia coli Affect Development of the Intestinal Microbiota"

The second manuscript: "Developing an In Vitro Method for Studying the Interaction between E. coli and the Intestinal Microbiota" 


\section{TABLE OF CONTENTS}

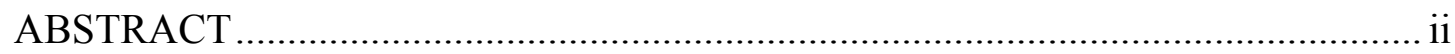

ACKNOWLEDGMENTS ………………………………............................. iv

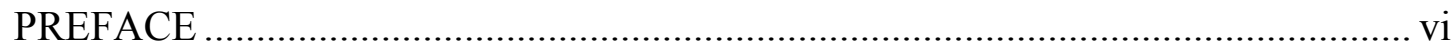

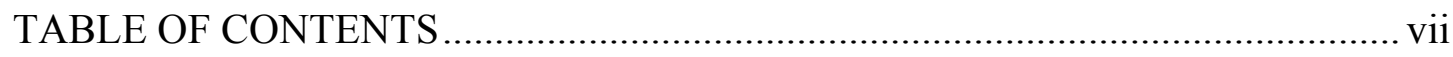

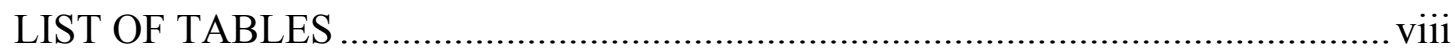

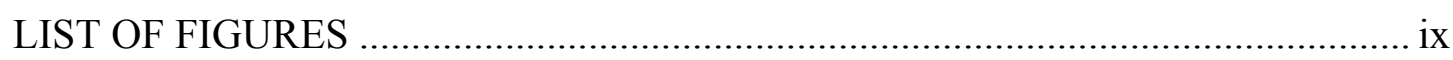

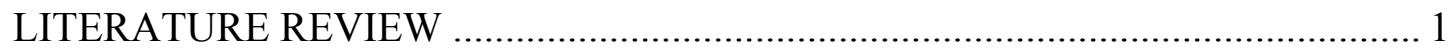

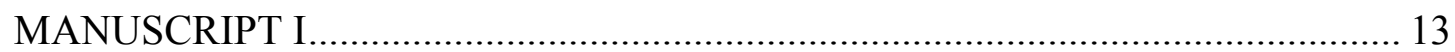

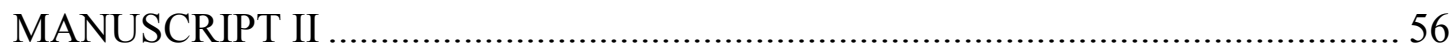




\section{LIST OF TABLES}

TABLE

PAGE

\section{MANUSCRIPT I}

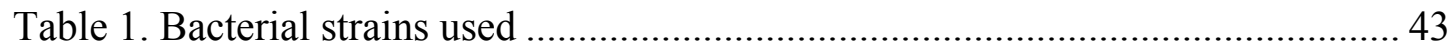

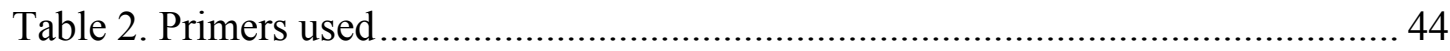

\section{MANUSCRIPT II}

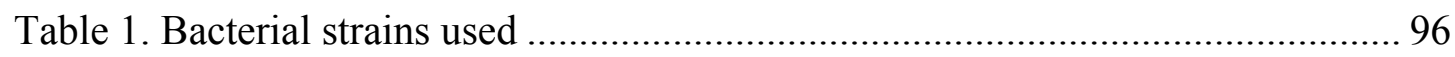

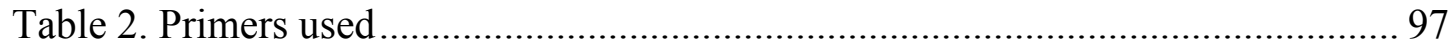




\section{LIST OF FIGURES}

FIGURE

PAGE

\section{MANUSCRIPT I}

Figure 1. Single strain of $E$. coli colonizations.

Figure 2. FISH image of E. coli EDL933. 46

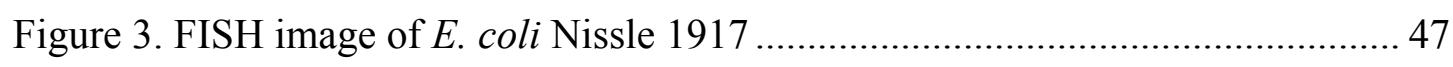

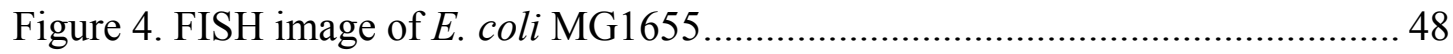

Figure 5. FISH image of E. coli MG1655 flhDC ................................................ 49

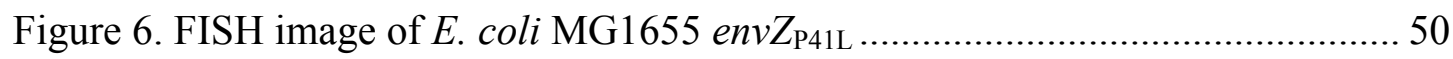

Figure 7. FISH image of streptomycin treated control ....................................... 51

Figure 8. Bar plot showing relative abundance of major phyla by treatment ............ 52

Figure 9. Bar plot showing relative abundance of major families by treatment ......... 53

Figure 10. Bar plot showing relative abundance of major phyla increased samples .. 54

Figure 11. Bar plot showing relative abundance of major families increased samples55

$$
\text { MANUSCRIPT II }
$$

Figure 1. FISH images of early in vitro system day 0 samples .............................. 98

Figure 2. FISH images of early in vitro system day 3 samples ............................. 99

Figure 3. FISH images of in vitro system with $500 \mathrm{ug} / \mathrm{ml}$ mucin day 5 and 6 samples

Figure 4. FISH images of in vitro system with and without $0.3 \%$ agarose day 6

samples.

Figure 5. FISH image of in vitro system with precolonized E. coli day 7 samples.. 102 


\section{MANUSCRIPT II}

Figure 6. Comparison of FISH images from in vivo sample day 10 Nissle 1917 colonized mouse and in vitro system precolonized with Nissle 1917 day 7 sample 103 Figure 7. FISH images of in vitro system without mucin or without Cleland's reagent day 7 samples 104

Figure 8. FISH images of in vitro system with no mucus or $0.2 \mathrm{mg} / \mathrm{ml}$ mucus day 7 samples 105

Figure 9. Bar plot showing relative abundance of major families for Nissle 1917 in vivo and in vitro samples. 106

Figure 10. Stacked bar plot showing relative abundance of major families for Nissle 1917 in vivo and in vitro samples. 107

Figure 11. Bar plot showing relative abundance of major phyla for Nissle 1917 in vivo and in vitro samples 108

Figure 12. Stacked bar plot showing relative abundance of major phyla for Nissle 1917 in vivo and in vitro samples

Figure 13. Crude rarefaction curves of Nissle 1917 in vivo and in vitro samples .... 110 Figure 14. FISH images of an in vitro sample in which the cecal mucus of an untreated “conventional" mouse was collected day 7 sample ...... 111 Figure 15. Bar plot showing relative abundance of major families for "conventional" in vivo and in vitro samples. 


\section{MANUSCRIPT II}

Figure 16. Stacked bar plot showing relative abundance of major families for "conventional" in vivo and in vitro samples

Figure 17. Bar plot showing relative abundance of major phyla for "conventional" in vivo and in vitro samples.

Figure 18. Stacked bar plot showing relative abundance of major phyla for "conventional" in vivo and in vitro samples

Figure 19. Crude rarefaction curves of "conventional" in vivo and in vitro samples 116

Figure 20. Competition experiments of Nissle 1917 early vs Nissle 1917 late 117

Figure 21. Competition experiments of MG1655 early vs MG1655 late 118

Figure 22. Competition experiments of Nissle 1917 early vs MG1655 late. 119

Figure 23. Competition experiments of MG1655 early vs Nissle 1917 late 120

Figure 24. Competition experiments of Nissle 1917 early vs EDL933 wildtype and EDL933 pckA-ppsA- late 121

Figure 25. Competition experiments of EDL933 wildtype vs EDL933 pckA-ppsA- 122 


\section{LITERATURE REVIEW}

\section{Introduction}

The human intestinal tract is known to maintain a diverse population of microorganisms represented by both anaerobic and facultative anaerobic species (10). It is well known that commensal strains of $E$. coli colonize as a minority member of these communities as a facultative anaerobe (22). Commensal strains include organisms that naturally inhabit a host organism's body without causing harm, and in some cases even providing the host with a particular advantage (21). In contrast, a pathogenic strain is usually an invasive organism that may be of the same species, such as E. coli EDL933, but disease is caused rather than a harmless coexistence (21).

\section{From ingestion to colonization}

When a host ingests $E$. coli from the environment the $E$. coli must be able to pass the acid barrier of the stomach, as well as be able to attain the nutrients necessary to begin logarithmic growth. As stationary phase bacteria are acid-tolerant (14), as few as $10 \mathrm{E}$. coli cells can lead to transmission (24). In order to exit lag phase and begin logarithmic growth upon reaching the colon, E. coli must compete for nutrients with a dense community (15), be able to penetrate into the mucus layer (31), and grow rapidly enough to make up for the constant turnover of the mucus layer (37) all while avoiding host defenses $(7,29)$. When successful in colonizing the colon, some E. coli cells are still removed with the turnover of mucus. These cells are able to re-enter the environment where they can be ingested by the next host, and thus spread and continue to exist $(34,35)$. 


\section{Basic principles of colonization}

According to Freter's nutrient-niche hypothesis, colonizing strains can coexist as long as they are able to outcompete one another on one or more sugars, or are able to bind to the intestinal wall. Thus if two strains (X and $\mathrm{Y}$ ) are in direct competition and $(\mathrm{X})$ can utilize all sugars better than $(\mathrm{Y})$, then the less efficient strain $(\mathrm{Y})$ cannot co-colonize (11). This hypothesis assumes that all available nutrients are homogenized, or equally mixed, throughout the intestine (15). As such, a diverse and stable community would hinder invading species and prevent them from colonizing. This ability to prevent invasion from outside species is called "colonization resistance" (41). Even with this in mind, E. coli strains can coexist due to diverse strategies for the utilization of limited nutrients within the colon.

\section{Central metabolism and intestinal colonization}

E. coli is a Gram-negative, prototrophic, facultative anaerobe. While E. coli grows best on sugars it cannot grow on larger polysaccharides, as it does not have the enzymes available to do so (12). It can also grow on substrates that feed into the TCA cycle, which require gluconeogenesis to metabolize. Other important central metabolism pathways in E. coli include the Embden-Meyerhof-Parnas glycolytic pathway (EMP), the pentose phosphate pathway (PP), the Entner-Duodoroff pathway (ED), and many fermentation pathways all of which are highly conserved (9).

\section{Catabolic pathway diversity in $E$. coli}

While the central metabolism genes are highly conserved across strains of $E$. coli, there is variation between strains in terms of the catabolic pathways that feed into these core central metabolism pathways $(9,32)$. In other words, some E. coli strains 
have different preferences in terms of growth on sugars or other substrates. It has been shown that while E. coli strains have similar catabolic potential, the sugars each strain uses to support their colonization differs significantly $(5,8,12,20,28,30,39)$.

\section{Nutrient availability in the intestine}

Mucus in the gut exists in two forms, the loose layer and the firm layer (19). The loose mucus layer is where most of the microbiota of the gut grow and form their biofilms, while the firm mucus layer resides closer to the epithelial layer of the intestines and prevents direct interaction of the commensal microbiota with host epithelium (19). The mucus itself consists of a large mixture of molecules, including but not limited to amino acids, large polysaccharides, mono- and disaccharides, and mucin (4). This mixture exists as a viscous liquid in which the microbes are suspended and in which form biofilms. This environment is mostly anaerobic, with minimal oxygen leaking from epithelial cells of the intestine $(6,16,18,23)$. Mucin is a glycoprotein with large polysaccharide strands with which the anaerobe populations of the gut can attach and form biofilms around (2). The biofilms formed by these anaerobes can break down the large polysaccharides of the mucus, and parts of the mucin, thus providing facultatives with usable mono- and disaccharides in bulk which would usually be limited $(22,33,40)$. This gives facultatives, such as $E$. coli, a reason for joining as minimal members in these anaerobe-formed biofilms, and perhaps even promoting the growth of preferential anaerobes that provide specific mono- and disaccharides (18). The facultatives that join these mixed biofilms likely provide the anaerobes with protection from the minimal amount of oxygen that is released from the epithelial tissue of the gut. 


\section{Competition for limited nutrients in the intestine}

In order to compete for limiting resources in the intestine, E. coli is able to expand their transcriptome in order to induce a broad set of gene systems used for carbon-source transport and catabolism (17). Additionally, it has been shown that glycogen stores are used for survival during times of carbon limitation and are also important for colonizing E. coli strains when colonizing the intestine (20). By expanding the gene systems used for carbon-source transport and catabolism, E. coli is able to use a diverse set of sugars and can use nutrients that are available which no other member of the microbiota has used. A specific E. coli strain can also outcompete other strains by growing faster on the available nutrients (13). Furthermore, if an E. coli strain is being outcompeted for its preferred nutrients it will activate other mechanisms in which it is no longer in direct competition (i.e. switching to use other available sugars or pathways such as gluconeogenesis) $(3,5,28,38)$. Finally, if a strain is able to enter a niche in which it forms a symbiotic relationship (i.e. in a mixed anaerobic biofilm) that provides its preferred sugar(s), it will be able to colonize away from direct competition with faster growing strains $(1,22)$.

\section{Biofilms in the intestine}

It has been shown that biofilms form in the mucus layers of the large intestines of healthy mammals $(25,26,33,40)$. Furthermore, biofilms containing Bacteroides, Enterobacter, and Clostridia species found in the intestine can form rapidly on mucin in continuous flow culture systems developed to mimic the human intestine (27), thus being able to develop faster than the flow of mucus (36). Recent studies of these bacterial biofilms in the intestines have shown that anaerobes form dense biofilms 
with E.coli as a minority member (22). These biofilms form around intestinal mucin and break down large polysaccharides, such as fiber, that cannot usually be utilized by facultative anaerobes $(22,33,40)$. Differences in the population of anaerobes within mixed biofilms would thus provide $E$. coli with various niches based on nutrients made available by the anaerobes preferred metabolic pathways.

\section{The "restaurant" hypothesis}

Our laboratory previously proposed an adjustment to the Freter's hypothesis which states that the mono- and disaccharides that E. coli strains use for growth in the intestine are made available locally from polysaccharide degradation by the anaerobes in the mixed biofilms that the E.coli inhabit, rather than evenly mixed throughout the intestine. Furthermore, if one strain can bind better to the anaerobes in the mixed biofilms, the colonization ability of this strain would be improved. Recent studies of bacterial biofilms in the intestines have shown that anaerobes form dense biofilms with E.coli as a minority member (22). These biofilms form around intestinal mucin and break down large polysaccharides, such as fiber, that cannot usually be utilized by facultative anaerobes $(22,33,40)$. Differences in the population of anaerobes within mixed biofilms would thus provide $E$. coli with various niches based on nutrients made available by the anaerobes preferred metabolic pathways.

While the anaerobes in mixed biofilms provide a source of nutrients for minimal members such as E. coli through breakdown of large polysaccharides, the facultative anaerobes may improve the environment for strict anaerobes by reducing

the concentration of oxygen within the biofilms. Oxygen diffuses from surrounding tissue into the intestines, oxygen from swallowed air is present in flatus, and at least 
one predominant anaerobe in the gut microbiome, Bacteroides fragilis, respires oxygen at low concentrations $(6,16,18,23)$. It has been shown that respiration in $E$. coli provides an important competitive edge when colonizing the intestine of streptomycin-treated mice. Mutants of ATP synthase or cytochrome $b d$ oxidase, both necessary for respiration, showed a significant loss in colonizing ability when colonized against wild type of the same strain (18). Since E. coli uses oxygen as the final electron-acceptor in respiration, the oxygen concentration within the intestine will be lower in the presence of E. coli.

\section{Conclusions}

While E. coli is only a minimal member of a large and dense microbial community found within the gut, it is still able to colonize and compete with such diversity even when co-colonized with other strains of E. coli. It is likely that the relationships formed by colonizing $E$. coli strains within dense anaerobe-formed biofilms help develop unique niches not only for the $E$. coli, but also for the anaerobes that are in direct interaction with them. Understanding how such a minor member is able to overcome such complexity, as well as the effects on the community it causes, is key to identifying mechanisms utilized by commensal and pathogenic bacteria to invade and colonize new hosts. As such, this thesis aims to identify the effects of colonization by various strains of $E$. coli and the effects they have on the overall intestinal microbiota. Furthermore, the development of a novel in vitro system used to aid in further understanding these relationships is discussed. 


\section{$\underline{\text { References }}$}

1. Adediran J, Leatham-Jensen MP, Mokszycki ME, Frimodt-Møller J, Krogfelt KA, Kazmierczak K, Kenney LJ, Conway T, Cohen PS. 2014. An Escherichia coli Nissle 1917 missense mutant colonizes the streptomycin treated mouse intestine better than the wild type but is not a better probiotic. Infect Immun 82:670-682.

2. Allen A. 1984. The structure and function of gastrointestinal mucus, p 3-11. In Boedeker EC (ed), Attachment of organisms to the gut mucosa, vol II. CRC Press, Boca Raton, FL.

3. Alteri CJ, Smith SN, Mobley HL. 2009. Fitness of Escherichia coli during urinary tract infection requires gluconeogenesis and the TCA cycle. PLoS Pathog 5:e1000448. 4. Atuma C, Strugala V, Allen A, Holm L. 2001. The adherent gastrointestinal mucus gel layer: thickness and physical state in vivo. Am J Physiol Gastrointest Liver Physiol 280:G922-929.

5. Autieri SM, Lins JJ, Leatham MP, Laux DC, Conway T, Cohen PS. 2007. L-fucose stimulates utilization of D-ribose by Escherichia coli MG1655 $\triangle$ fucAO and E. coli Nissle $1917 \triangle f u c A O$ mutants in the mouse intestine and in M9 minimal medium. Infect Immun 75:5465-5475.

6. Baughn, A. D., and M. H. Malamy. 2004. The strict anaerobe Bacteroides fragilis grows in and benefits from nanomolar concentrations of oxygen. Nature 427:441-444. 7. Bergstrom KS, Sham HP, Zarepour M, Vallance BA. 2012. Innate host responses to enteric bacterial pathogens: a balancing act between resistance and tolerance. Cell Microbiol 14:475-484. 
8. Chang DE, Smalley DJ, Tucker DL, Leatham MP, Norris WE, Stevenson SJ, Anderson AB, Grissom JE, Laux DC, Cohen PS, Conway T. 2004. Carbon nutrition of Escherichia coli in the mouse intestine. Proc Natl Acad Sci U S A 101:7427-7432.

9. Cook H, Ussery DW. 2013. Sigma factors in a thousand E. coli genomes. Environ Microbiol 15:3121-3129.

10. Dethlefsen L, S. Huse , M. L. Sogin, and D. A. Relman. 2008. The pervasive effects of an antibiotic on the human gut microbiota, as revealed by deep 16S rRNA sequencing. PLoS Biol. 6:2383-2400.

11. Egger, L. A., H. Park, and M. Inouye. 1997. Signal transduction via the histidyaspartyl phosphorelay. Genes Cells 2:167-184.

12. Fabich AJ, Jones SA, Chowdhury FZ, Cernosek A, Anderson A, Smalley D, McHargue JW, Hightower GA, Smith JT, Autieri SM, Leatham MP, Lins JJ, Allen RL, Laux DC, Cohen PS, Conway T. 2008. Comparison of carbon nutrition for pathogenic and commensal Escherichia coli strains in the mouse intestine. Infect Immun 76:1143-1152.

13. Fabich AJ, Leatham MP, Grissom JE, Wiley G, Lai H, Najar F, Roe BA, Cohen PS, Conway T. 2011. Genotype and phenotypes of an intestine-adapted Escherichia coli K-12 mutant selected by animal passage for superior colonization. Infect Immun 79:2430-2439.

14. Foster JW. 2004. Escherichia coli acid resistance: tales of an amateur acidophile. Nat Rev Microbiol 2:898-907. 
15. Freter, R., H. Brickner, J. Fekete, M. M. Vickerman, and K. E. Carey. 1983. Survival and implantation of Escherichia coli in the intestinal tract. Infect. Immun. 39:686-703.

16. He, G., R. A. Shankar, M. Chzhan, A. Samouilov, P. Kuppusamy, and J. L. Zweier. 1999. Noninvasive measurement of anatomic structure and intraluminal oxygenation in the gastrointestinal tract of living mice with spatial and spectral EPR imaging. Proc. Natl. Acad. Sci. USA 96:4586-4591.

17. Ihssen J, Egli T. 2005. Global physiological analysis of carbon- and energy-limited growing Escherichia coli confirms a high degree of catabolic flexibility and preparedness for mixed substrate utilization. Environ Microbiol 7:1568-1581.

18. Jones, S. A., F. Z. Chowdhury, A. J. Fabich, A. Anderson, D. M. Schreiner, A. L. House, S. M. Autieri, M. P. Leatham, J. L. Lins, M. Jorgensen, P. S. Cohen, and T. Conway. 2007. Respiration of Escherichia coli in the mouse intestine. Infec. And Imm. 75: 4891-4899.

19. Johansson ME, Larsson JM, Hansson GC. 2011. The two mucus layers of colon are organized by the MUC2 mucin, whereas the outer layer is a legislator of hostmicrobial interactions. Proc Natl Acad Sci USA 108 (Suppl 1):4659-4665.

20. Jones SA, Jorgensen M, Chowdhury FZ, Rodgers R, Hartline J, Leatham MP, Struve C, Krogfelt KA, Cohen PS, Conway T. 2008. Glycogen and maltose utilization by Escherichia coli O157:H7 in the mouse intestine. Infect Immun 76:2531-2540.

21. Leatham, M. P., S. Banerjee, S. M. Autieri, R. Mercado-Lubo, T. Conway, and P. S. Cohen. 2009. Precolonized human commensal Escherichia coli strains serve as a 
barrier to E. coli $\mathrm{O} 157: \mathrm{H} 7$ growth in the streptomycin-treated mouse intestine. Infect. Immun. 77:2876-2886.

22. Leatham-Jensen, M. P., J. Frimodt-Møller, J. Adediran, M. E. Mokszycki, M. E. Banner, J. E. Caughron, K. A. Krogfelt, T. Conway, P. S. Cohen. 2012. The streptomycin-treated mouse intestine selects Escherichia coli envZ missense mutants that interact with a dense and diverse intestinal microbiota. Infec. Immun. 80: 17161727.

23. Levitt, M. D., and J. H. Bond. 1980. Flatulence. Annu. Rev. Med. 31:127-137.

24. Lin J, Smith MP, Chapin KC, Baik HS, Bennett GN, Foster JW. 1996. Mechanisms of acid resistance in enterohemorrhagic Escherichia coli. Appl Environ Microbiol 62:3094-3100.

25. Macfarlane S. 2008. Microbial biofilm communities in the gastrointestinal tract. J Clin Gastroenterol 42(Suppl 3 Pt 1):S142-143.

26. Macfarlane S, Bahrami B, Macfarlane GT. 2011. Mucosal biofilm communities in the human intestinal tract. Adv ApplMicrobiol 75:111-143.

27. Macfarlane S, Woodmansey EJ, Macfarlane GT. 2005. Colonization of mucin by human intestinal bacteria and establishment of biofilm communities in a two-stage continuous culture system. Appl Environ Microbiol 71:7483-7492.

28. Maltby R, Leatham-Jensen MP, Gibson T, Cohen PS, Conway T. 2013. Nutritional basis for colonization resistance by human commensal Escherichia coli strains HS and Nissle 1917 against E. coli O157:H7 in the mouse intestine. PLoS One 8:e53957. 
29. McGuckin MA, Lindén SK, Sutton P, Florin TH. 2011. Mucin dynamics and enteric pathogens. Nat Rev Microbiol 9:265-278.

30. Miranda RL, Conway T, Leatham MP, Chang DE, Norris WE, Allen JH, Stevenson SJ, Laux DC, Cohen PS. 2004. Glycolytic and gluconeogenic growth of Escherichia coli O157:H7 (EDL933) and E. coli K-12 (MG1655) in the mouse intestine. Infect Immun 72:1666-1676.

31. Moller AK, Leatham MP, Conway T, Nuijten PJ, de Haan LA, Krogfelt KA, Cohen PS. 2003. An Escherichia coli MG1655 lipopolysaccharide deep-rough core mutant grows and survives in mouse cecal mucus but fails to colonize the mouse large intestine. Infect Immun 71:2142-2152.

32. Monk JM, Charusanti P, Aziz RK, Lerman JA, Premyodhin N, Orth JD, Feist AM, Palsson ВØ. 2013. Genome-scale metabolic reconstructions of multiple Escherichia coli strains highlight strain-specific adaptations to nutritional environments. Proc Natl Acad Sci U S A 110: 20338-20343.

33. Palestrant, D., Z. E. Holzknecht, B. H. Collins, W. Parker, S. E. Miller, and R. R. Bollinger. 2004. Microbial biofilms in the gut: visualization by electron microscopy and by acridine orange staining. Ultrastruct. Pathol. 28:23-27.

34. Poulsen LK, Lan F, Kristensen CS, Hobolth P, Molin S, Krogfelt KA. 1994. Spatial distribution of Escherichia coli in the mouse large intestine inferred from rRNA in situ hybridization. Infect Immun 62:5191-5194.

35. Poulsen LK, Licht TR, Rang C, Krogfelt KA, Molin S. 1995. Physiological state of Escherichia coli BJ4 growing in the large intestines of streptomycin-treated mice. J Bacteriol 177:5840-5845. 
36. Pratt LA, Kolter R. 1998. Genetic analysis of Escherichia coli biofilm formation: roles of flagella, motility, chemotaxis and type I pili. Mol Microbiol 30:285-293.

37. Rang CU, Licht TR, Midtvedt T, Conway PL, Chao L, Krogfelt KA, Cohen PS, Molin S. 1999. Estimation of growth rates of Escherichia coli BJ4 in streptomycintreated and previously germfree mice by in situ rRNA hybridization. Clin Diagn Lab Immunol 6:434-436.

38. Schinner SA, Mokszycki ME, Adediran J, Leatham-Jensen M, Conway T, Cohen PS. 2015. Escherichia coli EDL933 Requires Gluconeogenic Nutrients To Successfully Colonize the Intestines of Streptomycin- Treated Mice Precolonized with E. coli Nissle 1917. Infect Immun 83: 1983-1991.

39. Sweeney NJ, Laux DC, Cohen PS. 1996. Escherichia coli F-18 and E. coli K-12 eda mutants do not colonize the streptomycin-treated mouse large intestine. Infect Immun 64:3504-3511.

40. Swidsinski, A., J. Weber, V. Loening-Baucke, L. P. Hale, and H. Lochs. 2005. Spatial organization and composition of the mucosal flora in patients with inflammatory bowel disease. J. Clin. Microbiol. 43:3380-3389.

41. van der Waaij D, Berghuis-de Vries JM, Lekkerkerk-k-v. 1971. Colonization resistance of the digestive tract in conventional and antibiotic treated mice. J Hyg (Lond) 69:405-411. 


\section{MANUSCRIPT I}

Publication status: To be submitted to the American Society for Microbiology journal, Infection and Immunity, 2016.

Title: Analysis of how Different Strains of Escherichia coli Affect Development of the Intestinal Microbiota

Authors: Matthew E Mokszycki ${ }^{1}$, Jimmy Adediran ${ }^{1}$, Jon L Steffensen ${ }^{1}$, Mary P

Leatham-Jenkins ${ }^{1}$, Ying Zhang ${ }^{1}$, Karen A Krogfelt ${ }^{2}$, Tyrrell Conway ${ }^{3}$, and Paul S Cohen $^{1 *}$

Affiliation: ${ }^{1}$ Department of Cell and Molecular Biology, University of Rhode Island, Kingston, Rhode Island, USA

${ }^{2}$ Department for Infection and Microbiology Control, Statens Serum Institut, Copenhagen S, Denmark

${ }^{3}$ Department of Microbiology and Plant Biology, University of Oklahoma, Norman, Oklahoma, USA

*Corresponding Authors: Paul S Cohen, Department of Cell and Molecular Biology, 120 Flagg Rd., University of Rhode Island, Kingston, RI 02881, USA;

E-mail: pco1697u@uri.edu, 1-401-874-5920 


\title{
MANUSCRIPT I
}

Analysis of how Different Strains of Escherichia coli Affect Development of the Intestinal Microbiota

\begin{abstract}
We previously proposed that colonizing strains of $E$. coli likely occupy specific niches as minimal members of mixed biofilms formed primarily by anaerobic members of the gut flora. These "restaurants" formed by the different community members of the gut provide individual strains of $E$. coli with various unique binding pockets and locally provide mono- and disaccharides. This allows strains of E. coli that cannot grow as efficiently on available sugars to colonize if they are able to occupy niches that other competing strains could not. For example, if the less efficient strain could bind better to specific anaerobic members or had a higher tolerance for bile salts it would be able to co-colonize with a strain that could grow better on available sugars as it would not be in direct competition to occupy the same niche. As such, this study looks at how colonization with specific strains of E. coli can affect the development of the intestinal microbiota. Five representative E. coli strains were used for this study: Nissle 1917, EDL933, MG1655, and two MG1655 mutants selected by the mouse gut $\left(e n v Z_{\mathrm{P} 41 \mathrm{~L}}\right.$ and $\left.f l h D C\right)$. While slight variances were observed between strains, these were likely due to differences between hosts rather than the colonizing E. coli and no significant differences between the communities could be surmised.
\end{abstract}




\section{Introduction}

The human intestinal tract is known to maintain a diverse population of microorganisms represented by both anaerobic and facultative anaerobic species (11, 12). It is well known that commensal strains of $E$. coli colonize as a minority member of these communities as a facultative anaerobe (27). Commensal strains include organisms that naturally inhabit a host organism's body without causing harm, and in some cases even providing the host with a particular advantage (25). In contrast, a pathogenic strain is usually an invasive organism that may be of the same species, such as E. coli EDL933, but disease is caused rather than a harmless coexistence (25).

To prevent infection by pathogens, probiotic strains that block or reduce the colonizing ability of pathogenic strains can be used, such as E. coli Nissle 1917 (25). Once colonized, a probiotic strain will fill the niche normally used by the pathogenic strain, preventing the pathogen from settling in. According to Freter's nutrient-niche hypothesis, colonizing strains can coexist as long as they are able to outcompete one another on one or more sugars, or are able to bind to the intestinal wall. Thus if two strains $(\mathrm{X}$ and $\mathrm{Y})$ are in direct competition and $(\mathrm{X})$ can utilize all sugars better than (Y), then the less efficient strain (Y) cannot co-colonize (15). This hypothesis assumes that all available nutrients are homogenized, or equally mixed, throughout the intestine (15).

In order to compare the colonization ability of strains, mice are often used as a model system. In order to test E.coli strains within animal models, the niches that are already filled by normal flora must be cleared. If this is not done, any attempts at colonization will fail, as the niches are filled by other facultative anaerobes (8). There 
are currently two accepted models for testing the colonization ability of commensal strains in mice; the germ-free mouse model and the streptomycin treated mouse model $(9,24)$. In germ-free mice, no microbiota are present. This allows colonization to occur, but removes any relationships with anaerobes normally present as part of the microbiome (19). The streptomycin-treated mouse model does leave much of the population intact, while still clearing the facultative anaerobe population for colonization to occur. In this way the streptomycin-treated mouse model is superior, as relationships between anaerobes and the facultative anaerobes being tested are kept mostly intact (19).

E. coli strain MG1655 is a common laboratory strain used to test colonization ability. When colonized by said strain, the intestine selects for mutants with improved colonization ability. These include a non-motile strain with a deletion in the $f \operatorname{lh} D C$ region, and a motile strain with a missense mutation in the envZ gene $(16,26,27)$. The $f l h D C$ operon is responsible for making the $\mathrm{FlhD}_{4} \mathrm{C}_{2}$ complex, which activates transcription of class II flagellar genes and represses a number of metabolic genes, including those involving sugar catabolism $(14,43,44)$. The deletion in the flhDC region removes the ability to produce this regulatory complex and has been shown to improve growth when compared to the parent MG1655 in vitro on cecal mucus and other available carbon sources normally found within the intestine $(16,26)$. The envZ gene codes for the transmembrane osmolarity sensor protein EnvZ, a histidine kinase that acts on the OmpR regulatory protein as both a kinase and a phosphatase. OmpRphosphate regulates a number of genes including: $o m p C$, ompF, the sRNAs $o m r A$ and $o m r B$, and $f l h D C(13)$. The envZ missense mutant selected by the intestine, a P41L 
mutant (ccg to tcg), reduces the phosphatase activity of EnvZ which results in a higher concentration of OmpR-phosphate (27). In vitro the envZ missense mutation, hereafter called env $Z_{\mathrm{P} 41 \mathrm{~L}}$, results in a faster growth rate on several sugars relative to the parent MG1655 strain, and a slower growth rate relative to the flhDC deletion mutant on almost all sugars. However, when grown in vitro on galactose, the env $Z_{\mathrm{P} 41 \mathrm{~L}}$ strain is far superior to both the parent MG1655 and flhDC deletion strains (27).

The MG1655 env $Z_{\mathrm{P} 41 \mathrm{~L}}$ missense mutant strain was recently shown to have improved colonization ability against the parent MG1655 strain and colonized as well as the MG1655 flhDC deletion mutant (27). In accordance with Freter's hypothesis, the env $Z_{\mathrm{P} 41 \mathrm{~L}}$ and $f l h D C$ mutants should be able to co-colonize as both are able to grow well on different sugars and as such are not in direct competition. As expected, when both strains are simultaneously fed to mice in the same nubers (ie. $10^{5} \mathrm{CFU}$ per mouse) these mutant strains grow up to $10^{9} \mathrm{CFU} /$ gram of feces and co-colonize equally well thereafter. Also, when $10^{10} \mathrm{CFU}$ of the $f l h D C$ mutant is fed to mice along with $10^{5} \mathrm{CFU}$ of the env $Z_{\mathrm{P} 41 \mathrm{~L}}$ mutant, the env $Z_{\mathrm{P} 41 \mathrm{~L}}$ mutant is able to grow up in the intestine and almost reach the level of the $f l h D C$ mutant (21). This again agrees with Freter's hypothesis, as the strains are not in direct competition for sugars. However, when the $10^{5} \mathrm{CFU}$ of the flhDC mutant is fed to mice along with $10^{10} \mathrm{CFU}$

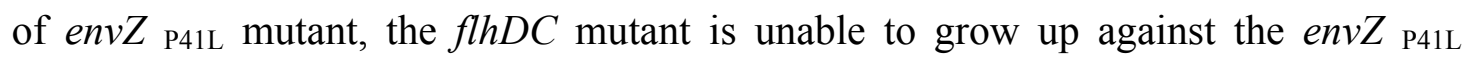
mutant (27). From these results, it can be inferred that there are at least two niches filled by envZ P41L mutant with some selective force that prevents $f h D C$ from colonizing one of these niches, and that $e n v Z_{\mathrm{P} 41 \mathrm{~L}}$ mutant is somehow able to prevent flhDC from growing up in the shared niche. 
Our laboratory previously proposed an adjustment to the Freter's hypothesis which states that the mono- and disaccharides that $E$. coli strains use for growth in the intestine are made available locally from polysaccharide degradation by the anaerobes in the mixed biofilms that the E.coli inhabit, rather than evenly mixed throughout the intestine. Furthermore, if one strain can bind better to the anaerobes in the mixed biofilms, the colonization ability of this strain would be improved. Recent studies of bacterial biofilms in the intestines have shown that anaerobes form dense biofilms with E.coli as a minority member (27). These biofilms form around intestinal mucin and break down large polysaccharides, such as fiber, that cannot usually be utilized by facultative anaerobes $(27,40,53)$. Differences in the population of anaerobes within mixed biofilms would thus provide E. coli with various niches based on nutrients made available by the anaerobes preferred metabolic pathways. If a specific mixed biofilm produced mostly galactose as a metabolic byproduct of polysaccharide breakdown, then $e n v Z_{\text {P4lL }}$ mutant would be provided with a significant competitive edge over the $f l h D C$ deletion mutant in that biofilm.

Due to the increased levels of OmpR-phosphate in the MG1655 env $Z_{\text {P41L }}$ mutant, the surface of the cells is different from both the parent MG1655 and the MG1655 flhDC mutants. OmpR-phosphate acts to upregulate two small RNAs (sRNAs), omrA and $o m r B$. These sRNAs are responsible for regulating outer membrane proteins by binding to the mRNA and preventing translation. One of the targets of these sRNAs is cirA, which produces a surface protein that binds colicin toxins produced by other bacteria (5). The MG1655 env $Z_{\text {P41L }}$ mutant has shown increased resistance to colicin V, a toxin produced by E. coli strain F-18, which could be representative of its 
resistance to other bacteriocins produced in certain mixed biofilms throughout the intestine (27). OmpR-phosphate also directly down regulates the production of the OmpF porin protein, which is known to transport bile salts into the cell. With this reduction in OmpF, less bile salts can move into the cell, and MG1655 env $Z_{\mathrm{P} 41 \mathrm{~L}}$ gains increased resistance to bile salts (27). The flagella of MG1655 env $Z_{\mathrm{P} 41 \mathrm{~L}}$ also remain intact allowing the cells to remain motile and adding yet another difference in the surface proteins of the MG1655 envZ p41L mutant vs. the MG1655 flhDC mutant. These differences in outer surfaces could provide the MG1655 env $Z_{\mathrm{P} 41 \mathrm{~L}}$ mutant with an improved affinity towards members of the mixed biofilm niche where it is in direct competition with the MG1655 flhDC mutant. With better binding affinity the

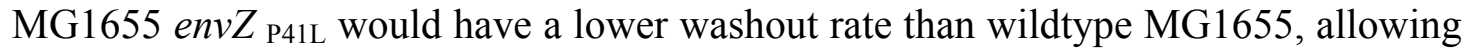
it to compete equally with the faster growth rate of the MG1655 flhDC mutant on most sugars. The improved resistance of MG1655 env $Z_{\mathrm{P} 41 \mathrm{~L}}$ to certain toxic substances in addition to improved binding affinity could increase the types of mixed biofilms with which it could associate.

While the anaerobes in mixed biofilms provide a source of nutrients for minimal members such as E. coli through breakdown of large polysaccharides, the facultative anaerobes may improve the environment for strict anaerobes by reducing the concentration of oxygen within the biofilms. Oxygen diffuses from surrounding tissue into the intestines, oxygen from swallowed air is present in flatus, and at least one predominant anaerobe in the gut microbiome, Bacteroides fragilis, respires oxygen at low concentrations $(2,18,21,28)$. It has been shown that respiration in $E$. coli provides an important competitive edge when colonizing the intestine of streptomycin- 
treated mice. Mutants of ATP synthase or cytochrome $b d$ oxidase, both necessary for respiration, showed a significant loss in colonizing ability when colonized against wild type of the same strain (21). Since E. coli uses oxygen as the final electron-acceptor in respiration, the oxygen concentration within the intestine will be lower in the presence of E. coli. Growth of anaerobes in close association with E. coli will be provided with a more preferential environment through depletion of oxygen, which is toxic to anaerobes. This will allow the anaerobes to provide a better niche for the E. coli through increased breakdown of large polysaccharides, leading to a mutualistic relationship in which both the anaerobes and E. coli in mixed biofilms benefit.

This study tested the hypothesis that the overall community structure of the gut may be influenced, and altered, by colonization with varying strains of E. coli. Based on the differing surface structures, binding affinities, and sugar preferences of the $E$. coli strains discussed thus far, each strain might prefer a different "restaurant," which would then lead to the preferential growth of the anaerobe members of the specific niche filled by each E. coli.

\section{Materials and Methods}

\section{Bacterial strains:}

Bacterial strains used in this study are listed in Table 1. The original E. coli $\mathrm{K}-12$ strain was obtained from a stool sample from a convalescing diphtheria patient in Palo Alto, CA, in 1922 (1). The sequenced E. coli MG1655 strain (CGSC 7740) was derived from the original K-12 strain, having only been cured of the temperate bacteriophage lambda and the F plasmid by means of UV light and acridine orange treatment (3). It has an IS1 element in the $f l h D C$ promoter (14). E. coli Nissle 1917 
was originally isolated during World War I from a soldier who escaped a severe outbreak of diarrhea (50). It has a beneficial effect on several types of intestinal disorders, is well tolerated by humans, and has been marketed as a probiotic remedy against intestinal disorders in several European countries since the 1920s (50). The allelic exchange method described by Datsenko and Wanner (10) was used to construct E. coli MG1655 $\operatorname{Str}^{\mathrm{R}} \Delta$ flhDC::cam (Table 1), 546-bp deletion encompassing region immediately downstream of ISI in regulatory region of $f l h D$ and into flhD. E. coli EDL933 is the prototype strain of enterohemorrhagic E. coli (EHEC) O157:H7 (42).

\section{Media and growth conditions:}

LB broth-Lennox (DIFCO) was prepared as directed $(20 \mathrm{~g} / \mathrm{L}$ in water) and sterilized. The approximate formula of LB broth Lennox (DIFCO) is listed as follows: $10 \mathrm{~g} / \mathrm{L}$ tryptone, $5 \mathrm{~g} / \mathrm{L}$ yeast extract, $5 \mathrm{~g} / \mathrm{L}$ sodium chloride. Bottles containing $10 \mathrm{ml}$ of LB broth Lennox (DIFCO) were inoculated with an individual strain of E. coli (Table 1) and allowed to grow for $18 \mathrm{~h}$ while shaking at $200 \mathrm{rpm}$ at $37^{\circ} \mathrm{C}$. The overnight cultures grew to approximately $10^{9} \mathrm{CFU} / \mathrm{ml}$, which were then diluted into $20 \%(\mathrm{w} / \mathrm{v}$ ) sucrose to $10^{5} \mathrm{CFU} / \mathrm{ml}$.

\section{Colonization experiments:}

The specifics of the streptomycin-treated mouse model used to compare the large intestine colonizing abilities of $E$. coli strains in mice have been described previously $(34,38,54,55,56)$. Briefly, sets of three male CD-1 mice (5 to 8 weeks old) were given drinking water containing streptomycin sulfate $(5 \mathrm{~g} / \mathrm{L})$ for $24 \mathrm{~h}$ to eliminate resident facultative bacteria (35). Following $18 \mathrm{~h}$ of starvation for food and water, the 
mice were fed $1 \mathrm{ml}$ of $20 \%(\mathrm{w} / \mathrm{v})$ sucrose containing $10^{5} \mathrm{CFU}$ of LB broth Lennox (DIFCO) grown E. coli strains. After ingesting the bacterial suspension, both the food (Teklad mouse and rat diet; Harlan Laboratories, Madison, WI) and streptomycinwater were returned to the mice, and $1 \mathrm{~g}$ of feces was collected after $5 \mathrm{~h}, 24 \mathrm{~h}$, and on odd-numbered days at the indicated times. Mice were housed individually in cages without bedding and were placed in clean cages at $24 \mathrm{~h}$ intervals. Individual fecal pellets were therefore no older than $24 \mathrm{~h}$. Each fecal sample (1 gram) was homogenized in $10 \mathrm{ml}$ of $1 \%$ Bacto-Tryptone (DIFCO), diluted in the same medium, and plated on Lactose MacConkey agar plates (DIFCO) with appropriate antibiotics. When appropriate, $1 \mathrm{ml}$ of a fecal homogenate (which were sampled after the feces have settled) were centrifuged at $12,000 \times g$, resuspended in $100 \mu 1$ of $1 \%$ BactoTryptone, and plated on a Latose MacConkey agar plate with appropriate antibiotics. This procedure increases the sensitivity of the assay from $10^{2} \mathrm{CFU} /$ gram of feces to 10 CFU/gram of feces. To distinguish the various E. coli strains in feces, dilutions were plated on lactose MacConkey agar containing streptomycin sulfate $(100 \mu \mathrm{g} / \mathrm{ml})$, streptomycin sulfate $(100 \mu \mathrm{g} / \mathrm{ml})$ and nalidixic acid $(50 \mu \mathrm{g} / \mathrm{ml})$, streptomycin sulfate $(100 \mu \mathrm{g} / \mathrm{ml})$ and rifampicin $(50 \mu \mathrm{g} / \mathrm{ml})$, or streptomycin sulfate $(100 \mu \mathrm{g} / \mathrm{ml})$ and chloramphenicol (30 $\mu \mathrm{g} / \mathrm{ml})$. Streptomycin sulfate, chloramphenicol, rifampicin, and nalidixic acid were purchased from Sigma-Aldrich (St. Louis, MO). All plates were incubated for 18 to $24 \mathrm{~h}$ at $37^{\circ} \mathrm{C}$ prior to counting (27). Mice were colonized with a single representative strain of $E$. coli for 10 days prior to harvesting of cecum. The $E$. coli strains used were (see Table 1): an O157:H7 pathogenic strain (EDL933), the probiotic strain (Nissle 1917), a common laboratory strain (MG1655), and the two 
mutants of MG1655 selected by the mouse intestine (envZ P41L and $f l h D C$ ). Also included were a set of mice inoculated with a placebo of uninoculated $20 \%$ sucrose.

\section{Fluorescent in situ Hybridization (FISH):}

In order to study how different strains of $E$. coli associate locally with members of the microbiota, we used Fluorescent In Situ Hybridization (FISH) on cross-sections of cecum from streptomycin-treated mice colonized with a single strain of $E$. coli. This was done in parallel with community analysis sequencing of bacterial populations in mucus samples obtained from the cecum of similarly treated mice to better understand how each strain of E. coli affects the development of the microbiome as a whole. The mice included an uninoculated control set (blank 20\% sucrose) and mice inoculated with one of five representative strains of $E$. coli listed above. Each strain, as well as the control, was fed simultaneously to 6 mice ( $10^{5} \mathrm{CFU} /$ mouse), which were colonized for 10 days. On the tenth day, mice were killed via $\mathrm{CO}_{2}$ and their ceca were harvested. Three of the mice from each set were used for FISH, while 3 of the mice from each set were used for community analysis sequencing of mucus samples.

The cecum of a mouse designated for FISH was cut into 1-2 cm sections, suspended in TissueTek ${ }^{\circledR}$ O.C.T compound (Sakura Finetek USA, Inc.) and snap frozen in 2-methylbutane suspended in liquid nitrogen. Sections were then stored at $80^{\circ} \mathrm{C}$ until ready for sectioning. For sectioning, the Vibratome UltraPro 5000 cryostat was used to cut sections at a thickness of $10 \mathrm{um}$, which were adhered to poly-L-lysine treated slides for visualization (LabScientific, Inc). Fixing of slides was done in $4 \%$ Paraformaldehyde for 1 hour at room temperature, followed by a wash in PBS for 10 min. Slides were allowed to dry overnight prior to hybridization. Fluorescent probes 
were diluted in hybridization solution consisting of $10 \mathrm{ml}$ of $1 \mathrm{M}$ Tris $\mathrm{pH} 7.2,18 \mathrm{ml}$ of $5 \mathrm{M} \mathrm{NaCl}$, and $0.1 \mathrm{~g}$ of SDS in a total volume of $100 \mathrm{ml} \mathrm{H}_{2} 0$. All slides with sections were treated using the FISH technique used by S. Macfarlane et al. (31), with hybridization of E.coli specific (5'-/5Cy3/CACCGTAGTGCCTCGTCATCA-3') Cy-3 probe (red) and Eubacteria specific (5'-GCTGCCTCCCGTAGGAGT/36-FAM/-3') FitC probe (green) at concentrations of $5 \mathrm{ng} / \mu 1$ and $25 \mathrm{ng} / \mu \mathrm{l}$, respectively. These probes were obtained from Integrated DNA Technologies (Coralville, IA). Briefly, $10 \mu 1$ of diluted probes in hybridization solution was pipetted to each slide, which were then covered with a HybriSlip hybridization cover (Life Technologies, Carlsbad, CA) and allowed to incubate in the dark for $2 \mathrm{~h}$ at $50^{\circ} \mathrm{C}$. After $2 \mathrm{~h}$ the slides were dipped in a wash buffer, which is simply hybridization solution without SDS added, and then allowed to soak in the wash buffer for $20 \mathrm{~min}$ at $50^{\circ} \mathrm{C}$. Slides were then rinsed with distilled water and allowed to dry overnight before viewing. Sections on poly-Llysine treated slides were imaged using the Zeiss axioimager M2 imaging system with the Zeiss LSM 700 confocal microscope and corresponding lasers (Carl Zeiss, Oberkochen, Germany). The images acquired from the poly-L-lysine treated slides were used to observe the biofilms with which the individual E. coli strains associate. The poly-L-lysine treated slides were additionally treated with Vectashield (Vector Laboratories, Inc.), an antibleaching agent which helps prolong fluorescence for imaging. This involves placing a small drop of Vectashield on the hybridized slide and then covering with a coverslip. Allowing $30 \mathrm{~min}$ at room temperature for the Vectashield to dry made viewing easier, but was not absolutely necessary. 


\section{Isolation of cecal mucus and DNA in cecal mucus:}

For each mouse cecum being used in sampling of microbiota in the mucus, mucus samples were scraped and collected into $5 \mathrm{ml}$ of HEPES-Hanks buffer (pH7.2). Microbial DNA was isolated using a MO BIO PowerSoil ${ }^{\mathrm{TM}}$ DNA Isolation Kit.

\section{Sequencing:}

PCRs to prepare samples for sequencing were done similarly for all mucus scrapings. Primers were designed to match those used in a study of the human gut microbiome which targeted the V4 variable region of the 16S rRNA (57). These primers were obtained from Integrated DNA Technologies (Coralville, IA) and were as follows: Forward (5'-TCG TCG GCA GCG TCA GAT GTG TAT AAG A-3') and Reverse (5'-GTC TCG TGG GCT CGG AGA TGT GTA TAA G-3'). Taq DNA polymerase (New England BioLabs, Ipswich, MA.) was added to each PCR reaction, which consisted of $25 \mu 1$ reactions: $2.5 \mu 1$ 10x Standard taq Reaction Buffer (New England BioLabs Inc.), $0.5 \mu 1 \mathrm{dNTP}$ Solution Mix containing $10 \mathrm{mM}$ of each dNTP (New England BioLabs Inc.), $0.5 \mu 1$ of a $100 \mu \mathrm{M}$ solution of each primer, $0.5 \mu 1$ of the aforementioned taq DNA polymerase (New England BioLabs), all added to $17.5 \mu$ of DEPC treated nuclease free sterile water (Fisher Scientific). Each PCR reaction began with an initial denaturation of $95^{\circ} \mathrm{C}$ for four min followed by a cycle of three steps repeated 35 times. These were as follows: denature at $95^{\circ} \mathrm{C}$ for $30 \mathrm{~s}$, annealing at $55^{\circ} \mathrm{C}$ for $20 \mathrm{~s}$, and extension at $72^{\circ} \mathrm{C}$ for $30 \mathrm{~s}$. The PCR ended with a final primer extension at $72^{\circ} \mathrm{C}$ for 4 min. PCR was done using an Eppendorf ${ }^{\circledR}$ Mastercycler 5331 Gradient PCR Thermocycler (Westbury, NY). PCR products were checked via gel 
electrophoresis to be sure they contained one band of approximately $300 \mathrm{bp}$ before submission to the Rhode Island Genomics and Sequencing Center (RIGSC).

Once submitted to the RIGSC, after amplicon submission, a second round of PCR ( 5 cycles) to attach Nextera (Illumina) indices and adapters was performed. Round 2 PCR reactions were cleaned with Agencourt Ampure XP (Beckman Coulter, Inc.), visualized by agarose gel electrophoresis, and selected samples were analyzed using the Agilent BioAnalyzer DNA1000 chip (Illumina). Qubit quantification was performed on all samples prior to pooling, and KAPA quantification was performed on the final pooled library prior to loading on the MiSeq flow cell. The samples were then run on the Illumina MiSeq (Illumina RTA 1.17.28) hi-throughput sequencer.

\section{Sequencing analysis:}

Data output from the MiSeq comes as raw fastq files, which were then classified using the published Mothur pipeline version 1.33 (49). Sequence processing was aligned, cleaned of chimeric sequences, and classified using the MiSeq SOP (standard operating procedure) made available by the Mothur authors (49).

\section{Statistics}

Means and standard deviations derived from the indicated samples were compared by an unpaired Student's $t$ test ( $P$ values). A $P$ value of $>0.05$ was interpreted as indicating no significant difference, and a $P$ value of $<0.05$ was interpreted as indicating a significant difference. 


\section{$\underline{\text { Results }}$}

\section{Comparing communities}

The quantification of the level of colonization by each strain was measured by diluting and plating feces collected from colonized mice, as previously described (Fig. 1). Each E. coli strain was able to colonize mice at between $10^{8}$ and $10^{9} \mathrm{CFU} / \mathrm{g}$ feces. As the control mice were fed a $20 \%$ sucrose placebo (without the addition of any $E$. coli) strain, no E. coli colonies should have grown when plated on MacConkey agar without any antibiotics added. As expected, no colonies were seen. FISH images confirm that the strains exist in close proximity to other members of the gut microbiota as a minimal member in larger biofilms (Fig 2-7). It can also be seen in these images that the non- $E$. coli microbes are diverse in cell morphology.

Once the interaction between the E. coli strains and the members of the microbiota had been confirmed, as well as the diversity of the microbial community, the community structure of each individual strain was compared. This was done at the phylum and family levels. As seen in (Fig. 8), all colonized mice showed similar levels of Bacteroidetes, and Firmicutes. For the E.coli Nissle 1917 and E. coli EDL933 colonized mice, Deferribacteres seemed to be at lower levels than for mice colonized with the other E. coli. Upon comparing the Nissle 1917 and EDL933 colonized mice to mice colonized with all of the other E. coli strains through an unpaired students t test, it was shown that these low levels are only statistically relevant when compared to the control and conventional mice $(\mathrm{P}<0.0001)$. Mice that were not colonized with any of the tested $E$. coli strains, i.e. the streptomycin treated controls and untreated conventional mice, showed very little Proteobacteria at this 
level of classification. In contrast, the E. coli colonized mice showed much higher levels of Proteobacteria, with the exception of the MG1655 envZ P41L and $f l h D C$ mutants. The env $Z_{\mathrm{P} 41 \mathrm{~L}}$ and $f l h D C$ mice showed lower levels of Proteobacteria when compared to the other treatments inoculated by E. coli strains, but only the env $Z_{\text {P4IL }}$ was statistically different in terms of Proteobacteria and only when compared to Nissle $1917(\mathrm{P}<0.05)$. Even the Proteobacteria in the conventional and control mice were only statistically different from Nissle $1917(\mathrm{P}<0.05)$.

It appears that mice colonized with all the $E$. coli strains display similar diversity at the family level (Fig. 9), with high levels of many of the same major members across all mice. Statistically relevant differences between the population of s24-7, a member of the Firmicutes phylum found in mice, is lower in Nissle 1917 samples when compared to MG1655 env $Z_{\mathrm{P} 41 \mathrm{~L}}$ samples $(\mathrm{P}<0.02)$, streptomycin treated controls $(\mathrm{P}<0.01)$, and the MG1655 flhDC mutant samples $(\mathrm{P}<0.002)$. Deferribacteraceae is considerably lower in Nissle 1917 and EDL933 colonized mice when compared to control $(\mathrm{P}<0.0001)$ and conventional mice $(\mathrm{P}<0.0001)$. EDL933 colonized mice had the lowest level of Lachnospiraceae, which was only a statistically significant difference when compared to MG1655 envZ P41L colonized mice $(\mathrm{P}<$ 0.05). Mice colonized with the MG1655 env $Z_{\mathrm{P} 41 \mathrm{~L}}$ and MG1655 flhDC mutants had lower levels of Enterobacteriaceae when compared to the mice colonized with the other E. coli strains, but only Nissle 1917 colonized mice were statistically higher and only when compared to mice colonized with the MG1655 env $Z_{\mathrm{P} 41 \mathrm{~L}}$ mutant $(\mathrm{P}<0.05)$. The same was true for the control and conventional mice, with only Nissle 1917 colonized mice being statistically different in levels of Enterobacteriaceae $(\mathrm{P}<0.05)$. 


\section{Increasing the sample set for Nissle 1917 and MG1655}

From the initial MiSeq sample set it was concluded that no significant difference could be observed in the cecal mucus community structures of mice colonized with the 5 different $E$. coli strains. While certain differences did appear (i.e. s24-7 in Nissle 1917) this may have been due to the limited sample set $(n=3)$, and so a second MiSeq run was performed. Rather than testing only a few additional mice for each strain, 2 strains were chosen so as a larger data set could be gathered for each: Nissle 1917 and MG1655. These strains were chosen as they are known to have different preferences in terms of growth on sugars, and are able to co-colonize the gut without being in direct competition (28).

An additional 11 mice colonized with MG1655 and 12 mice with Nissle 1917 were used. This would clarify if a larger sample size would allow visualization of changes in the overall microbial community caused by colonization with specific strains of $E$. coli. The relative abundance of major members of the gut microbiota was compared at the phylum and family level in order to ascertain if colonization by individual $E$. coli strains resulted in a percentage shifts of the major members, or if different major members appeared.

As is seen in the (Fig. 10), Nissle 1917 colonized mice have a higher relative abundance of Proteobacteria when compared to MG1655 (P < 0.02), and both Nissle 1917 and MG1655 fed mice have more Proteobacteria than the streptomycin treated control mice $(\mathrm{P}<0.0001$ and $\mathrm{P}<0.02$, respectively). This difference is seen again at the family level (Fig. 11) as represented by Enterobacteriaceae (a family in the Proteobacteria phylum) with Nissle 1917 colonized mice having more 
Enterobacteriaceae than MG1655 colonized mice $(\mathrm{P}<0.02)$, and both Nissle 1917 and MG1655 colonized mice having more Enterobacteriaceae than the streptomycin treated control mice $(\mathrm{P}<0.0001$ and $\mathrm{P}<0.02$, respectively). As the mice were treated with streptomycin in order to clear natural Proteobacteria from the niches that colonizing strains would inhabit, this difference in levels when compared to the streptomycin treated controls would be expected. As for the other members of the microbiota, there were no statistically significant differences between the individual $E$. coli treatments.

\section{Discussion}

In the present study, we examined the community structure of mice colonized with various strains of $E$. coli and their individual effects on the diversity of the cecal mucus population. It has been shown that $E$. coli inhabits the gut as a minimal member of mixed biofilms consisting of large anaerobe populations (27, Fig. 2-7), and while certain major members of the population may be influenced by colonization with specific strains of $E$. coli, more samples are likely necessary in order to elucidate any statistically relevant shift in a population. This is shown in comparing the Nissle 1917 data, which in the first sample set $(n=3)$ showed changes in levels of s24-7 and Deferribacteriaceae, but increasing the sample size $(n=15)$ debunks this finding as Deferribacteriaceae and s24-7 are present at a higher relative abundance (Fig. 9 vs Fig. 11). It is important to note however that the depth of sequencing is important for identifying key differences in these experiments, as the family level shows much greater differences than the phylum level. Future work would likely need to focus on 
the family level, or if able to, the genus level of classification to elucidate key differences caused by the colonizing $E$. coli strains.

Deferribacteres is a relatively recently described lineage, but one genus of Deferribacteres, Mucispirillum, has been identified as existing in the mammalian gut and being able to degrade mucin $(20,48)$. Lachnospiraceae is a member of the Firmicutes that is able to produce butyric acid and has been previously linked to obesity (36). Ruminococcaceae, another Firmicutes, has been previously shown to exist in the gut, but is difficult to classify and is often a mistakenly identified Lachnospiraceae (30). Paenibacillaceae is a Firmicutes with species that exist as plant growth promoting rhizobacteria and may have been introduced through the feed given to mice (4). The s24-7 family is a member of the Bacteroidetes that has been found to inhabit the mouse gut, but little else has been described (17). Another bacteroidetes, Porphyromonadaceae, has been previously shown to occasionally inhabit the gut, but more often resides in oral cavities as a pathogen (39). Rikanellaceae is another Bacteroidetes that has a recently reclassified member, Alistepes putredinis which was previously classified as a Bacteroides and shows similarities with Bacteroides fragilis and members of Porphyromonadaceae (47). Bacteroidaceae contains the Bacteroides genus, which can use simple sugars when available, but use glycans as a main source of energy (33).

Variation in the microbial communities amongst different hosts is common, and even hosts from a common facility or litter may have differences amongst the populations that inhabit their guts $(29,37,45)$. This is illustrated by the fact that mice used to test the same E. coli strain, and at the same time and under identical 
conditions, show differences in their community structures. As seen in (Fig. 9), showing the relative abundance at the family level of an individual $E$. coli strain, the standard deviation is considerable for many of the organisms present. Some families aren't even present in some of the mice, but are in high enough number to be represented in another mouse. As such, it is possible that any small effect in colonization by an individual E. coli strain could be masked by this diversity amongst hosts.

In addition to variation amongst hosts, the microbiota also consists of a vast amount of members (between 500-1000 commensal strains [6, 7, 22, 41, 46, 51, 52]). This could further mask any alteration in the community structure induced by colonization with specific $E$. coli strains. If a specific organism were present as a major member of the microbiota in one mouse, but only a minor member (or not present at all) in another mouse, this would result in a large standard deviation for that organism. So, even if a colonizing E. coli had an effect on this specific organism in the population, it would look the same as if it were just an artifact of having different hosts. This is further complicated by the overall noise level of the gut, again comprising of 500-1000 different organisms.

While the diversity between mice, as well as the large and complicated community of the gut, may mask shifts in the populations caused by colonizing $E$. coli it is still likely that the overall composition of the gut is not affected by the colonization of a specific E. coli strain. However, this does not mean E. coli is not important within the community and could still have a more localized effect on members of the population. Direct cell to cell interactions between E. coli and 
members of the microbiota that are within close proximity of one another may be more directly affected by these individual strains, as opposed to an obvious shift in large populations within the microbiome. Redundancy of gene programs and processes may allow the overall population to remain mostly unaffected by a minimal member missing from the population (19), but a more subtle effect may occur in localized niches. Further studies of direct cell to cell interactions may be necessary to elucidate how an individual E. coli strain can affect the communities of the mammalian gut, such as laser capture micro-dissections (LCM) (23). LCM coupled with FISH techniques would allow the targeting of fluorescently labeled E. coli cells within mixed biofilms to be captured and used for community analysis sequencing. This would allow only the members in close association with the $E$. coli to be studied, and remove much of the noise created by the overall communities of the gut.

In summary, the data presented here suggest that colonization with different strains of $E$. coli does not affect the overall composition of the microbial communities found within mouse cecal mucus. While increasing the sample size may give clarity to some minute effects that occur due to colonization with these individual strains, it is likely the overall noise level of the gut and the variation in the communities between hosts will mask these effects. Moving forward, it could prove useful to directly study the members that closely associate with the colonizing E. coli strains, through use of laser capture micro-dissections, in order to avoid the clutter of the dense microbial communities. Furthermore, focusing on deeper levels of classification could help elucidate differences in these populations. 


\section{$\underline{\text { References }}$}

1. Bachmann BJ. 1996. Derivations and genotypes of some mutant derivatives of Escherichia coli K-12, p 2460-2488. In Neidhardt FC, et al., editors. (ed), Escherichia coli and Salmonella typhimurium: cellular and molecular biology, 2nd ed, vol 2 American Society for Microbiology, Washington, DC.

2. Baughn, A. D., and M. H. Malamy. 2004. The strict anaerobe Bacteroides fragilis grows in and benefits from nanomolar concentrations of oxygen. Nature 427:441-444. 3. Blattner FR, Plunkett G 3rd, Bloch CA, Perna NT, Burland V, Riley M, ColladoVides J, Glasner JD, Rode CK, Mayhew GF, Gregor J, Davis NW, Kirkpatrick HA, Goeden MA, Rose DJ, Mau B, Shao Y. 1997. The complete genome sequence of Escherichia coli K-12. Science 277: 1453-1462.

4. Bloemberg GV, Lugtenberg BJ. 2001. Molecular basis of plant growth promotion and biocontrol by rhizobacteria. Curr Opin Plant Biol. 4:343-350.

5. Braun, V., S. I. Patzer, and K. Hantke. 2002. Ton-dependent colicins and microcins: modular design and evolution. Biochimie 84:365-380.

6. Clarke MB, Sperandio V. 2005. Events at the host-microbial interface of the gastrointestinal tract III. Cell-to-cell signaling among microbial flora, host, and pathogens: there is a whole lot of talking going on. Am J Physiol Gastrointest Liver Physiol 288:G1105-1109.

7. Cole AM, Ganz T. 2005. Defensins and other antimicrobial peptides: innate defense of mucosal surfaces, p 17-34. In J. P. Nataro, P. S. Cohen, H. L. T. Mobley, and J. N. Weiser (ed.), Colonization of mucosal surfaces. American Society for Microbiology Press, Washington, DC. 
8. Conlan, J. W., S. L. Bardy, R. KuoLee, A. Webb, and M. B. Perry. 2001. Ability of Escherichia coli $\mathrm{O} 157: \mathrm{H} 7$ isolates to colonize the intestinal tract of conventional adult CD1 mice is transient. Can. J. Microbiol. 47: 91-95.

9. Conway, T., K. A. Krogfelt, and P. S. Cohen. 29 December 2004, posting date. The life of commensal Escherichia coli in the mammalian intestine. In R. Curtiss III, et al. (ed.), EcoSal—Escherichia coli and Salmonella: cellular and molecular biology. ASM Press, Washington, DC.

10. Datsenko KA, Wanner BL. 2000. One-step inactivation of chromosomal genes in Escherichia coli K-12 using PCR products. Proc. Natl. Acad. Sci. USA. 97:66406645

11. Dethlefsen L, S. Huse, M. L. Sogin, and D. A. Relman. 2008. The pervasive effects of an antibiotic on the human gut microbiota, as revealed by deep 16S rRNA sequencing. PLoS Biol. 6:2383-2400.

12. Eckburg, P. B., E. M. Bik, C. N. Bernstein, E. Purdom, L. Dethlefsen, M. Sargent, S. R. Gill, K. E. Nelson, and D. A. Relman. 2005. Diversity of the human intestinal microbial flora. Science 308:1635-1638.

13. Egger, L. A., H. Park, and M. Inouye. 1997. Signal transduction via the histidyaspartyl phosphorelay. Genes Cells 2:167-184.

14. Fabich A. J., M. P. Leatham, J. E. Grissom, G. Wiley, H. Lai, F. Najar, B. A. Roe, P. S. Cohen, and T. Conway. 2011. Genotype and phenotypes of an intestine-adapted Escherichia coli K-12 mutant selected by animal passage for superior colonization. Infect Immun. 79:2430-2439. 
15. Freter, R., H. Brickner, J. Fekete, M. M. Vickerman, and K. E. Carey. 1983.

Survival and implantation of Escherichia coli in the intestinal tract. Infect. Immun. 39:686-703.

16. Gauger E. J., M. P. Leatham, R. Mercado-Lubo, D. C. Laux, T. Conway, and P.S. Cohen. 2007. Role of motility and the flhDC operon in Escherichia coli MG1655 colonization of the mouse intestine. Infect. Immun. 75:3315-3324.

17. Harris, J. K., El Kasmi, K. C., Anderson, A. L., Devereaux, M. W., Fillon, S. A., Robertson, C. E., Wagner B. D., Stevens M. J., Pace N. R., Sokol, R. J. 2014. Specific Microbiome Changes in a Mouse Model of Parenteral Nutrition Associated Liver Injury and Intestinal Inflammation. PLOS ONE, 9(10), e110396.

18. He, G., R. A. Shankar, M. Chzhan, A. Samouilov, P. Kuppusamy, and J. L. Zweier. 1999. Noninvasive measurement of anatomic structure and intraluminal oxygenation in the gastrointestinal tract of living mice with spatial and spectral EPR imaging. Proc. Natl. Acad. Sci. USA 96:4586-4591.

19. Hentges, D. J., J. U. Que, S. W. Casey, and A. J. Stein. 1984. The influence of streptomycin on colonization in mice. Microecol. Ther. 14: 53-62.

20. Huber, H. \& Stetter, K. O. 2001. Class I. Deferribacteres class. nov. In Bergey's Manual of Systematic Bacteriology, 2nd edn, vol. 1, p. 465. Edited by D. R. Boone, R. W. Castenholz \& G. M. Garrity. New York: Springer.

21. Jones, S. A., F. Z. Chowdhury, A. J. Fabich, A. Anderson, D. M. Schreiner, A. L. House, S. M. Autieri, M. P. Leatham, J. L. Lins, M. Jorgensen, P. S. Cohen, and T. Conway. 2007. Respiration of Escherichia coli in the mouse intestine. Infec. And Imm. 75: 4891-4899. 
22. Kaper JB, Sperandio V. 2005. Bacterial cell-to-cell signaling in the gastrointestinal tract. Infect Immun 73:3197-3209.

23. Klitgaard, K, L. Mølbak, T.K. Jensen, C.F. Lindboe, and M. Boye. 2005. Laser capture mixrodissection of bacterial cells targeted by fluorescence in situ hybridization. Biotechniques. 39: 864-868.

24. Laux, D. C., P. S. Cohen, and T. Conway. 2005. Role of the mucus layer in bacterial colonization of the intestine, p. 199-212. In J. P. Nataro, P. S. Cohen, H. L. T. Mobley, and J. N. Weiser (ed.), Colonization of mucosal surfaces. American Society for Microbiology Press, Washington, DC.

25. Leatham, M. P., S. Banerjee, S. M. Autieri, R. Mercado-Lubo, T. Conway, and P. S. Cohen. 2009. Precolonized human commensal Escherichia coli strains serve as a barrier to $E$. coli $\mathrm{O} 157: \mathrm{H} 7$ growth in the streptomycin-treated mouse intestine. Infect. Immun. 77:2876-2886.

26. Leatham, M. P., S. J. Stevenson, E. J. Gauger, K. A. Krogfelt, J. J. Lins, T. L. Haddock, S. M. Autieri, T. Conway, and P. S. Cohen. 2005. The mouse intestine selects nonmotile flhDC mutants of Escherichia coli MG1655 with increased colonizing ability and better utilization of carbon sources. Infect. Immun. 73:80398049.

27. Leatham-Jensen, M. P., J. Frimodt-Møller, J. Adediran, M. E. Mokszycki, M. E. Banner, J. E. Caughron, K. A. Krogfelt, T. Conway, P. S. Cohen. 2012. The streptomycin-treated mouse intestine selects Escherichia coli envZ missense mutants that interact with a dense and diverse intestinal microbiota. Infec. Immun. 80: 17161727. 
28. Levitt, M. D., and J. H. Bond. 1980. Flatulence. Annu. Rev. Med. 31:127-137.

29. Li, M. et al. Symbiotic gut microbes modulate human metabolic phenotypes. Proc. Natl Acad. Sci. USA 105, 2117-2122 (2008).

30. Liu, C.; Finegold, S. M.; Song, Y.; Lawson, P. A. 2008. Reclassification of Clostridium coccoides, Ruminococcus hansenii, Ruminococcus hydrogenotrophicus, Ruminococcus luti, Ruminococcus productus and Ruminococcus schinkii as Blautia coccoides gen. nov., comb. nov., Blautia hansenii comb. nov., Blautia hydrogenotrophica comb. nov., Blautia luti comb. nov., Blautia producta comb. nov., Blautia schinkii comb. nov. and description of Blautia wexlerae sp. nov., isolated from human faeces. International Journal of Systematic and Evolutionary Microbiology (Society for General Microbiology) 58 (8): 1896-1902.

31. Macfarlane, S, E. J. Woodmansey, and G.T. Macfarlane. Colonization of mucin by human intestinal bacteria and establishment of biofilm communities in a two-stage continuous culture system. 2005. App. And Enviro. Microbiol. 71: 7483-7492.

32. Maltby R, Leatham-Jensen MP, Gibson T, Cohen PS, Conway T. Nutritional Basis for Colonization Resistance by Human Commensal Escherichia coli Strains HS and Nissle 1917 against E. coli O157:H7 in the Mouse Intestine. Ibekwe AM, ed. PLoS ONE. 2013;8(1):e53957. doi:10.1371/journal.pone.0053957.

33. Martens EC, Chiang HC, Gordon JI. 2008. Mucosal Glycan Foraging Enhances Fitness and Transmission of a Saccharolytic Human Gut Bacterial Symbiont. Cell Host Microbe 13 (4): 447-57. 
34. McCormick, B. A., D. P. Franklin, D. C. Laux, and P. S. Cohen. 1989. Type 1 pili are not necessary for colonization of the streptomycin-treated mouse large intestine by type 1-piliated Escherichia coli F-18 and E. coli K-12. Infect. Immun. 57:3022-3029. 35. Miller, C. P., and M. Bohnhoff. 1963. Changes in the mouse's enteric microbiota associated with enhanced susceptibility to Salmonella infection following streptomycin treatment. J. Infect. Dis. 113:59-66.

36. Meehan, Conor J \& Beiko, Robert G. 2014. A Phylogenomic View of Ecological Specialization in the Lachnospiraceae, a Family of Digestive Tract-associated Bacteria. Genome Biol Evol. doi: 10.1093/gbe/evu050

37. Mueller, S. et al. 2006. Differences in fecal microbiota in different European study populations in relation to age, gender, and country: a cross-sectional study. Appl. Environ. Microbiol. 72, 1027-1033.

38. Myhal, M. L., D. C. Laux, and P. S. Cohen. 1982. Relative colonizing abilities of human fecal and K 12 strains of Escherichia coli in the large intestines of streptomycin treated mice. Eur. J. Clin. Microbiol. 1:186-192.

39. Naito M, Hirakawa H, Yamashita A, et al. 2008. Determination of the Genome Sequence of Porphyromonas gingivalis Strain ATCC 33277 and Genomic Comparison with Strain W83 Revealed Extensive Genome Rearrangements in P. gingivalis. DNA Res. 15 (4): 215-25.

40. Palestrant, D., Z. E. Holzknecht, B. H. Collins, W. Parker, S. E. Miller, and R. R. Bollinger. 2004. Microbial biofilms in the gut: visualization by electron microscopy and by acridine orange staining. Ultrastruct. Pathol. 28:23-27. 
41. Pasetti MF, Salerno-Gonçalves R, Sztein MB. 2005. Mechanisms of adaptive immunity that prevent colonization of mucosal surfaces, p 35-48. In Nataro JP, Cohen PS, Mobley HLT, Weiser JN (ed), Colonization of mucosal surfaces. ASM Press, Washington, DC.

42. Perna NT, Plunkett G 3rd, Burland V, Mau B, Glasner JD, Rose DJ, Mayhew GF, Evans PS, Gregor J, Kirkpatrick HA, Pósfai G, Hackett J, Klink S, Boutin A, Shao Y, Miller L, Grotbeck EJ, Davis NW, Lim A, Dimalanta ET, Potamousis KD, Apodaca J, Anantharaman TS, Lin J, Yen G, Schwartz DC, Welch RA, Blattner FR. 2001. Genome sequence of enterohaemorrhagic Escherichia coli O157:H7. Nature 409:529533.

43. Prüß, B. M., J. W. Campbell, T. K. Van Dyk, C. Zhu, Y. Kogan, and P. Matsumura. 2003. FlhD/FlhC is a regulator of anaerobic respiration and the EntnerDoudoroff pathway through induction of the methyl-accepting chemotaxis protein Aer. J. Bacteriol. 185:534-543.

44. Prüß, B. M., X. Liu, W. Hendrickson, and P. Matsumura. 2001. FlhD/FlhC774 regulated promoters analyzed by gene array and lacZ gene fusions. FEMS Microbiol. Lett. 197:91-97.

45. Qin, J. et al. A human gut microbial gene catalogue established by metagenomic sequencing. Nature 464, 59-65 (2010).

46. Sansonetti PJ. 2004. War and peace at mucosal surfaces. Nat Rev Immunol 4:953964.

47. Rautio M, Eerola E, Vaisanen-Tunkelrott ML, Molitoris D, Lawson P, Collins MD, Jousimies-Somar H. 2003. Reclassification of Bacteroides putredinis (Weinberg 
et al., 1937) in a new genus Alistipes gen. nov., as Alistipes putredinis comb. nov., and description of Alistipes finegoldii sp. nov., from human sources. Syst Appl Microbiol. 26(2):182-8.

48. Robertson BR, O'Rourke JL, Neilan BA, Vandamme P, On SLW, Fox JG et al. 2005. Mucispirillum schaedleri gen. nov., sp. nov., a spiral-shaped bacterium colonizing the mucus layer of the gastrointestinal tract of laboratory rodents. Int J Syst Evol Microbiol. 55: 1199-1204.

49. Schloss, P.D., et al., Introducing mothur: Open-source, platform-independent, community-supported software for describing and comparing microbial communities. Appl Environ Microbiol, 2009. 75(23):7537-41.

50. Schulze, J, Sonnenborn, U. 1995. Oral administration of a certain strain of live Escherichia coli for intestinal disorders? Infection 23:184-188.

51. Stecher B, Berry D, Loy A. 2013. Colonization resistance and microbial ecophysiology: using gnotobiotic mouse models and single-cell technology to explore the intestinal jungle. FEMS Microbiol Rev 37:793-829.

52. Stecher B, Hardt WD. 2011. Mechanisms controlling pathogen colonization of the gut. Curr Opin Microbiol 14:82-91.

53. Swidsinski, A., J. Weber, V. Loening-Baucke, L. P. Hale, and H. Lochs. 2005. Spatial organization and composition of the mucosal flora in patients with inflammatory bowel disease. J. Clin. Microbiol. 43:3380-3389.

54. Sweeney, N. J., P. Klemm, B. A. McCormick, E. Moller-Nielsen, M. Utley, M. A. Schembri, D. C. Laux, and P. S. Cohen. 1996. The Escherichia coli K-12 gntP gene 
allows $E$. coli F-18 to occupy a distinct nutritional niche in the streptomycin-treated mouse large intestine. Infect. Immun. 64:3497-3503.

55. Sweeney, N. J., D. C. Laux, and P. S. Cohen. 1996. Escherichia coli F-18 and K12 eda mutants do not colonize the streptomycin-treated mouse large intestine. Infect. Immun. 64:3504-3511.

56. Wadolkowski, E. A., D. C. Laux, and P. S. Cohen. 1988. Colonization of the streptomycin-treated mouse large intestine by a human fecal Escherichia coli strain: role of growth in mucus. Infec. Immun. 56: 1030-1035.

57. Yatsunenko T et al. 2012. Human gut microbiome viewed across age and geography. Nature 486:222-227. 
Table 1 - Bacterial strains

\begin{tabular}{|c|c|c|c|}
\hline E. coli strain & Genotype/phenotype & $\begin{array}{l}\text { Designation in } \\
\text { the text }\end{array}$ & $\begin{array}{l}\text { Source or } \\
\text { reference }\end{array}$ \\
\hline MG1655 $\mathrm{Str}^{\mathrm{R}}$ & $\begin{array}{l}\text { Spontaneous streptomycin } \\
\text { resistant mutant of MG1655 }\end{array}$ & MG1655 & 3 \\
\hline $\begin{array}{l}\text { MG1655 } \\
\operatorname{Str}^{\mathrm{R}} \Delta f l h D:: \mathrm{cam}\end{array}$ & $\begin{array}{l}\text { 546-bp deletion beginning } \\
\text { immediately downstream of } \\
\text { IS } 1 \text { in the regulatory region of } \\
\text { flhD and ending in } f l h D, \\
\text { streptomycin and } \\
\text { chloramphenicol resistant }\end{array}$ & $\begin{array}{l}\text { MG1655 } \\
\text { flhDC }\end{array}$ & 15,23 \\
\hline $\begin{array}{l}\text { MG1655 envZ } \\
\text { P41L } \operatorname{Str}^{\mathrm{R}}\end{array}$ & $\begin{array}{l}\text { P41L envZ missense mutant of } \\
\text { MG1655 } \mathrm{Str}^{\mathrm{R}}\end{array}$ & $\begin{array}{l}\text { MG1655 } \\
\text { env } Z_{\mathrm{P} 41 \mathrm{~L}} \\
\text { mutant }\end{array}$ & 24 \\
\hline Nissle $1917 \mathrm{Str}^{\mathrm{R}}$ & $\begin{array}{l}\text { Spontaneous streptomycin } \\
\text { resistant mutant of Nissle } 1917\end{array}$ & Nissle 1917 & 22,41 \\
\hline EDL933 $\mathrm{Str}^{\mathrm{R}} \mathrm{Rif}^{\mathrm{R}}$ & $\begin{array}{l}\text { Spontaneous streptomycin } \\
\text { resistant mutant of EDL933 }\end{array}$ & EDL933 & 35 \\
\hline
\end{tabular}


Table 2 - Primers used

\begin{tabular}{|l|l|}
\hline Primer designation & Sequence \\
\hline $\begin{array}{l}\text { of } \text { E.coli specific Cy-3 probe } \\
\text { (red) used for FISH }\end{array}$ & 5'-/5Cy3/CACCGTAGTGCCTCGTCATCA-3' \\
\hline $\begin{array}{l}\text { Eubacteria FitC probe (green) } \\
\text { used for FISH }\end{array}$ & 5'-GCTGCCTCCCGTAGGAGT/36-FAM/-3' \\
\hline $\begin{array}{l}\text { 16S V4 forward used for } \\
\text { community analysis sequencing }\end{array}$ & 5'-TCG TCG GCA GCG TCA GAT GTG TAT \\
\hline $\begin{array}{l}\text { 16S V4 reverse used for } \\
\text { community analysis sequencing }\end{array}$ & 5'-GTC TCG TGG GCT CGG AGA TGT GTA \\
\hline
\end{tabular}




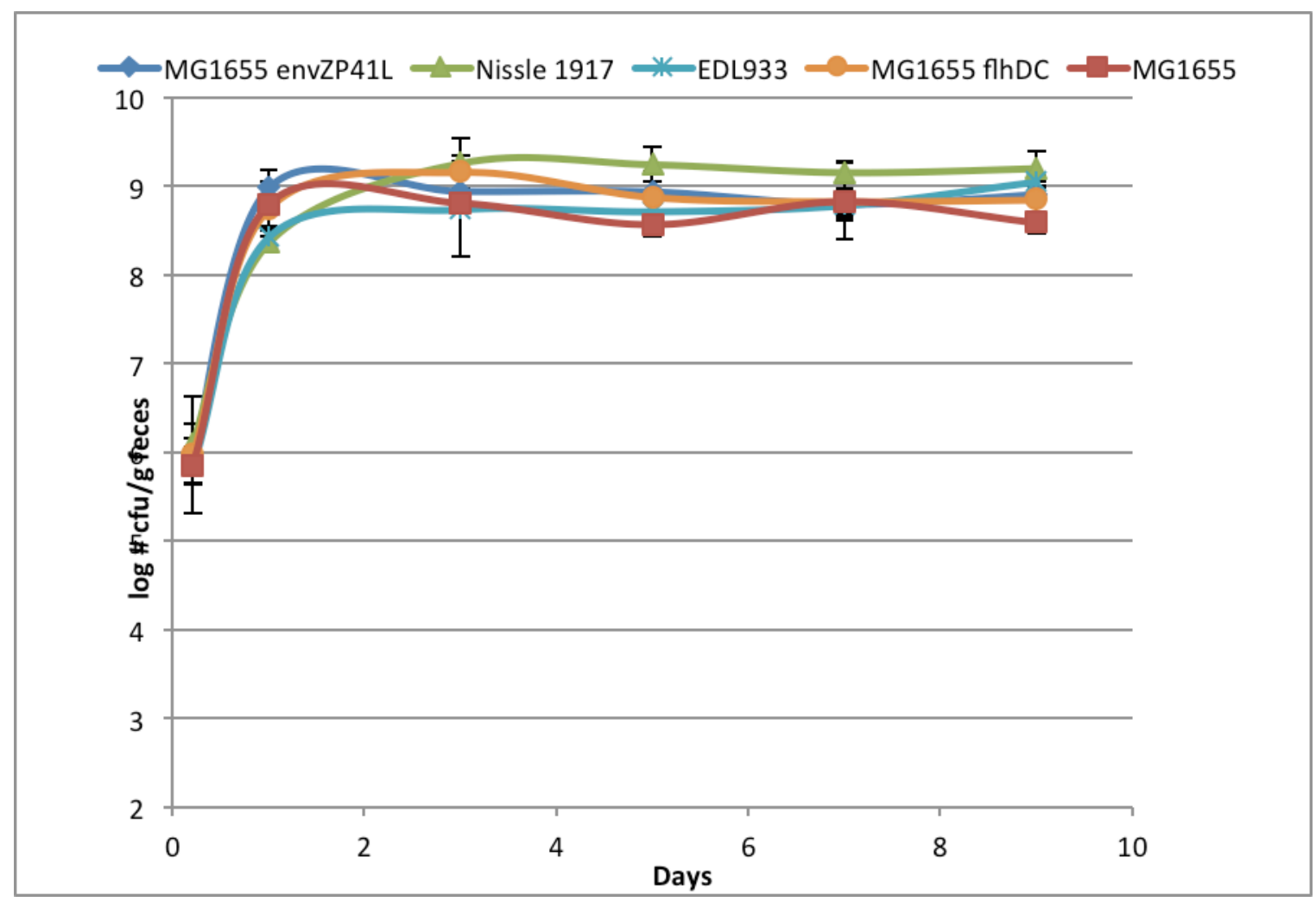

Fig 1. Single strain colonizations of mice colonized with individual strains of $E$. coli. This shows that the individual $E$. coli strains are able to colonize the mice at similar levels. 


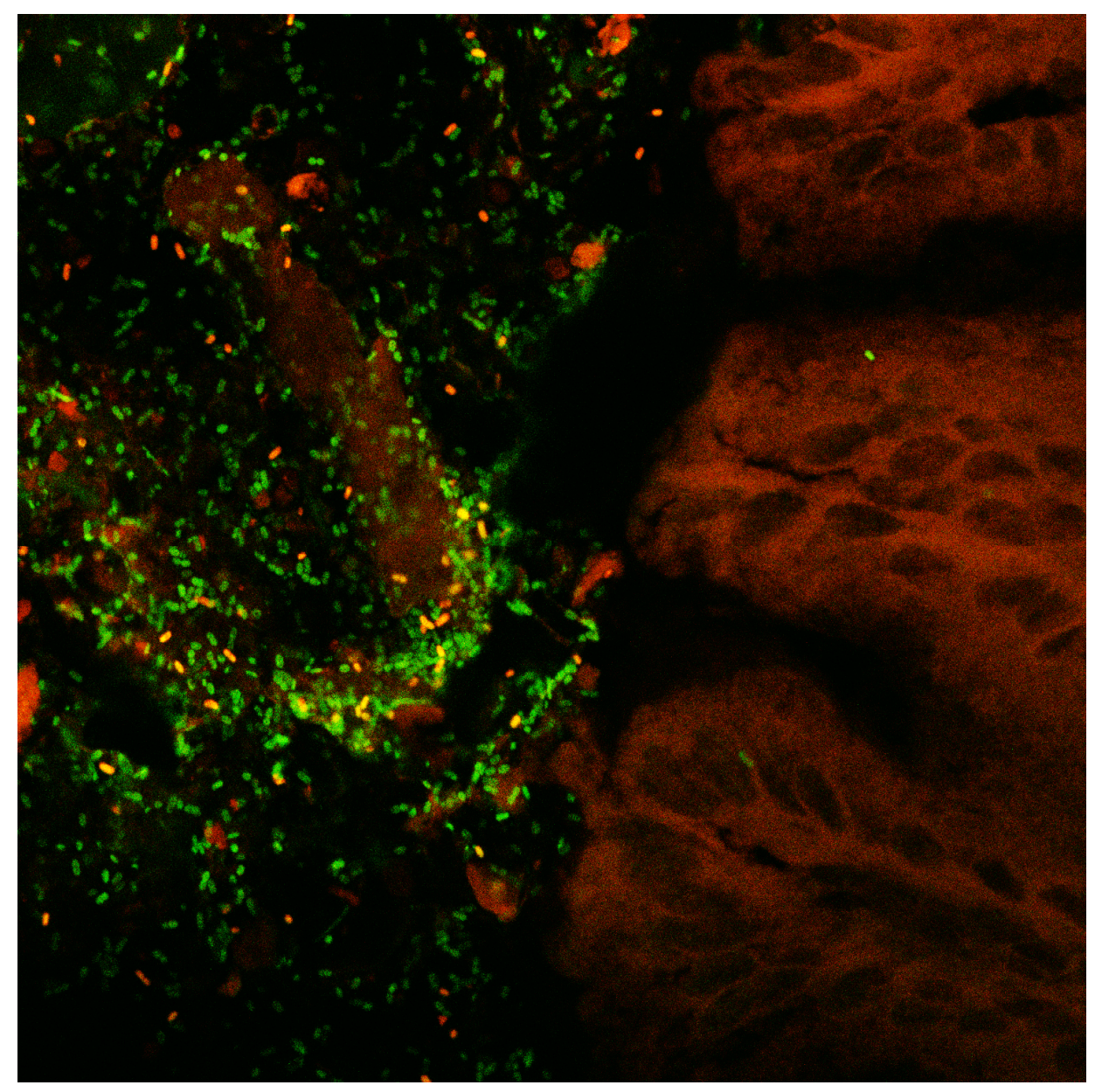

Fig 2. FISH image of a cross-section of cecum collected from mice colonized with EDL933 for 10 days. Red bacterial cells represent $E$. coli labeled by the Cy3-probe, while green bacterial cells represent all Eubacteria labeled by the FitC-probe. 


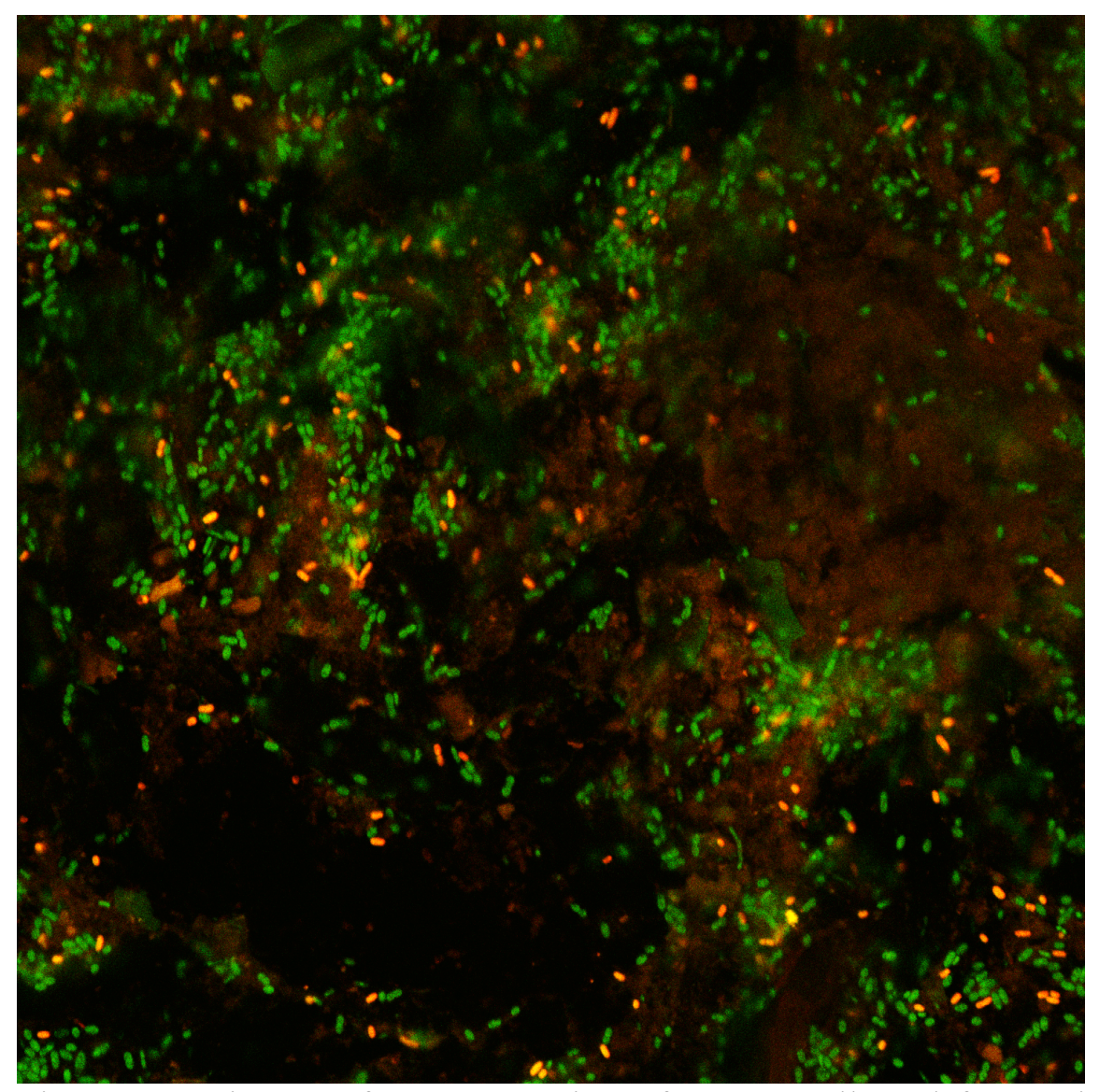

Fig 3. FISH image of a cross-section of cecum collected from mice colonized with Nissle 1917 for 10 days. Red bacterial cells represent E. coli labeled by the Cy3probe, while green bacterial cells represent all Eubacteria labeled by the FitC-probe. 


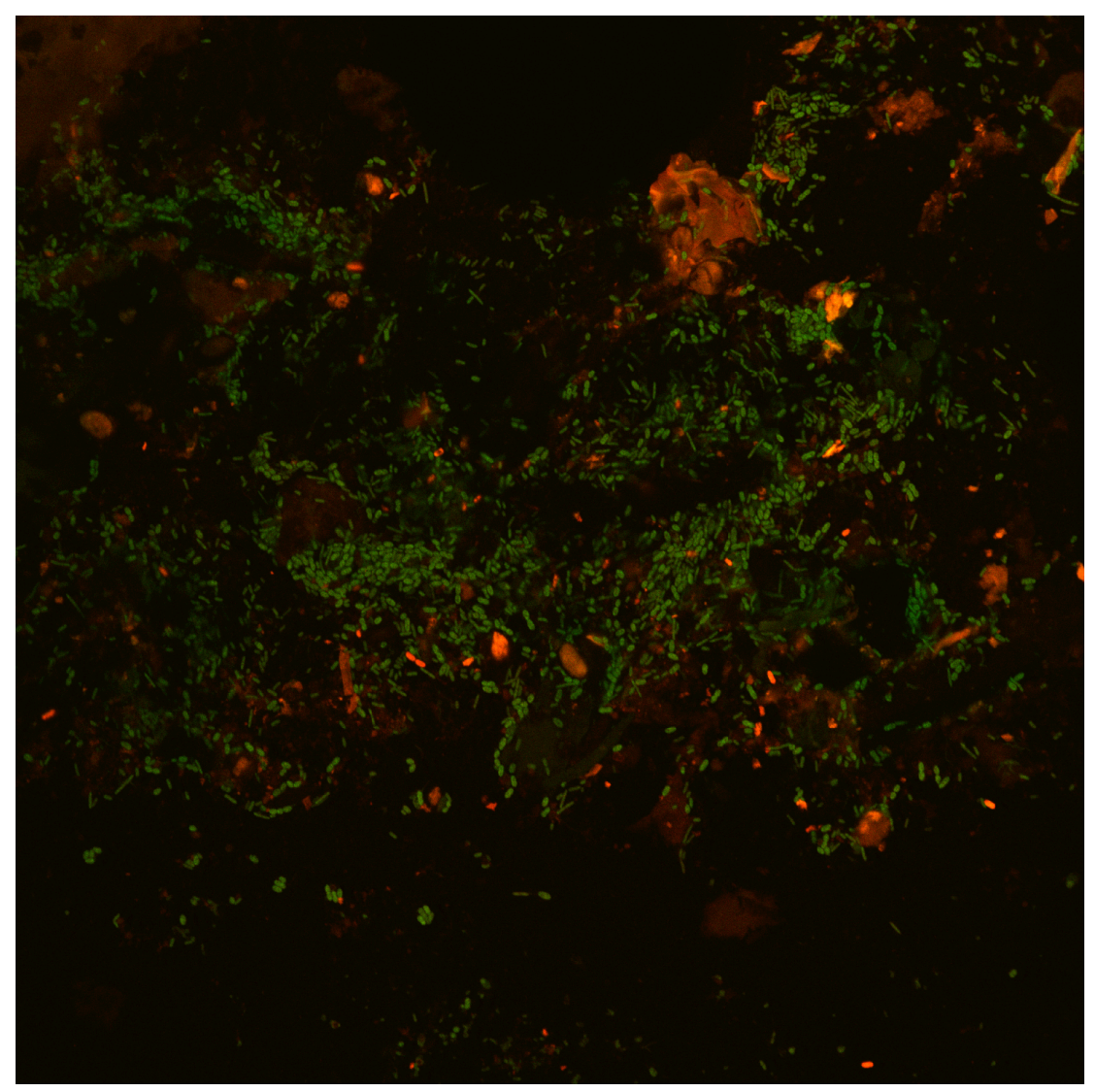

Fig 4. FISH image of a cross-section of cecum collected from mice colonized with MG1655 for 10 days. Red bacterial cells represent E. coli labeled by the Cy3-probe, while green bacterial cells represent all Eubacteria labeled by the FitC-probe. 


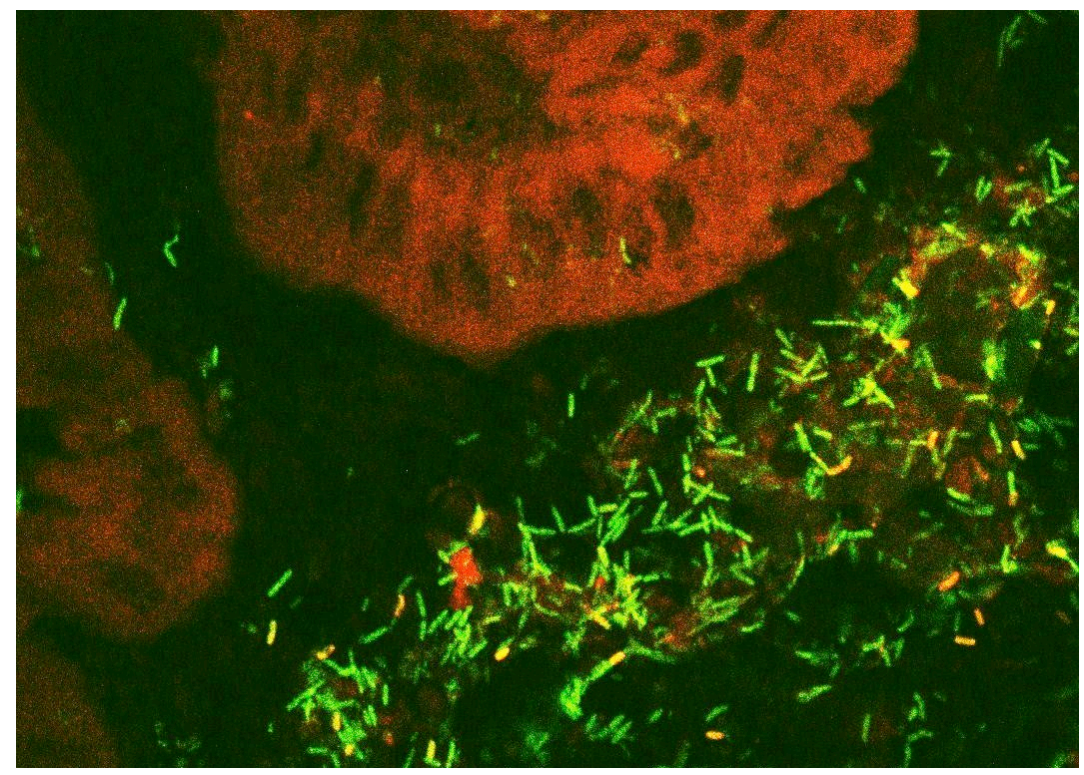

Fig 5. FISH image of a cross-section of cecum collected from mice colonized with MG1655 flhDC for 10 days. Red bacterial cells represent E. coli labeled by the Cy3probe, while green bacterial cells represent all Eubacteria labeled by the FitC-probe. 


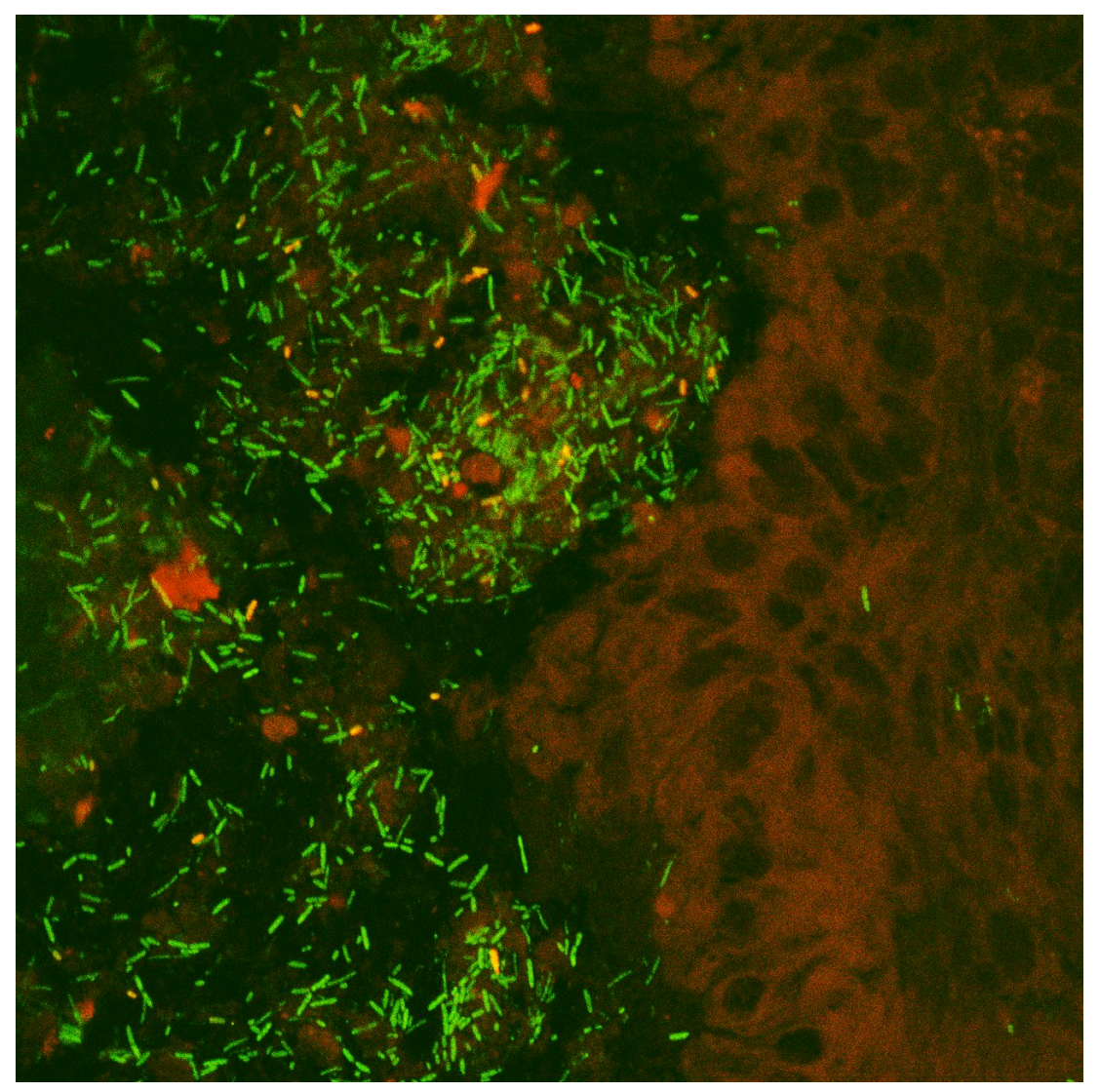

Fig. 6. FISH image of a cross-section of cecum collected from mice colonized with MG1655 env $Z_{\mathrm{P} 41 \mathrm{~L}}$ for 10 days. Red bacterial cells represent $E$. coli labeled by the Cy3-probe, while green bacterial cells represent all Eubacteria labeled by the FitCprobe. 


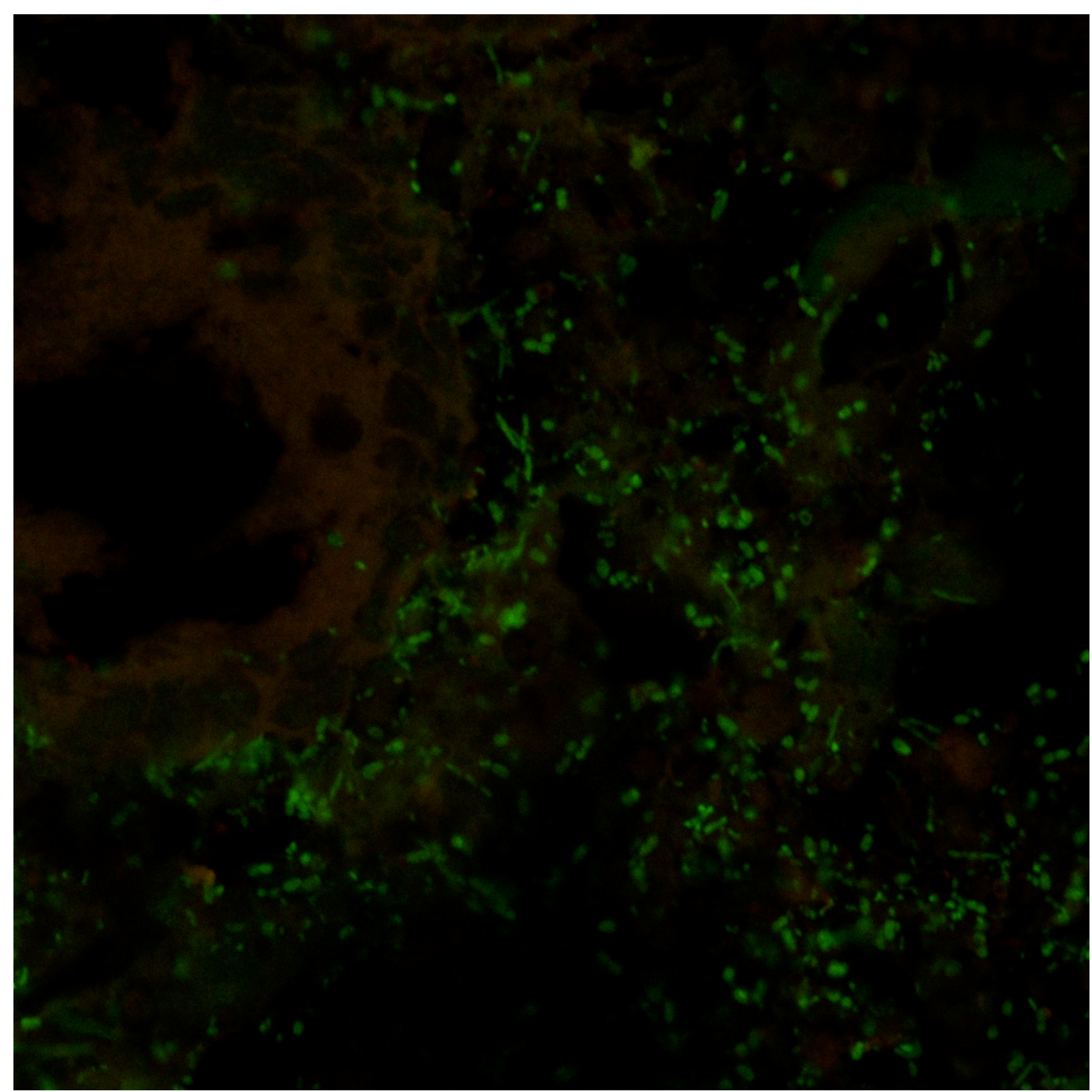

Fig. 7 FISH image of a cross-section of cecum collected from mice treated with streptomycin but not colonized with any E. coli. Green bacterial cells represent all Eubacteria labeled by the FitC-probe. 


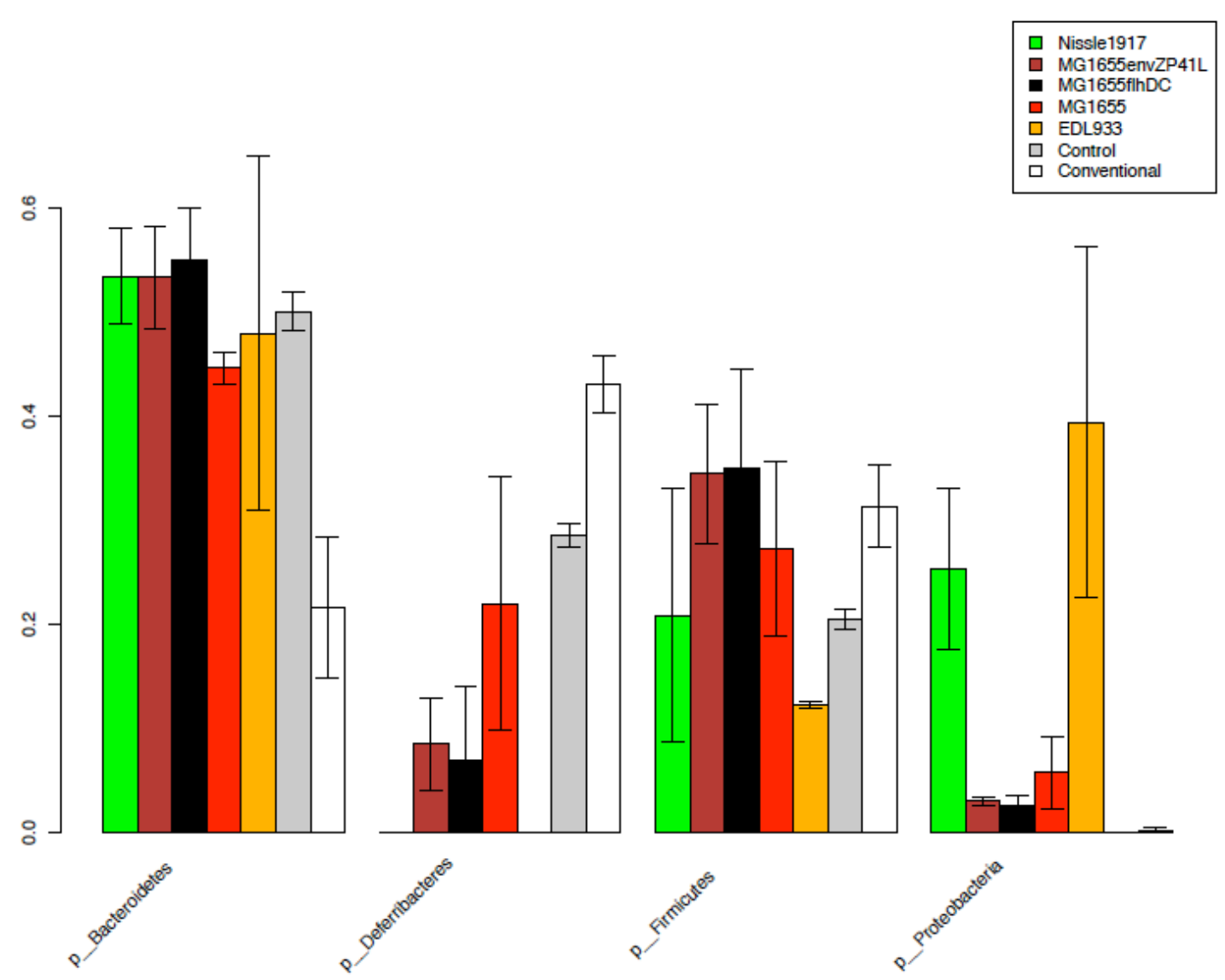

Fig. 8 Bar plot showing relative abundance of major phyla in mucus samples by treatment. In this set of experiments $n=3$. Error bars indicate standard error of the mean. EDL933 and Nissle 1917 colonized mice show lower levels of Deferribacteres when compared to the control and conventional mice $(\mathrm{P}<0.0001)$. Only Nissle 1917 shows greater levels of Proteobacteria, and only when compared to MG1655 env $Z_{P 4 I L}$ and the control and conventional mice $(\mathrm{P}<0.05)$. 


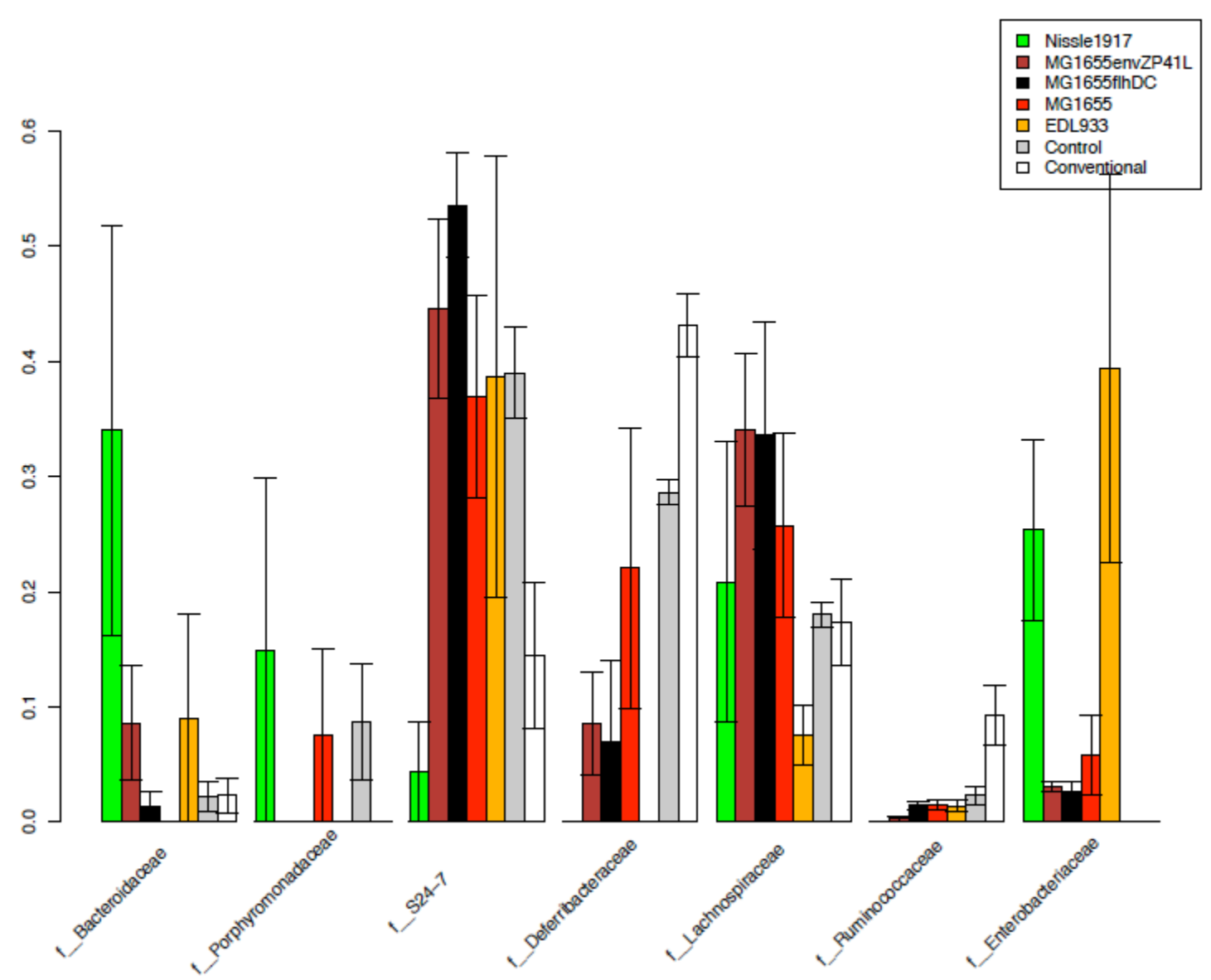

Fig. 9 Bar plot showing relative abundance of major families in mucus samples by treatment. In this set of experiments $n=3$. Error bars indicate standard error of the mean. The level of s24-7 in the Nissle 1917 colonized mice was lower when compared to the MG1655 mutants $\left(e n v Z_{P 41 L} \mathrm{P}<0.02\right.$ and flhDC $\left.\mathrm{P}<0.002\right)$ and the streptomycin treated control $(\mathrm{P}<0.01)$. Deferribacteraceae was lower in Nissle 1917 and EDL933 colonized mice when compared to the control and conventional mice $(\mathrm{P}<0.0001)$. EDL933 colonized mice had the lowest level of Lachnospiraceae, which was only a statistically significant difference when compared to MG1655 envZP41L colonized mice $(\mathrm{P}<0.05)$. Enterobacteriaceae were lower in the env $Z_{P 41 L}$, control and conventional mice when compared to Nissle 1917 mice $(\mathrm{P}<0.05)$ 


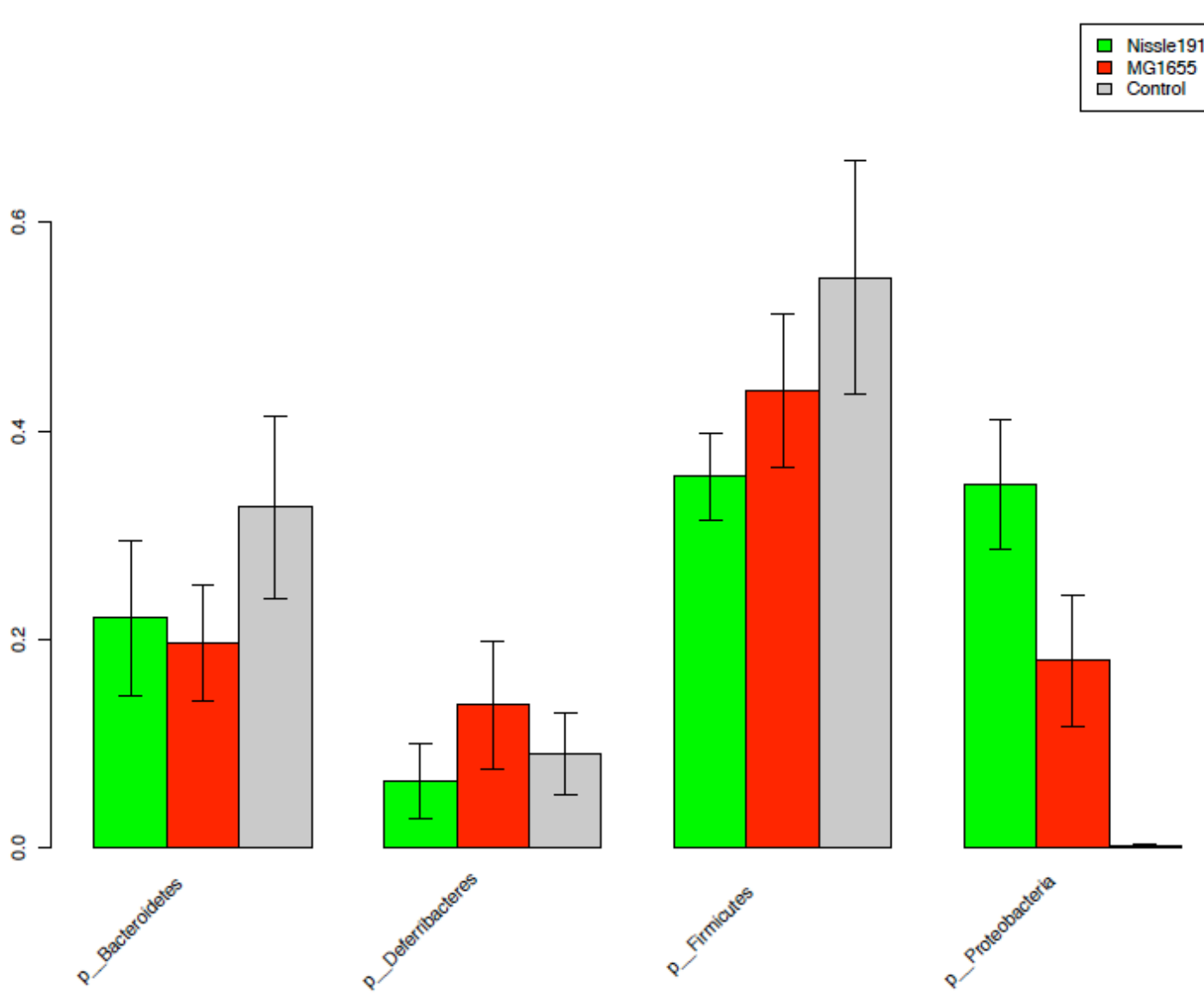

Fig. 10 Bar plot showing relative abundance of major phyla in mucus samples by treatment. For Nissle1917 samples $\mathrm{n}=15$. For MG1655 samples $\mathrm{n}=14$. For streptomycin treated control samples $n=15$. Error bars indicate standard error of the mean. The ony statistically significant differences were seen in the levels of Proteobacteria, with Nissle 1917 fed mice having more than MG1655 fed mice (P < 0.02), and both Nissle 1917 and MG1655 fed mice having more Proteobacteria than the streptomycin treated controls $(\mathrm{P}<0.0001$ and $\mathrm{P}<0.02$, respectively $)$ 


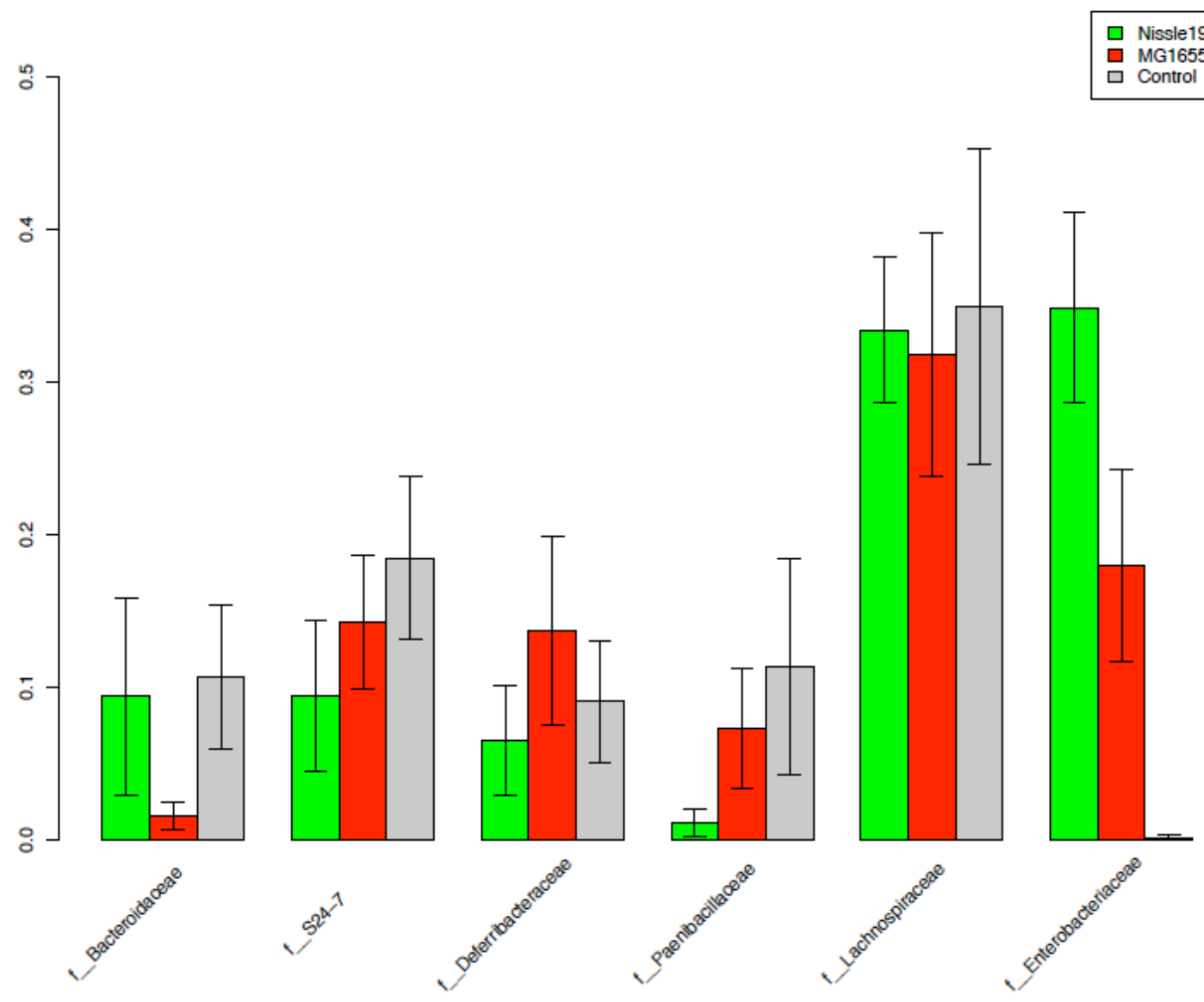

Fig. 11 Bar plot showing relative abundance of major families in mucus samples by treatment. For Nissle1917 samples $\mathrm{n}=15$. For MG1655 samples $\mathrm{n}=14$. For streptomycin treated control samples $n=15$. Error bars indicate standard error of the mean. Nissle 1917 colonized mice having more Enterobacteriaceae than MG1655 colonized mice $(\mathrm{P}<0.02)$, and both Nissle 1917 and MG1655 colonized mice having more Enterobacteriaceae than the streptomycin treated control mice $(\mathrm{P}<0.0001$ and $\mathrm{P}<0.02$, respectively) 


\section{MANUSCRIPT II}

Publication status: To be submitted to the American Society for Microbiology journal, Infection and Immunity, 2016.

Title: Developing an In Vitro Method for Studying the Interaction between E. coli and the Intestinal Microbiota

Authors: Matthew E Mokszycki ${ }^{1}$, Jon L Steffensen ${ }^{1}$, Ying Zhang ${ }^{1}$, Karen A Krogfelt $^{2}$, Tyrrell Conway ${ }^{3}$, and Paul S Cohen ${ }^{1 *}$

Affiliation: ${ }^{1}$ Department of Cell and Molecular Biology, University of Rhode Island, Kingston, Rhode Island, USA

${ }^{2}$ Department for Infection and Microbiology Control, Statens Serum Institut, Copenhagen S, Denmark

${ }^{3}$ Department of Microbiology and Plant Biology, University of Oklahoma, Norman, Oklahoma, USA

*Corresponding Authors: Paul S Cohen, Department of Cell and Molecular Biology, 120 Flagg Rd., University of Rhode Island, Kingston, RI 02881, USA;

E-mail: pco1697u@uri.edu, 1-401-874-5920 


\title{
MANUSCRIPT II
}

Developing an In Vitro Method for Studying the Interaction between E. coli and the Intestinal Microbiota

\begin{abstract}
In order to better understand the interactions between $E$. coli and the members of the intestinal microbiota, a novel in vitro method was developed. This method was designed to be simple and inexpensive while providing an environment meant to replicate the natural habitat of these organisms: the mammalian gut. The current study examines the development of said in vitro model and its ability to mimic the mouse gut in terms of diversity of organisms, as well as its usefulness in examining the colonizing ability of competing E. coli strains. It is shown that, while still in development, this system is currently able to maintain diversity comparable to what is seen in mice. While the abundance of these diverse organisms is not necessarily at the levels seen in mice, the model is already an effective system for studying the microbial community of the gut in a controlled environment. Furthermore, the system is able to mimic certain colonization experiments of competing $E$. coli strains done in mice, and with improvements to bolster the growth of the diverse population could be used as a non-invasive method for studying gut microbes.
\end{abstract}

\section{Introduction}

While there are a diverse group of phyla represented within the mammalian gut, the microbiota is dominated by two: Firmicutes and Bacteroidetes $(15,30,55)$. Facultative anaerobes, such as E. coli, are minimal yet important members of the gut community, and it has been shown that E. coli inhabits mixed biofilms formed by 
anaerobes as a minority member (28). According to Freter's nutrient-niche hypothesis the community structure of the intestine is decided by nutrient availability, but also assumes that all available nutrients within the intestine are perfectly mixed (17). We previously proposed an adjustment to Freter's nutrient-niche hypothesis, the "Restaurant" hypothesis, which can be used to explain how the anaerobes in mixed biofilms inhabited by E. coli provide them with mono- and di-saccharides locally, rather than from a perfectly mixed pool available to all species (28). Furthermore, it was hypothesized that differences in the outer surface between strains of E. coli may have an effect on the binding affinity to the mixed biofilms and their consequent growth (28).

Mucus in the gut exists in two forms, the loose layer and the firm layer (24). The loose mucus layer is where most of the microbiota of the gut grow and form their biofilms, while the firm mucus layer resides closer to the epithelial layer of the intestines and prevents direct interaction of the commensal microbiota with host epithelium (24). The mucus itself consists of a large mixture of molecules, including but not limited to amino acids, large polysaccharides, mono- and disaccharides, and mucin (3). This mixture exists as a viscous liquid in which the microbes are suspended and in which form biofilms. This environment is mostly anaerobic, with minimal oxygen leaking from epithelial cells of the intestine $(4,20,25,29)$. Mucin is a glycoprotein with large polysaccharide strands with which the anaerobe populations of the gut can attach and form biofilms around (1). The biofilms formed by these anaerobes can break down the large polysaccharides of the mucus, and parts of the mucin, thus providing facultatives with usable mono- and disaccharides in bulk which 
would usually be limited $(28,43,56)$. This gives facultatives, such as E. coli, a reason for joining as minimal members in these anaerobe-formed biofilms, and perhaps even promoting the growth of preferential anaerobes that provide specific mono- and disaccharides (25). The facultatives that join these mixed biofilms likely provide the anaerobes with protection from the minimal amount of oxygen that is released from the epithelial tissue of the gut.

In vitro biofilm models allow the study of microbial communities as they form complex biofilm structures in a contained and controllable environment $(14,21,61)$. Various biofilm models have been adapted to represent specific environments in order to best mimic biofilm formation in vivo. These systems are diverse in setup and function, ranging from flow displacement systems in which a constant flow of growth medium in and waste products out $(4,21)$, to cell-culture-based models which allow biofilms to develop on reconstituted human epithelia (50).

One system that is commonly used to study biofilms due to its simplicity is the microtiter plate based model $(8,26,46,59)$. The biofilms using this model are grown in microtiter well plates ranging from 6 to 96 well plates depending on necessity. This allows for many environmentally identical biofilms to be studied at once, or individual variables to be tested in each well (42). This system also allows for easy adjustment over time in order to view the effects of variation in the media or additives on biofilm development or maintenance $(9,23)$. However, a disadvantage of the microtiter plate based models is that the system does not take into account the flow through of certain environments such as the mouse gut $(11,47)$. This would mean that biofilms growing 
in the wells of the microtiter plate would eventually deplete available nutrients while also accumulating waste (11).

Other systems take into account that the flow of new media into and old media out of the system is important. These flow models vary in design, with some developed to maintain a perfect mixture of nutrients and other more simplistic systems which allow the flow of the media to develop a natural gradient from one end of the flow to the other (21). The continuous flow stirred tank reactor (CFSTR), a system utilized by the CDC for biofilm studies, has an influx that matches the flow out of the system with constant stirring where the biofilms grow (21). Planktonic cells can be flushed out of the system by having the dilution rate of the media set faster than the doubling time of the organisms in the system, leaving behind the attached organisms in biofilms (21). The plug flow reactor (PFR) is similar in the control of media flow, but does not have a container of media with constant stirring. Instead, plugs seeded with biofilm forming organisms are locked in a row and media is allowed to flush past them. Thus the media will have a higher concentration of substrates earlier in the flow with a gradual decline in concentration further down the system $(11,21)$. While these systems are designed to mimic the natural flow of available substrates in certain environmental habitats, they also come with disadvantages. The continuous flow stirred tank reactor setup tends to be labor intensive, with specialized equipment that can be difficult to use or maintain. Both flow systems suffer from only being able to test a single biofilm forming community per setup or experiment, as is a similar issue with the media flowing into the system. The media required to maintain the system is 
also a substantial amount, as the constant flow requires fresh media to be prepared based on the rate of flow (11).

In order to avoid some of the disadvantages of the previously described systems, a simple in vitro system was developed with the specific intention of mimicking bacterial growth in the mammalian gut. The developed gut system was designed to be simplistic in nature, making it accessible to other researchers interested in studying microbial communities in biofilms. The flow through of the natural gut was also considered, and the system was developed with a dilution system meant to mimic the diminishing and regrowth of the populations due to the constant flow of mucus (47). Additionally, due to the simple dilution of growth into fresh media, multiple variables could be tested on biofilms developed from a single source thus allowing the observation of multiple conditions on identical biofilm communities. The developed system is also small enough to be contained in a single microcentrifuge tube, which allows for multiple samples or experiments to be run in tandem.

\section{Materials and Methods}

\section{Bacterial strains:}

Bacterial strains used in this study are listed in Table 1. The original E. coli K12 strain was obtained from a stool sample from a convalescing diphtheria patient in Palo Alto, CA, in 1922 (Bachman BJ, 1996). The sequenced E. coli MG1655 strain (CGSC 7740) was derived from the original K-12 strain, having only been cured of the temperate bacteriophage lambda and the F plasmid by means of UV light and acridine orange treatment (7). It has an IS1 element in the $f l h D C$ promoter (16). E. coli Nissle 1917 was originally isolated during World War I from a soldier who escaped a severe 
outbreak of diarrhea (53). It has a beneficial effect on several types of intestinal disorders, is well tolerated by humans, and has been marketed as a probiotic remedy against intestinal disorders in several European countries since the 1920s (53). E. coli EDL933 is the prototype strain of enterohemorrhagic E. coli (EHEC) O157:H7 (45). The allelic exchange method described by Datsenko and Wanner (datsenko wanner 2001) was used to construct E. coli EDL933 $\operatorname{Str}^{\mathrm{R}} \Delta p p s A \Delta p c k A$ ::cam (Table 1), with deletions of 2,367 and 1,341 bp in the ppsA gene and the pckA gene, respectively. Phosphoenolpyruvate carboxykinase converts oxaloacetate to phosphoenolpyruvate and is encoded by the E. coli pckA gene (35). Phosphoenolpyruvate synthase is encoded by the E. coli ppsA gene and converts pyruvate to phosphoenolpyruvate (41). Since the conversion of TCA cycle intermediates to phosphoenolpyruvate is completely blocked in a ppsA pckA double mutant, it is unable to grow on gluconeogenic substrates "below" the step of phosphoenolpyruvate, but glycolytic pathways are not affected (18).

\section{Media and growth conditions:}

LB broth-Lennox (DIFCO) was prepared as directed (20 g/L in water) and sterilized. The approximate formula of LB broth Lennox (DIFCO) is listed as follows: $10 \mathrm{~g} / \mathrm{L}$ tryptone, $5 \mathrm{~g} / \mathrm{L}$ yeast extract, $5 \mathrm{~g} / \mathrm{L}$ sodium chloride. Bottles containing $10 \mathrm{ml}$ of LB broth Lennox (DIFCO) were inoculated with an individual strain of E. coli (Table 1) and allowed to grow for $18 \mathrm{~h}$ while shaking at $200 \mathrm{rpm}$ at $37^{\circ} \mathrm{C}$. The

overnight cultures grew to approximately $10^{9} \mathrm{CFU} / \mathrm{ml}$, which were then diluted to $10^{5}$ $\mathrm{CFU} / \mathrm{ml}$ in $20 \%(\mathrm{w} / \mathrm{v})$ sucrose when intended for mouse colonization, or HEPESHanks buffer when diluted for addition into the in vitro system. 
HEPES-Hanks buffer is $8 \mathrm{~g} / \mathrm{L} \mathrm{NaCl}, 0.4 \mathrm{~g} / \mathrm{L} \mathrm{KCl}, 0.185 \mathrm{~g} / \mathrm{L} \mathrm{CaCl}, 0.2 \mathrm{~g} / \mathrm{L} \mathrm{MgSO}_{4}, 0.5$ $\mathrm{g} / \mathrm{L} \mathrm{Na}_{2} \mathrm{HPO}_{4}, 0.35 \mathrm{~g} / \mathrm{L} \mathrm{KH}_{2} \mathrm{PO}_{4}$, and $2.6 \mathrm{~g} / \mathrm{L}$ HEPES in distilled water. This solution was brought to $\mathrm{pH} 7.2$ through addition of $\mathrm{NaOH}$ and filter sterilized (12). For the experiments in which agarose was added, agarose was prepared separately at $0.6 \%$ agarose $(\mathrm{w} / \mathrm{v})$ in distilled water and HEPES-Hanks buffer was prepared at twice the above listed concentrations. The agarose was prepared fresh daily, and, as autoclaving the agarose expels oxygen, provided further removal of oxygen from the samples. The agarose and HEPES-Hanks were then mixed 1:1.

For the in vitro gut model, cecal mucus samples were harvested from the $E$. coli colonized streptomycin-treated mice into $1 \mathrm{ml}$ of HEPES-Hanks buffer (pH7.2) including a reducing agent ( $3 \mathrm{mM}$ Cleland's reagent) to help prevent oxygen poisoning of the anaerobe population within the sample, as well as $500 \mathrm{ug} / \mathrm{ml}$ porcine intestinal mucin (Sigma). This sample was mixed thoroughly via pipetting, and then incubated in a BD anaerobic GasPak ${ }^{\mathrm{TM}}$ system (Becton, Dickinson and Company) overnight at $37^{\circ} \mathrm{C}$. The following day, a $100 \mu$ sample of the overnight growth cecal mucus bacterial culture was used to inoculate a fresh $1 \mathrm{ml}$ sample of HEPES-Hanks containing $2 \mathrm{mg} / \mathrm{ml}$ lyophilized mucus, $500 \mu \mathrm{g} / \mathrm{ml}$ Porcine intestinal mucin (Sigma), 3 $\mathrm{mM}$ Cleland's reagent, and $0.3 \%$ agarose. The freshly inoculated $1 \mathrm{ml}$ sample was labeled as Day 0 and incubated in a $\mathrm{BD}$ anaerobic GasPak ${ }^{\mathrm{TM}}$ system (Becton, Dickinson and Company) overnight at $37^{\circ} \mathrm{C}$. This procedure was repeated for 7 days, using $100 \mu \mathrm{l}$ to inoculate a new $1 \mathrm{ml}$ sample of fresh HEPES-Hanks containing 2 $\mathrm{mg} / \mathrm{ml}$ lyophilized mucus, $500 \mu \mathrm{g} / \mathrm{ml}$ Porcine intestinal mucin, $3 \mathrm{mM}$ Cleland's reagent, and $0.3 \%$ agarose. 
When using the in vitro method to compare colonization ability, slight alterations were made to accommodate multiple strains. Initial sampling remained the same, with pre-colonized mouse mucus being collected into $1 \mathrm{ml}$ of HEPES-Hanks buffer ( $\mathrm{pH}$ 7.2) including a reducing agent ( $3 \mathrm{mM}$ Cleland's reagent) to help prevent oxygen poisoning of the anaerobe population within the sample, as well as $500 \mu \mathrm{g} / \mathrm{ml}$ porcine intestinal mucin (Sigma). This sample was mixed thoroughly via pipetting, and then incubated in a $\mathrm{BD}$ anaerobic GasPak ${ }^{\mathrm{TM}}$ system (Becton, Dickinson and Company) overnight at $37^{\circ} \mathrm{C}$. On the same day as collection, strains to be used for competitions were grown overnight in $\mathrm{LB}$ at $37^{\circ} \mathrm{C}$ while shaking. The following day, a $10 \mu \mathrm{l}$ sample of the overnight culture was used to inoculate a fresh $1 \mathrm{ml}$ sample of HEPES-Hanks buffer containing $2 \mathrm{mg} / \mathrm{ml}$ lyophilized mucus, $500 \mu \mathrm{g} / \mathrm{ml}$ Porcine intestinal mucin (Sigma), 3mM Cleland's reagent, and $0.3 \%$ agarose. At this point, $10 \mu 1$ of the strains to be used for competition were diluted in at a final concentration of $10^{2}-10^{3}$ CFU, having been diluted in HEPES-Hanks buffer from the overnight culture. $10 \mu 1$ of the freshly made sample was used for serial dilutions and plating on Lactose MacConkey agar (DIFCO) containing antibiotics as previously described (also described below in 'Colonization Experiments') to obtain counts of, and differentiate between strains of $E$. coli within the population.

\section{Preparation of lyophilized cecal mucus}

Cecal mucus was collected via scraping from 15 mice into $30 \mathrm{ml}$ of HEPESHanks buffer. The mucus collections were then centrifuged using a Sorvall ${ }^{\mathrm{TM}} \mathrm{RC} 6$ Plus (Thermo Scientific) at an ref of $10,000 \times \mathrm{g}$ for 10 mins. The supernatant was collected without disturbing the pellet, at which point the collected supernatant was 
frozen at $-80^{\circ} \mathrm{C}$ and the pellet was discarded. Afterwards, the frozen supernatant was placed in a FreeZone Plus 12 Liter Cascade Console Freeze Dry System (LABCONCO) for $48 \mathrm{~h}$ to remove all liquid from the collected mucus. The lyophilized mucus was then stored at $-20^{\circ} \mathrm{C}$ until needed. This was done for each in vitro experiment.

\section{Colonization experiments:}

The specifics of the streptomycin-treated mouse model used to compare the large intestine colonizing abilities of E. coli strains in mice have been described previously $(34,39,56,58,60)$. Briefly, sets of three male CD-1 mice (5 to 8 weeks old) were given drinking water containing streptomycin sulfate $(5 \mathrm{~g} / \mathrm{L})$ for $24 \mathrm{~h}$ to eliminate resident facultative bacteria (37). Following $18 \mathrm{~h}$ of starvation for food and water, the mice were fed $1 \mathrm{ml}$ of $20 \%(\mathrm{w} / \mathrm{v})$ sucrose containing $10^{5} \mathrm{CFU}$, or $10^{10}, \mathrm{CFU}$ of LB broth Lennox (DIFCO) grown E. coli strains. After ingesting the bacterial suspension, both the food (Teklad mouse and rat diet; Harlan Laboratories, Madison, WI) and streptomycin-water were returned to the mice, and $1 \mathrm{~g}$ of feces was collected after $5 \mathrm{~h}, 24 \mathrm{~h}$, and on odd-numbered days at the indicated times. Mice were housed individually in cages without bedding and were placed in clean cages at 24-h intervals. Individual fecal pellets were therefore no older than $24 \mathrm{~h}$. Each fecal sample (1 gram) was homogenized in $10 \mathrm{ml}$ of $1 \%$ Bacto-Tryptone (DIFCO), diluted in the same medium, and plated on Lactose MacConkey agar plates (DIFCO) with appropriate antibiotics. When appropriate, $1 \mathrm{ml}$ of a fecal homogenate (which were sampled after the feces settled) were centrifuged at $12,000 \mathrm{x} g$, resuspended in $100 \mu \mathrm{l}$ of $1 \%$ BactoTryptone, and plated on a Lactose MacConkey agar plate (DIFCO) with appropriate 
antibiotics. This procedure increases the sensitivity of the assay from $10^{2} \mathrm{CFU} / \mathrm{gram}$ of feces to $10 \mathrm{CFU} / \mathrm{gram}$ of feces. To distinguish the various $E$. coli strains in feces, dilutions were plated on Lactose MacConkey agar (DIFCO) containing streptomycin sulfate $(100 \mu \mathrm{g} / \mathrm{ml})$, streptomycin sulfate $(100 \mu \mathrm{g} / \mathrm{ml})$ and nalidixic acid $(50 \mu \mathrm{g} / \mathrm{ml})$, streptomycin sulfate $(100 \mu \mathrm{g} / \mathrm{ml})$ and rifampicin $(50 \mu \mathrm{g} / \mathrm{ml})$, or streptomycin sulfate (100 $\mu \mathrm{g} / \mathrm{ml})$ and chloramphenicol (30 $\mu \mathrm{g} / \mathrm{ml})$. Streptomycin sulfate, chloramphenicol, rifampicin, and nalidixic acid were purchased from Sigma-Aldrich (St. Louis, MO). All plates were incubated for 18 to $24 \mathrm{~h}$ at $37^{\circ} \mathrm{C}$ prior to counting (28).

\section{Fluorescent in situ Hybridization (FISH):}

In order to observe how E. coli associate locally with members of the microbiota in vivo, we used Fluorescent In Situ Hybridization (FISH) on crosssections of cecum from streptomycin-treated mice colonized with a single strain of $E$. coli. These observations were used to compare the similar interactions in the in vitro system. This was done in parallel with community analysis sequencing of bacterial populations in mucus samples obtained from the cecum of similarly treated mice in order to compare the diversity of the in vivo and in vitro models. The mice included an uninoculated control set (blank $20 \%$ sucrose) and mice inoculated with E. coli Nissle 1917. Samples of conventional and Nissle 1917 inoculated mice were done simultaneously for 6 mice, which were colonized for 10 days. On the tenth day, mice were killed via $\mathrm{CO}_{2}$ and their ceca were harvested. Three of the mice from each set were used for FISH, while 3 of the mice from each set were used for community analysis sequencing of mucus samples. For in vitro samples, $10 \mu \mathrm{l}$ of the sample was 
used to prepare slides for FISH and the remaining sample was used for community analysis sequencing.

The cecum of a mouse designated for FISH was cut into $1-2 \mathrm{~cm}$ sections, suspended in TissueTek ${ }^{\circledR}$ O.C.T compound (Sakura Finetek USA, Inc.) and snap frozen in 2-methylbutane suspended in liquid nitrogen. Sections were then stored at $-80^{\circ} \mathrm{C}$ until ready for sectioning. For sectioning, the Vibratome UltraPro 5000 cryostat was used to cut sections at a thickness of $10 \mu \mathrm{m}$, which were adhered to polyL-lysine treated slides for visualization (LabScientific, Inc). Fixing of slides was done in 4\% Paraformaldehyde for 1 hour at room temperature, followed by a wash in PBS for $10 \mathrm{~min}$. Slides were allowed to dry overnight prior to hybridization. Fluorescent probes were diluted in hybridization solution consisting of $10 \mathrm{ml}$ of $1 \mathrm{M}$ Tris $\mathrm{pH} 7.2$, $18 \mathrm{ml}$ of $5 \mathrm{M} \mathrm{NaCl}$, and $0.1 \mathrm{~g}$ of SDS in a total volume of $100 \mathrm{ml} \mathrm{H}_{2} 0$. All slides with sections were treated using the FISH technique used by S. Macfarlane et al. (32), with hybridization of E.coli specific (5'-/5Cy3/CACCGTAGTGCCTCGTCATCA-3') Cy-3 probe (red) and Eubacteria specific (5'-GCTGCCTCCCGTAGGAGT/36-FAM/-3') FitC probe (green) at concentrations of $5 \mathrm{ng} / \mu \mathrm{l}$ and $25 \mathrm{ng} / \mu \mathrm{l}$, respectively. These probes were obtained from Integrated DNA Technologies (Coralville, IA). Briefly, $10 \mu \mathrm{l}$ of diluted probes in hybridization solution was pipetted to each slide, which were then covered with a HybriSlip hybridization cover (Life Technologies, Carlsbad, CA) and allowed to incubate in the dark for $2 \mathrm{~h}$ at $50^{\circ} \mathrm{C}$. After $2 \mathrm{~h}$ the slides were dipped in a wash buffer, which is simply hybridization solution without SDS added, and then allowed to soak in the wash buffer for $20 \mathrm{~min}$ at $50^{\circ} \mathrm{C}$. Slides were then rinsed with distilled water and allowed to dry overnight before viewing. Sections on poly-L- 
lysine treated slides were imaged using the Zeiss axioimager M2 imaging system with the Zeiss LSM 700 confocal microscope and corresponding lasers (Carl Zeiss, Oberkochen, Germany). The poly-L-lysine treated slides were additionally treated with Vectashield (Vector Laboratories, Inc.), an antibleaching agent which helps prolong fluorescence for imaging. This involves placing a small drop of Vectashield on the hybridized slide and then covering with a coverslip. Allowing 30 mins at room temperature for the Vectashield to dry made viewing easier, but was not absolutely necessary.

\section{Isolation of cecal mucus and DNA in cecal mucus and in in vitro samples:}

For each mouse cecum being used in sampling of microbiota in the mucus, mucus samples were scraped and collected into $5 \mathrm{ml}$ of HEPES-Hanks buffer (pH7.2). The in vitro samples were collected directly from overnight growth into DNA isolation kits. Microbial DNA was isolated using a MO BIO PowerSoil ${ }^{\mathrm{TM}}$ DNA Isolation Kit.

\section{Sequencing:}

PCR reactions to prepare samples for sequencing were performed similarly for all mucus scrapings and in vitro samples. Primers were designed to match those used in a study of the human gut microbiome which targeted the V4 variable region of the 16S rRNA (62). These primers were obtained from Integrated DNA Technologies (Coralville, IA) and were as follows: Forward (5'-TCG TCG GCA GCG TCA GAT GTG TAT AAG A-3') and Reverse (5'-GTC TCG TGG GCT CGG AGA TGT GTA TAA G-3'). Taq DNA polymerase (New England BioLabs, Ipswich, MA.) was added to each PCR reaction, which consisted of $25 \mu 1$ reactions: $2.5 \mu 1$ 10x Standard taq 
Reaction Buffer (New England BioLabs Inc.), 0.5 $\mu$ dNTP Solution Mix containing 10 $\mathrm{mM}$ of each dNTP (New England BioLabs Inc.), $0.5 \mu \mathrm{l}$ of a $100 \mu \mathrm{M}$ solution of each primer, $0.5 \mu \mathrm{l}$ of the aforementioned taq DNA polymerase (New England BioLabs), all added to $17.5 \mu \mathrm{l}$ of DEPC treated nuclease free sterile water (Fisher Scientific). Each PCR reaction began with an initial denaturation of $95^{\circ} \mathrm{C}$ for four min followed by a cycle of three steps repeated 35 times. These were as follows: denature at $95^{\circ} \mathrm{C}$ for 30 $\mathrm{s}$, annealing at $55^{\circ} \mathrm{C}$ for $20 \mathrm{~s}$, and extension at $72^{\circ} \mathrm{C}$ for $30 \mathrm{~s}$. Each PCR reaction ended with a final primer extension at $72^{\circ} \mathrm{C}$ for $4 \mathrm{~min}$. PCR was done using an Eppendorf® Mastercycler 5331 Gradient PCR Thermocycler (Westbury, NY). PCR products were checked via gel electrophoresis to be sure they contained one band of approximately $300 \mathrm{bp}$ before submission to the Rhode Island Genomics and Sequencing Center (RIGSC).

Once submitted to the RIGSC, after amplicon submission, a second round of PCR (5 cycles) to attach Nextera (Illumina) indices and adapters was performed. Round 2 PCR reactions were cleaned with Agencourt Ampure XP (Beckman Coulter, Inc.), visualized by agarose gel electrophoresis, and selected samples were analyzed using the Agilent BioAnalyzer DNA1000 chip (Illumina). Qubit quantification was performed on all samples prior to pooling, and KAPA quantification was performed on the final pooled library prior to loading on the MiSeq flow cell. The samples were then run on the Illumina MiSeq (Illumina RTA 1.17.28) hi-throughput sequencer.

\section{Sequencing analysis:}

Data output from the MiSeq comes as raw fastq files, which were then classified using the published Mothur pipeline version 1.33 (52). Sequence processing 
was aligned, cleaned of chimeric sequences, and classified using the MiSeq SOP (standard operating procedure) made available by the Mothur authors (52).

\section{The in vitro system observations:}

In order to visualize early microbial communities and how E. coli affects the growth of the anaerobes within mixed biofilms during early development in the in vitro system, FISH images were taken daily. $10 \mu$ of the overnight growth of the in vitro system was used to prepare and observe a slide using previously described FISH techniques. Another $10 \mu \mathrm{l}$ was used for serial dilutions and plating on Lactose MacConkey agar (DIFCO) containing antibiotics as previously described to obtain counts of $E$. coli within the population.

\section{Generating crude rarefaction curves}

Crude rarefaction curves were generated using the classifications generated through the Mothur pipeline (52) to group the sequences at the family level. This is done by randomly sampling from the families, with consideration that each family represents a unique member of the microbiota. A higher abundance of a specific family increases the likelihood that this specific family will be sampled, thus experiments with a majority of its members being represented by one or two families will have a lower measure of diversity when compared to those with abundance spread across more families. Actually having more unique families within an experiment will also increase the measure of diversity. Sampling was done from 100 picks to 5000 picks, with intervals of 100, and each was repeated 100 times. 


\section{Statistics}

Means and standard deviations derived from the indicated samples were compared by an unpaired Student's $t$ test $(P$ values). A $P$ value of $>0.05$ was interpreted as indicating no significant difference, and a $P$ value of $<0.05$ was interpreted as indicating a significant difference.

\section{$\underline{\text { Results }}$}

\section{Initial experiments to develop the in vitro system}

The in vitro model of the gut was designed to mimic the loose mucus layer found in the cecum of mice. To do this, the anaerobe populations needed to be protected from excessive oxygen stress. This was accomplished by adding $3 \mathrm{mM}$ of Cleland's reagent, a reducing agent that sequesters oxygen, thus providing the anaerobes with an oxygen free environment. In addition to this, $100 \mu \mathrm{g} / \mathrm{ml}$ of mucin was added to provide nutrients and an attachment site for the anaerobes to begin forming biofilms. $2 \mathrm{mg} / \mathrm{ml}$ of mucus was also added to provide an additional source of nutrients. All of these additives were dissolved into HEPES-Hanks buffer at $\mathrm{pH}$ 7.2, a buffer used for gut microbes that lacks any source of carbon or nitrogen (12). In order to mimic the constant flow through and growth present in the gut, samples were diluted into fresh mixtures containing Cleland's, mucin, and mucus in HEPES-Hanks buffer every 24 hours. It was shown that while the microbial populations collected from the mouse gut could survive 1-2 days in this in vitro system (Fig. 1), a majority of the anaerobic population was lost after 3 days (Fig. 2). In addition to losing diversity and quantity of anaerobes, $E$. coli that was spiked into the system grew to be 
a majority of the sample (Fig. 2). This contrasts what is seen in the natural environment inside mice, where $E$. coli is a minimal member of vast microbial biofilms (28).

\section{Increasing mucin concentration to $500 \mu \mathrm{g} / \mathrm{ml}$ improves diversity beyond day 3}

In an attempt to improve survivability of the anaerobe population, the mucin concentration was increased to $500 \mu \mathrm{g} / \mathrm{ml}$. The increase of mucin concentration not only provided anaerobes with more binding sites for initiating biofilm formation and food in the form of large polysaccharide chains, but also visibly increased the viscosity of the solution. This increase in viscosity better mimicked the loose mucus of the gut, possibly providing the microbe populations with an environment more akin to what they prefer in their natural hosts. This 5-fold increase in mucin concentration improved the in vitro system to the point where the anaerobe populations survived well up to day 5. However, day 6 showed a steep loss of anaerobe populations and again showed the E. coli taking over as the majority (Fig. 3).

\section{Adding agarose increases viscosity of solution and anaerobe survival}

While increasing the concentration of mucin in the system increased the viscosity of the samples, they were still not quite as viscous as what is seen in the loose layer of mucus. To increase the viscosity further, $0.3 \%$ agarose was added to the solution. The specific amount of agarose to add was found to be the highest amount that could be added and still be feasibly pipetted. This addition of agarose created an environment that appeared to be similar in viscosity to mucus of the loose layer. As such, biofilms formed by the microbes of the gut would no longer settle to the bottom of the sample and could instead create networks throughout. The agarose may also 
have provided additional protection from oxygen, as it would be more difficult for the oxygen to penetrate deep into the samples. The addition of agarose showed considerable improvement in the survivability of the anaerobe populations, with the populations remaining robust and diverse through day 6 (Fig. 4).

Precolonizing the mouse with E.coli prior to mucus collection further improves anaerobe survival in the in vitro system

In all previous experiments, E. coli was added after mucus samples were collected into the in vitro system. While the addition of agarose improved the longevity of anaerobe populations, E. coli growth was still higher than that seen in the mouse beyond day 6 . The anaerobe populations also seemed to decline, albeit slowly, as time progressed beyond day 6 . It was possible that this was due to E. coli being added to the cecal mucus preparations in vitro and not in vivo. In order to alleviate this, E. coli was fed to mice and allowed to colonize for 3 days prior to collection of the microbiota. This allowed the E. coli to form their relationships with their preferred anaerobes in the natural environment of these organisms. When E. coli was precolonized in mice prior to collection of the microbiota, anaerobe populations remained in high number and diversity through day 7 and beyond (Fig. 5, 6). Additionally, E. coli populations no longer grew to take over as majority members of the sample (Fig. 5, 6).

\section{Testing the necessity of the individual additives in the in vitro system}

Once the anaerobe populations were surviving beyond day 7 and the E. coli population was kept in check, it was necessary to test if all of the components within the in vitro system were actually involved in maintaining said populations. To 
accomplish this, growth in vitro was tested after the removal of a single component in parallel with a sample containing every component. In samples sans Cleland's reagent or mucin the anaerobe populations were lost within 1-2 days and the E. coli population grew to $10^{8} \mathrm{CFU} / \mathrm{ml}$ (Fig. 7). Without mucus, both the anaerobes and E. coli were lost (Fig. 8).

Can the concentration of mucus be adjusted in order to control the E. coli population?

With the in vitro system becoming more similar to the mouse gut, an attempt to control the E. coli population by adjusting the mucus concentration was tested. Several concentrations were tested: no mucus, $0.2 \mathrm{mg} / \mathrm{ml}$ mucus, and $2 \mathrm{mg} / \mathrm{ml}$ mucus (Fig. 8). While 10-fold less mucus $(0.2 \mathrm{mg} / \mathrm{ml})$ showed no noticeable decline in the $E$. coli population, the anaerobe population suffered considerably (Fig. 8). Even without any added mucus the $E$. coli was able to maintain itself to some degree $\left(1 \times 10^{7}\right.$ $\mathrm{CFU} / \mathrm{ml}$ ) (Fig. 8), likely due to the mucin not being completely purified of mono- and disaccharides.

\section{Comparing diversity of in vivo and in vitro samples}

To better compare the diversity of the in vitro system to what is seen in vivo, samples were taken from the in vitro Nissle 1917 pre-fed experiments after 7 days and used for community analysis sequencing. The pre-fed experiments were those in which mice were first colonized with Nissle 1917 for 3 days prior to collecting into the in vitro system. Community analysis of the in vitro samples at day 7 shows some diversity amongst major members of the population at the family level (Fig. 9). A stacked bar plot was generated to compare the diversity in individual experiments 
(Fig. 10). The in vivo and in vitro samples of Nissle 1917 have similar diversity with representation from the same set of families except Deferribacteraceae. However, the in vitro samples do have Deferribacteraceae at low levels, and are statistically similar when compared to the in vivo samples in terms of Deferribacteraceae using the student's t-test $(\mathrm{P}>0.05)$. At the phylum level, Bacteroidetes and Firmicutes are comparable to what is seen in vivo, but Deferribacteres has little representation (Fig. 11, Fig. 12). Again, the difference in levels of Deferribacteres are not statistically significant between the in vivo and in vitro samples $(\mathrm{P}>0.05)$.

In order to see if the overall population was similar in terms of overall diversity between the in vitro and the in vivo methods, a crude rarefaction curve was generated for select samples of each experimental type. When comparing 3 samples of E. coli Nissle 1917 in vitro to 3 samples of E. coli Nissle 1917 in vivo at the family level, both experimental types have similar levels of diversity (Fig. 13). This similarity in diversity when comparing the entire population, as opposed to the most abundant organisms within the population, suggests that the in vitro system is truly near the mouse gut in terms of community structure.

\section{Using conventional mice for the in vitro system}

While streptomycin treatment is important for testing the colonization ability of $E$. coli, cultivating the unaltered gut microbiome in vitro may be of more interest. As such, mice that were not treated with streptomycin (thus still containing the natural Proteobacteria) were killed and their mucus was collected for the in vitro system. Slides were prepared with FISH and images were taken for 7 days. Through day 7 , in vitro samples showed diversity in cell morphology and E. coli labeled cells were seen 
within mixed biofilms (Fig. 14). Community analysis of the samples at day 7 in vitro showed diversity amongst major members of the population at the family level (Fig. 15, Fig. 16), with members present within the in vitro system being comparable to those seen in in vivo samples, although differences between the in vitro and in vivo samples were seen in the Bacteroideaceae $(\mathrm{P}<0.0001)$, Deferribacteraceae $(\mathrm{P}<$ 0.001), and Lachnospiraceae $(\mathrm{P}<0.001)$. At the phylum level, Bacteroidetes were more abundant relative to Firmicutes in the conventional in vitro samples compared to what was seen in the in vivo samples, and Deferribacteres had little representation in vitro (Fig. 17, Fig. 18). The differences seen between each phylum; Bacteroidetes, Deferribacteres, and Firmicutes, are statistically significant $(\mathrm{P}<0.001$ for each). The loss of Firmicutes can be traced to the Lachnospiraceae family, which has a high abundance in the samples taken directly from mice but is considerably lower in the in vitro samples $(\mathrm{P}<0.01)$ (Fig. 15).

In order to see if the overall population was similar in terms of overall diversity between the in vitro and the in vivo methods, a crude rarefaction curve was generated for select samples of each experimental type. When comparing 3 conventional in vitro samples to 3 conventional in vivo samples at the family level, both experimental types have similar levels of diversity (Fig. 19). It is also apparent that conventional samples are more diverse than Nissle 1917 samples, likely due to the treatment of streptomycin prior to colonization. This similarity in diversity when comparing the entire population, as opposed to the most abundant organisms within the population, suggests that the in vitro system is truly near the mouse gut in terms of community structure. 
Testing the ability of pre-colonized strains to prevent later colonization with the same strain

When mice are pre-colonized with an E. coli strain, they are resistant to subsequent intestinal colonization by the same strain $(2,27)$. This is likely because the niches usually taken by these $E$. coli strains are already filled by the preexisting population. To test if this is true in the in vitro system, mice were pre-colonized with either Nissle 1917 or MG1655 and then collected into the in vitro system after 3 days of colonization. After 7 days in the in vitro system, the identical strain was spiked in at $10^{3} \mathrm{CFU} / \mathrm{ml}$ (Nissle 1917 for Nissle 1917, and MG1655 for MG1655). As expected, pre-colonized Nissle 1917 prevented the late fed Nissle 1917 from growing up (Fig. 20), and pre-colonized MG1655 prevented late fed MG1655 from growing to higher numbers (Fig. 21).

\section{Testing the colonization ability of Nissle vs MG1655 in vitro}

Once the populations were maintained, it was important to test if the in vitro system was truly mimicking the mouse gut. To do this, competition between E. coli strains that had been previously tested in mouse colonization experiments were used. Mice were initially inoculated with the Nissle 1917 for 3 days, and then the microbiota was collected into the in vitro system. The populations were sustained for 7 days, and then MG1655 was spiked in at $10^{5} \mathrm{CFU} / \mathrm{ml}$. In vivo, mice fed Nissle 1917 early and MG1655 late show no direct competition between the strains, i.e. as Nissle 1917 and MG1655 can outcompete one another on one or more sugars, they are able to cocolonize in vivo without issue (17). In vitro, MG1655 was not able to co-colonize 
with Nissle 1917, and dropped below detectable numbers 4 days after being spiked in (Fig. 22). However, the reverse showed more promising results. When MG1655 is fed early and Nissle 1917 fed late in mice, they are able to co-colonize as they are not in direct competition (17). This proved to be true in vitro as well, when MG1655 was fed early to mice before collection and Nissle 1917 was spiked in at day 7 in vitro (Fig. 23).

In the presence of E. coli Nissle 1917, E. coli EDL933 uses gluconeogenesis to colonize the in vitro system as it does in vivo.

In vivo, EDL933 uses gluconeogenesis when co-colonized with Nissle 1917 in order to maintain itself within the gut (51). This is known because when a mouse is pre-colonized with Nissle 1917 for 10 days and then fed $10^{5}$ CFU each of EDL933 wildtype and EDL933 ppsA pckA (a mutant unable to grow on gluconeogenic nurients "below" phosphoenolpyruvate) the mutant EDL933 is unable to compete and falls to undetectable numbers (51).

In order to test if the in vitro system mimicked the mouse gut, this experiment was repeated in vitro. To do this, Nissle 1917 was pre-colonized in mice at $10^{5}$ CFU/ml for 10 days, and EDL933 and EDL933 ppsA- pckA- were spiked into the in vitro system at $10^{3} \mathrm{CFU} / \mathrm{ml}$ one day after collection. EDL933 wildtype and the EDL933 ppsA-pckA- mutant were spiked at $10^{3} \mathrm{CFU} / \mathrm{ml}$ because they were spiked into a fresh dilution of the microbiota, which would leave Nissle 1917 at approximately $10^{7} \mathrm{CFU} / \mathrm{ml}$. This would give a difference of $10^{4} \mathrm{CFU} / \mathrm{ml}$, the same difference when fed late to mice. When the in vitro experiment was performed with Nissle 1917 pre-colonized for 10 days after which the wildtype EDL933 and the 
EDL933 ppsA-pckA- mutant were spiked into the in vitro system one day after collection, it mimicked the mouse experiments (Fig. 24), i.e Nissle 1917 colonized at approximately $10^{8} \mathrm{CFU} / \mathrm{ml}$, EDL933 wildtype maintained itself at approximately $10^{4}$ CFU/ml, and EDL933 ppsA- pckA- fell below detectable numbers by day 4 .

\section{EDL933 vs. EDL933 ppsA-pckA-}

In mice, EDL933 and EDL933 ppsA-pckA- can co-colonize equally well in the absence of Nissle 1917 (51), suggesting that in the absence of Nissle 1917, EDL933 is not forced to use gluconeogenic substrates in order to compete and thus the nongluconeogenic mutant is not at a disadvantage. This was tested in the in vitro system by collecting mucus from streptomycin treated mice for collection into the in vitro solution, and EDL933 and EDL933 ppsA- pckA- were spiked into the in vitro system at $10^{3} \mathrm{CFU} / \mathrm{ml} 1$ day after collection. Initially, both strains were able to grow to similar counts at approximately $10^{7} \mathrm{CFU} / \mathrm{ml}$, but eventually the EDL933 ppsA- pckAmutant began to drop. Unlike in mice, the EDL933 and EDL933 ppsA-pckA- were unable to co-colonize, with the EDL933 ppsA- pckA- mutant falling below detectable numbers after 10 days in vitro (Fig. 25).

\section{Discussion}

In this study, an in vitro method for cultivating the microbiota of the mammalian gut was developed. This method will allow us to study the relationship between $E$. coli and the rest of the gut microbiota with more control and accessibility than in in vivo models, such as the streptomycin treated mouse model. While other in vitro methods have been developed to study biofilms from various environments, this 
novel method was designed specifically for the gut microbiota, and it was kept as simple and user friendly as possible.

During the development of this in vitro method, samples of growth from the in vitro system were submitted for community analysis sequencing of the microbial community. These samples were taken from day 7 in vitro samples of Nissle 1917 and another set of samples in which the cecal mucus of untreated mice (not colonized with $E$. coli or treated with streptomycin) were collected into the in vitro system (labeled "conventional"). The in vitro samples were compared to in vivo samples prepared similarly, by either pre-colonizing mice with Nissle 1917 for 10 days, at which point the mice were killed and mucus was collected, or in vivo samples that were collected from untreated (conventional) mice.

By comparing the Nissle 1917 in vivo and in vitro samples at the phylum level it can be seen that a similar spread of major members of the population can survive within the in vitro system, but a loss in the relative abundance of certain organisms occurs (Fig. 11, Fig. 12). While the abundance of Firmicutes and Bacteroidetes are comparable between the in vivo and in vitro methods, Deferribacteres seems to have trouble surviving the in vitro system. Deferribacteres is not completely lost, as it is present at lower levels in these samples but still exists.

At the family level, both Nissle 1917 in vitro and in vivo samples have representatives from the same families (Fig. 9, Fig. 10). Deferribacteriaceae has relatively low levels of representation in the in vitro system, but again is still present. However, the loss of relative abundance of these major members does not coincide 
with an overall loss of diversity as shown by (Fig. 13) with both in vivo and in vitro samples of Nissle 1917 showing similar levels of diversity.

When comparing phyla of the conventional samples, in vitro to in vivo, a similar loss of Deferribacteres is seen (Fig. 17). Again, this loss is not a complete clearing of Deferribacteres but rather a loss in the relative abundance of the organism. The diversity of major members at the family level is much higher in the conventional samples (in vitro and in vivo), with a larger spread across various families than that seen in the Nissle 1917 samples (Fig. 15). Furthermore, the diversity of the individual conventional samples was much more robust than the Nissle 1917 samples both in vivo and in vitro, showing higher diversity in a crude rarefaction curve (Fig. 19). This shows that the conventional samples in vitro are truly diverse, and also mimic the in vivo conventional samples in level of diversity.

Deferribacteres is a relatively recently described lineage, but one genus of Deferribacteres, Mucispirillum, has been identified as existing in the mammalian gut and being able to degrade mucin $(22,49)$. Interestingly, Deferribacteres were lower in many of the in vitro samples, possibly due to the low concentration of mucin which Mucispirillum utilizes for growth. Lachnospiraceae is a member of the Firmicutes that is able to produce butyric acid and has been previously linked to obesity (36). Ruminococcaceae, another Firmicutes, has been previously shown to exist in the gut, but is difficult to classify and is often a mistakenly identified Lachnospiraceae (31). Paenibacillaceae is a Firmicutes with species that exist as plant growth promoting rhizobacteria and may have been introduced through the feed given to mice (5). The s24-7 family is a member of the Bacteroidetes that has been found to inhabit the 
mouse gut, but little else has been described (19). Another bacteroidetes, Porphyromonadaceae, has been previously shown to occasionally inhabit the gut, but more often resides in oral cavities as a pathogen (40). Rikanellaceae is another Bacteroidetes that has a recently reclassified member, Alistepes putredinis which was previously classified as a Bacteroides and shows similarities with Bacteroides fragilis and members of Porphyromonadaceae (48). Bacteroidaceae contains the Bacteroides genus, which can use simple sugars when available, but use glycans as a main source of energy (33).

In order to show that the novel in vitro system could mimic the mouse in terms of colonization ability, a series of tests were done using the new in vitro system in parallel to those done with mice. Early attempts at comparing in vivo colonization experiments to those done in vitro proved that the system was not quite identical to the mouse, but similarities were present. When mice are pre-colonized with an E. coli strain, they are resistant to subsequent intestinal colonization by the same strain $(2$, 27). This was tested in the in vitro method with Nissle 1917 and MG1655, and this colonization resistance was also seen in the in vitro system (Fig. 20, Fig. 21). However, it was previously shown that colonization by a different strain would be possible, so long as the pre-fed strain and the new strain were not in direct competition for sugars (17). This was again tested in vitro using Nissle 1917 and MG1655. When MG1655 was pre-fed and Nissle 1917 was added late, Nissle 1917 was able to grow up with MG1655 as is seen in mice (Fig. 23). In contrast, when Nissle 1917 was prefed and MG1655 was added late, MG1655 was unable to grow up against Nissle 1917 and was eventually washed out of the system (Fig. 22). This may be due to the system 
developing early with Nissle 1917, thus promoting an anaerobe population that is more preferential for the growth of Nissle 1917. If said population only produced mono- and disaccharides that resulted in Nissle 1917 and MG1655 growing in direct competition, with Nissle 1917 being able to grow faster on the supplied sugars, MG1655 would be unable to colonize and would eventually fall below detectable numbers. It is also possible that Nissle 1917 may use up all the nutrients in vitro, but not in vivo, as nutrients are likely more limited in the in vitro system. Another possibility is that the flow through of the gut is important for either directly keeping the population of Nissle 1917 in check, or for keeping certain key anaerobes in check that give Nissle 1917 a competitive edge over MG1655. This same effect could be carried out by the innate immune system of the gut. Considering that when MG1655 was pre-fed and Nissle 1917 was added late both were able to grow and colonize equally well, it is unlikely to be due to population control via flow or the innate immune system. It is important to note that as these experiments were done early in the development of the system, mice were only pre-colonized for 3 days prior to being moved into the in vitro system, and then allowed a further 7 days for the pre-colonized E. coli strain to settle before spiking in the competing strain. Perhaps allowing the pre-colonized strain to remain in mice for the full 10 days prior to collection into the in vitro system could improve these colonizations.

Another competition chosen was Nissle 1917 fed early against EDL 933 wildtype and EDL933 ppsA- pckA-. EDL933 is an enterohemorrhagic E. coli (EHEC), and the mutant EDL933 ppsA- pckA- is unable to utilize gluconeogenic substrates (51). In mice, Nissle 1917 keeps EDL933 wildtype from colonizing higher 
than $10^{6} \mathrm{CFU} / \mathrm{gfeces}$ and EDL933 ppsA- pckA- is unable to colonize, falling below detectable numbers after only a few days (51). In the mice, late fed strains are fed 10 days after the pre-colonizing strain. To better mimic this, an experiment was done in which the pre-colonizing strain was allowed to remain in the mice for 10 days prior to collecting into the in vitro system. In this experiment, Nissle 1917 was fed to the mice while the EDL 933 and EDL 933 ppsA-pckA- strains were added later to the in vitro system. This experiment mimicked the mouse experiment, showing that the in vitro method was beginning to more mimic the mouse (Fig. 24).

A final experiment was done to see how closely the in vitro system mimicked the mouse gut in terms of colonization ability. In the absence of Nissle 1917, EDL933 and EDL933 ppsA-pckA- are able to colonize equally well when initially colonized at the same concentration (51). This was tested in the in vitro system by collecting mucus from streptomycin treated mice and spiking EDL933 and EDL933 ppsA- pckAinto the collection solution. While the experiment went well early on, with both strains growing to $10^{7} \mathrm{CFU} / \mathrm{ml}$, an eventual loss in EDL933 pps A- pckA- shows that the system is not yet perfect (Fig. 25). It is likely that the lower concentration of mucin and mucus in the in vitro system results in less mono- and disaccharides being made available by the anaerobe population for the EDL933 and EDL933 ppsA-pckAstrains to grow without the use of gluconeogenic substrates. Through limitation of glycolytic substrates, this forced gluconeogenic shift would give the wildtype EDL933 a distinct advantage over EDL933 ppsA- pckA-, as the mutant cannot use gluconeogenesis. 
At this point the novel in vitro model designed to mimic the mouse gut is capable of cultivating the microbiota of the gut, but is only able to mimic certain colonization experiments of E. coli competitions. In terms of mimicking the diversity of the gut, only the relative abundance of certain members of the community is affected by growth in the in vitro system. This may be overcome by slight alterations to the system, such as an increase in the concentrations of mucin and/or mucus in order to provide more nutrients to these populations. This may also have an effect on the colonization experiments, as the key factor in these competitions is the availability of specific substrates within specific niches. Even continued streptomycin treatment within the in vitro system must be considered, as at this point streptomycin treatment stops once removed from the mouse. The streptomycin may be important for maintaining a clear niche for some of these competing strains to move into, thus resulting in the loss of a competitive advantage by not continuing streptomycin treatment within the in vitro system. Furthermore, the early competitions involving Nissle 1917 and MG1655 may be improved if the pre-colonizing strain is allowed to remain in mice for a full 10 days prior to collection. The innate host immune system may also be key in maintaining a balanced ecosystem within the gut $(10,13,44,54)$, and as such may be important for the development of available niches to colonizing $E$. coli strains. Thus, while the system is useful for observing the microbial community of the mouse gut and the interactions with a single colonizing E. coli strain, the novel in vitro gut model must be further improved in order to assess colonization ability of individual E. coli strains. 


\section{$\underline{\text { References }}$}

1. Allen A. 1984. The structure and function of gastrointestinal mucus, p 3-11. In Boedeker EC (ed), Attachment of organisms to the gut mucosa, vol II. CRC Press, Boca Raton, FL.

2. Apperloo-Renkema H. Z., B. D. Van der Waaij, and D. Van der Waaij. 1990. Determination of colonization resistance of the digestive tract by biotyping of Enterobacteriaceae. Epidemiol Infect. 105(2): 355-361.

3. Atuma C, Strugala V, Allen A, Holm L. 2001. The adherent gastrointestinal mucus gel layer: thickness and physical state in vivo. Am J Physiol Gastrointest Liver Physiol 280:G922-929.

4. Baughn, A. D., and M. H. Malamy. 2004. The strict anaerobe Bacteroides fragilis grows in and benefits from nanomolar concentrations of oxygen. Nature 427:441-444.

5. Bloemberg GV, Lugtenberg BJ. 2001. Molecular basis of plant growth promotion and biocontrol by rhizobacteria. Curr Opin Plant Biol. 4:343-350.

6. Busscher, H.J., van der Mei, H.C., 2006. Microbial adhesion in flow displacement systems. Clin. Microbiol. Rev. 19, 127-141.

7. Blattner FR, Plunkett G III, Bloch CA, Perna NT, Burland V, Riley M, ColladoVides J, Glasner JD, Rode CK, Mayhew GF, Gregor J, Davis NW, Kirkpatrick HA, Goeden MA, Rose DJ, Mau B, Shao Y. 1997. The complete genome sequence of Escherichia coli K-12. Science 277: 1453-1462.

8. Cerca, N., Martins, S., Cerca, F., Jefferson, K.K., Pier, G.B., Oliveira, R., Azeredo, J., 2005. Comparative assessment of antibiotic susceptibility of coagulase-negative 
staphylococci in biofilm versus planktonic cultures as assessed by bacterial enumeration or rapid XTT colorimetry. J. Antimicrob. Chemother. 56, 331-336.

9. Chandra, J., Kuhn, D.M., Mukherjee, P.K., Hoyer, L.L., McCormick, T., Ghannoum, M.A., 2001. Biofilm formation by the fungal pathogen Candida albicans: development, architecture and drug resistance. J. Bacteriol. 183, 5385-5394.

10. Clarke MB, Sperandio V. 2005. Events at the host-microbial interface of the gastrointestinal tract III. Cell-to-cell signaling among microbial flora, host, and pathogens: there is a whole lot of talking going on. Am J Physiol Gastrointest Liver Physiol 288:G1105-1109.

11. Coenye T, Nelis HJ. 2010. In vitro and in vivo model systems to study microbial biofilm formation. J Microbiol Methods. 83(2):89-105.

12. Cohen, P.S. and Laux, D.C., Bacterial adhesion to and penetration of intestinal mucus in vitro. In Methods in Enzymology, Adhesion of Microbial Pathogens, R.J. Doyle and I. Ofek (eds.), Academic Press, Orlando, FL 253:309-315, 1995.

13. Cole AM, Ganz T. 2005. Defensins and other antimicrobial peptides: innate defense of mucosal surfaces, p 17-34. In Nataro JP, Cohen PS, Mobley HLT, Weiser JN (ed), Colonization of mucosal surfaces. ASM Press, Washington, DC.

14. Doyle, R.J., 1999. Methods in Enzymology Volume 310: Biofilms. Academic Press, San Diego, California.

15. Eckburg, P. B., E. M. Bik, C. N. Bernstein, E. Purdom, L. Dethlefsen, M. Sargent, S. R. Gill, K. E. Nelson, and D. A. Relman. 2005. Diversity of the human intestinal microbial flora. Science 308:1635-1638. 
16. Fabich A. J., M. P. Leatham, J. E. Grissom, G. Wiley, H. Lai, F. Najar, B. A. Roe, P. S. Cohen, and T. Conway. 2011. Genotype and phenotypes of an intestine-adapted Escherichia coli K-12 mutant selected by animal passage for superior colonization. Infect Immun. 79:2430-2439.

17. Freter, R., H. Brickner, J. Fekete, M. M. Vickerman, and K. E. Carey. 1983. Survival and implantation of Escherichia coli in the intestinal tract. Infect. Immun. 39:686-703.

18. Goldie, A. H., and B. D. Sanwal. 1980. Genetic and physiological characterization of Escherichia coli mutants deficient in phosphoenolpyruvate carboxykinase activity. J. Bacteriol. 141:1115-1121.

19. Harris, J. K., El Kasmi, K. C., Anderson, A. L., Devereaux, M. W., Fillon, S. A., Robertson, C. E., Wagner B. D., Stevens M. J., Pace N. R., Sokol, R. J. 2014. Specific Microbiome Changes in a Mouse Model of Parenteral Nutrition Associated Liver Injury and Intestinal Inflammation. PLoS ONE, 9(10), e110396.

20. He, G., R. A. Shankar, M. Chzhan, A. Samouilov, P. Kuppusamy, and J. L. Zweier. 1999. Noninvasive measurement of anatomic structure and intraluminal oxygenation in the gastrointestinal tract of living mice with spatial and spectral EPR imaging. Proc. Natl. Acad. Sci. USA 96:4586-4591.

21. Heersink, J., Goeres, D., 2003. Reactor design considerations. In: Hamilton, M., Heersink, J., Buckingham-Meyer, K., Goeres, D. (Eds.), The Biofilm Laboratory: Step-by-step Protocols for Experimental Design, Analysis, and Data Interpretation. Cytergy Publishing, Bozeman, pp. 13-15. 
22. Huber, H. \& Stetter, K. O. 2001. Class I. Deferribacteres class. nov. In Bergey's Manual of Systematic Bacteriology, 2nd edn, vol. 1, p. 465. Edited by D. R. Boone, R. W. Castenholz \& G. M. Garrity. New York: Springer.

23. Imamura, Y., Chandra, J., Mukherjee, P.K., Lattif, A.A., Szczotka-Flynn, L.B., Pearlman, E., Lass, J.H., O'Donnell, K., Ghannoum, M.A., 2008. Fusarium and Candida albicans biofilms on soft contact lenses: model development, influence of lens type, and susceptibility to lens care solutions. Antimicrob. Agents Chemother. 52: $171-182$.

24. Johansson ME, Larsson JM, Hansson GC. 2011. The two mucus layers of colon are organized by the MUC2 mucin, whereas the outer layer is a legislator of hostmicrobial interactions. Proc Natl Acad Sci U S A 108 (Suppl 1):4659-4665.

25. Jones, S. A., F. Z. Chowdhury, A. J. Fabich, A. Anderson, D. M. Schreiner, A. L. House, S. M. Autieri, M. P. Leatham, J. L. Lins, M. Jorgensen, P. S. Cohen, and T. Conway. 2007. Respiration of Escherichia coli in the mouse intestine. Infec. And Imm. 75: 4891-4899

26. Krom, B.P., Cohen, J.B., McElhaney Feser, G.E., Cihlar, R.L., 2007. Optimized Candida biofilm microtiter assay. J. Microbiol. Method 68, 421-423.

27. Leatham, M. P., S. Banerjee, S. M. Autieri, R. Mercado-Lubo, T. Conway, and P. S. Cohen. 2009. Precolonized human commensal Escherichia coli strains serve as a barrier to E. coli $\mathrm{O} 157: \mathrm{H} 7$ growth in the streptomycin-treated mouse intestine. Infect. Immun. 77:2876-2886.

28. Leatham-Jensen, M. P., J. Frimodt-Møller, J. Adediran, M. E. Mokszycki, M. E. Banner, J. E. Caughron, K. A. Krogfelt, T. Conway, P. S. Cohen. 2012. The 
streptomycin-treated mouse intestine selects Escherichia coli envZ missense mutants that interact with a dense and diverse intestinal microbiota. Infec. Immun. 80: 17161727.

29. Levitt, M. D., and J. H. Bond. 1980. Flatulence. Annu. Rev. Med. 31:127-137.

30. Ley, R. E., F. Backhed, P. Turnbaugh, C. A. Lozupone, R. D. Knight, and J. I. Gordon. 2005. Obesity alters gut microbial ecology. Proc. Natl. Acad. Sci. USA. 102:11070-11075.

31. Liu, C.; Finegold, S. M.; Song, Y.; Lawson, P. A. 2008. Reclassification of Clostridium coccoides, Ruminococcus hansenii, Ruminococcus hydrogenotrophicus, Ruminococcus luti, Ruminococcus productus and Ruminococcus schinkii as Blautia coccoides gen. nov., comb. nov., Blautia hansenii comb. nov., Blautia hydrogenotrophica comb. nov., Blautia luti comb. nov., Blautia producta comb. nov., Blautia schinkii comb. nov. and description of Blautia wexlerae sp. nov., isolated from human faeces. International Journal of Systematic and Evolutionary Microbiology (Society for General Microbiology) 58 (8): 1896-1902.

32. Macfarlane, S, E. J. Woodmansey, and G.T. Macfarlane. Colonization of mucin by human intestinal bacteria and establishment of biofilm communities in a two-stage continuous culture system. 2005. App. And Enviro. Microbiol. 71: 7483-7492.

33. Martens EC, Chiang HC, Gordon JI. 2008. Mucosal Glycan Foraging Enhances Fitness and Transmission of a Saccharolytic Human Gut Bacterial Symbiont. Cell Host Microbe 13 (4): 447-57. 
34. McCormick, B. A., D. P. Franklin, D. C. Laux, and P. S. Cohen. 1989. Type 1 pili are not necessary for colonization of the streptomycin-treated mouse large intestine by type 1-piliated Escherichia coli F-18 and E. coli K-12. Infect. Immun. 57:3022-3029. 35. Medina, V., R. Pontarollo, D. Glaeske, H. Tabel, and H. Goldie. 1990. Sequence of the pckA gene of Escherichia coli K-12: relevance to genetic and allosteric regulation and homology of E. coli phosphoenolpyruvate carboxykinase with the enzymes from Trypanosoma brucei and Saccharomyces cerevisiae. J. Bacteriol. 172:7151-7156.

36. Meehan, Conor J \& Beiko, Robert G. 2014. A Phylogenomic View of Ecological Specialization in the Lachnospiraceae, a Family of Digestive Tract-associated Bacteria. Genome Biol Evol. doi: 10.1093/gbe/evu050

37. Miller, C. P., and M. Bohnhoff. 1963. Changes in the mouse's enteric microbiota associated with enhanced susceptibility to Salmonella infection following streptomycin treatment. J. Infect. Dis. 113:59-66.

38. Miranda RL, Conway T, Leatham MP, Chang DE, Norris WE, Allen JH, Stevenson SJ, Laux DC, Cohen PS 2004. Glycolytic and gluconeogenic growth of Escherichia coli O157:H7 (EDL933) and E. coli K-12 (MG1655) in the mouse intestine. Infect Immun 72:1666-1676.

39. Myhal, M. L., D. C. Laux, and P. S. Cohen. 1982. Relative colonizing abilities of human fecal and K 12 strains of Escherichia coli in the large intestines of streptomycin treated mice. Eur. J. Clin. Microbiol. 1:186-192.

40. Naito M, Hirakawa H, Yamashita A, et al. 2008. Determination of the Genome Sequence of Porphyromonas gingivalis Strain ATCC 33277 and Genomic 
Comparison with Strain W83 Revealed Extensive Genome Rearrangements in P. gingivalis. DNA Res. 15 (4): 215-25.

41. Niersbach, M., F. Kreuzaler, R. H. Geerse, P. W. Postma, and H. J. Hirsch.1992. Cloning and nucleotide sequence of the Escherichia coli K-12 ppsA gene, encoding PEP synthase. Mol. Gen. Genet. 231:332-336.

42. Niu, C., Gilbert, E.S., 2004. Colorimetric method for identifying plant essential oil components that affect biofilm formation and structure. Appl. Environ. Microbiol. 70: $6951-6956$.

43. Palestrant, D., Z. E. Holzknecht, B. H. Collins, W. Parker, S. E. Miller, and R. R. Bollinger. 2004. Microbial biofilms in the gut: visualization by electron microscopy and by acridine orange staining. Ultrastruct. Pathol. 28:23-27.

44. Pasetti MF, Salerno-Gonçalves R, Sztein MB. 2005. Mechanisms of adaptive immunity that prevent colonization of mucosal surfaces, p 35-47. In Nataro JP, Cohen PS, Mobley HLT, Weiser JN (ed), Colonization of mucosal surfaces. ASM Press, Washington, DC.

45. Perna NT, Plunkett G 3rd, Burland V, Mau B, Glasner JD, Rose DJ, Mayhew GF, Evans PS, Gregor J, Kirkpatrick HA, Pósfai G, Hackett J, Klink S, Boutin A, Shao Y, Miller L, Grotbeck EJ, Davis NW, Lim A, Dimalanta ET, Potamousis KD, Apodaca J, Anantharaman TS, Lin J, Yen G, Schwartz DC, Welch RA, Blattner FR. 2001. Genome sequence of enterohaemorrhagic Escherichia coli O157:H7. Nature 409:529533. 
46. Ramage, G., Vande Walle, K., Wickes, B.L., Lopez-Ribot, J.L., 2001. Standardized method for in vitro antifungal susceptibility testing of Candida albicans biofilms. Antimicrob. Agents Chemother. 45, 2475-2479.

47. Rang CU, Licht TR, Midtvedt T, Conway PL, Chao L, Krogfelt KA, Cohen PS, Molin S. 1999. Estimation of growth rates of Escherichia coli BJ4 in streptomycintreated and previously germfree mice by in situ rRNA hybridization. Clin Diagn Lab Immunol 6:434-436.

48. Rautio M, Eerola E, Vaisanen-Tunkelrott ML, Molitoris D, Lawson P, Collins MD, Jousimies-Somar H. 2003. Reclassification of Bacteroides putredinis (Weinberg et al., 1937) in a new genus Alistipes gen. nov., as Alistipes putredinis comb. nov., and description of Alistipes finegoldii sp. nov., from human sources. Syst Appl Microbiol. 26(2):182-8.

49. Robertson BR, O'Rourke JL, Neilan BA, Vandamme P, On SLW, Fox JG et al. 2005. Mucispirillum schaedleri gen. nov., sp. nov., a spiral-shaped bacterium colonizing the mucus layer of the gastrointestinal tract of laboratory rodents. Int J Syst Evol Microbiol. 55: 1199-1204.

50. Schaller, M., Zakikhany, K., Naglik, J.R., Weindl, G., Hube, B., 2006. Models of oral and vaginal candidiasis based on in vitro reconstituted human epithelia. Nat. Protoc. 1: 2767-2773.

51. Schinner SA, Mokszycki ME, Adediran J, Leatham-Jensen M, Conway T, Cohen PS. 2015. Escherichia coli EDL933 Requires Gluconeogenic Nutrients To Successfully Colonize the Intestines of Streptomycin-Treated Mice Precolonized with E. coli Nissle 1917. Infect Immun 83:1983-1991. 
52. Schloss, P.D., et al., Introducing mothur: Open-source, platform-independent, community-supported software for describing and comparing microbial communities. Appl Environ Microbiol, 2009. 75(23):7537-41.

53. Schulze, J, Sonnenborn, U. 1995. Oral administration of a certain strain of live Escherichia coli for intestinal disorders? Infection 23:184-188.

54. Stecher B, Hardt WD. 2011. Mechanisms controlling pathogen colonization of the gut. Curr Opin Microbiol 14:82-91.

55. Stecher, B., R. Robbiani, A. W. Walker, A. M. Westendorf, M. Barthel, M. Kremer, S. Chaffron, A. J. MacPherson, J. Buer, J. Parkhill, G. Dougan, C. von Mering, and W. D. Hardt. 2007. Salmonella enterica serovar typhimurium exploits inflammation to compete with the intestinal microbiota. PLoS Biol. 5:2177-2189.

56. Swidsinski, A., J. Weber, V. Loening-Baucke, L. P. Hale, and H. Lochs. 2005. Spatial organization and composition of the mucosal flora in patients with inflammatory bowel disease. J. Clin. Microbiol. 43:3380-3389.

57. Sweeney, N. J., P. Klemm, B. A. McCormick, E. Moller-Nielsen, M. Utley, M. A. Schembri, D. C. Laux, and P. S. Cohen. 1996. The Escherichia coli K-12 gntP gene allows $E$. coli $\mathrm{F}-18$ to occupy a distinct nutritional niche in the streptomycin-treated mouse large intestine. Infect. Immun. 64:3497-3503.

58. Sweeney, N. J., D. C. Laux, and P. S. Cohen. 1996. Escherichia coli F-18 and K12 eda mutants do not colonize the streptomycin-treated mouse large intestine. Infect. Immun. 64:3504-3511.

59. Walker, C., Sedlacek, M.J., 2007. An in vitro biofilm model of subgingival plaque. Oral Microbiol. Immunol. 22, 152-161. 
60. Wadolkowski, E. A., D. C. Laux, and P. S. Cohen. 1988. Colonization of the streptomycin-treated mouse large intestine by a human fecal Escherichia coli strain: role of growth in mucus. Infec. Immun. 56: 1030-1035.

61. Wolfaardt, G.M., Korber, D.R., Lawrence, J.R., 2007. Cultivation of microbial consortia and communities, In: Hurst, C.J., Crawford, R.L., Garland, J.L., Lipson, D.A., Mills, A.L., Stetzenbach, L.D. (Eds.), Manual of Environmental Microbiology, 3 rd Ed. American Society for Microbiology Press, Washington, D.C., pp. 101-111. 62. Yatsunenko $\mathrm{T}$ et al. 2012. Human gut microbiome viewed across age and geography. Nature 486:222-227 
Table 1. Bacterial strains

\begin{tabular}{|c|c|c|c|}
\hline E. coli strain & Genotype/phenotype & $\begin{array}{l}\text { Designation in } \\
\text { text }\end{array}$ & $\begin{array}{l}\text { Source or } \\
\text { reference }\end{array}$ \\
\hline MG1655 $\mathrm{Str}^{\mathrm{R}}$ & $\begin{array}{l}\text { Spontaneous streptomycin } \\
\text { resistant mutant of MG1655 }\end{array}$ & MG1655 & 6 \\
\hline $\begin{array}{l}\text { Nissle } 1917 \mathrm{Str}^{\mathrm{R}} \\
\mathrm{Nal}^{\mathrm{R}}\end{array}$ & $\begin{array}{l}\text { Spontaneous naladixic acid } \\
\text { resistant mutant of Nissle } \\
1917 \mathrm{Str}^{\mathrm{R}}\end{array}$ & Nissle 1917 & 24,44 \\
\hline EDL933 $\mathrm{Str}^{\mathrm{R}} \mathrm{Rif}^{\mathrm{R}}$ & $\begin{array}{l}\text { Spontaneous streptomycin } \\
\text { resistant mutant of EDL933 }\end{array}$ & EDL933 & 38 \\
\hline $\begin{array}{l}\text { EDL933 } \mathrm{Str}^{\mathrm{R}} \\
\Delta p p s A \Delta p c k A: \text { :cam }\end{array}$ & $\begin{array}{l}\text { Double deletion mutant of } \\
\text { EDL933 } \mathrm{Str}^{\mathrm{r}} \text {, carrying cat in } \\
\text { the } p c k A \text { deletion and } \\
\text { retaining the pO157 } \\
\text { virulence plasmid }\end{array}$ & $\begin{array}{l}\text { EDL933 ppsA- } \\
p c k A \text { - mutant }\end{array}$ & 42,32 \\
\hline
\end{tabular}


Table 2. Primers

\begin{tabular}{|l|l|}
\hline Primer designation & Sequence \\
\hline E.coli specific Cy-3 probe (red) & 5'-/5Cy3/CACCGTAGTGCCTCGTCATCA-3' \\
\hline Eubacteria FitC probe (green) & 5'-GCTGCCTCCCGTAGGAGT/36-FAM/-3' \\
used for FISH & \\
\hline 16S V4 forward used for & 5'-TCG TCG GCA GCG TCA GAT GTG TAT \\
community analysis sequencing & AAG A-3' \\
\hline 16S V4 reverse used for & 5'-GTC TCG TGG GCT CGG AGA TGT GTA \\
community analysis sequencing & TAA G-3' \\
\hline
\end{tabular}



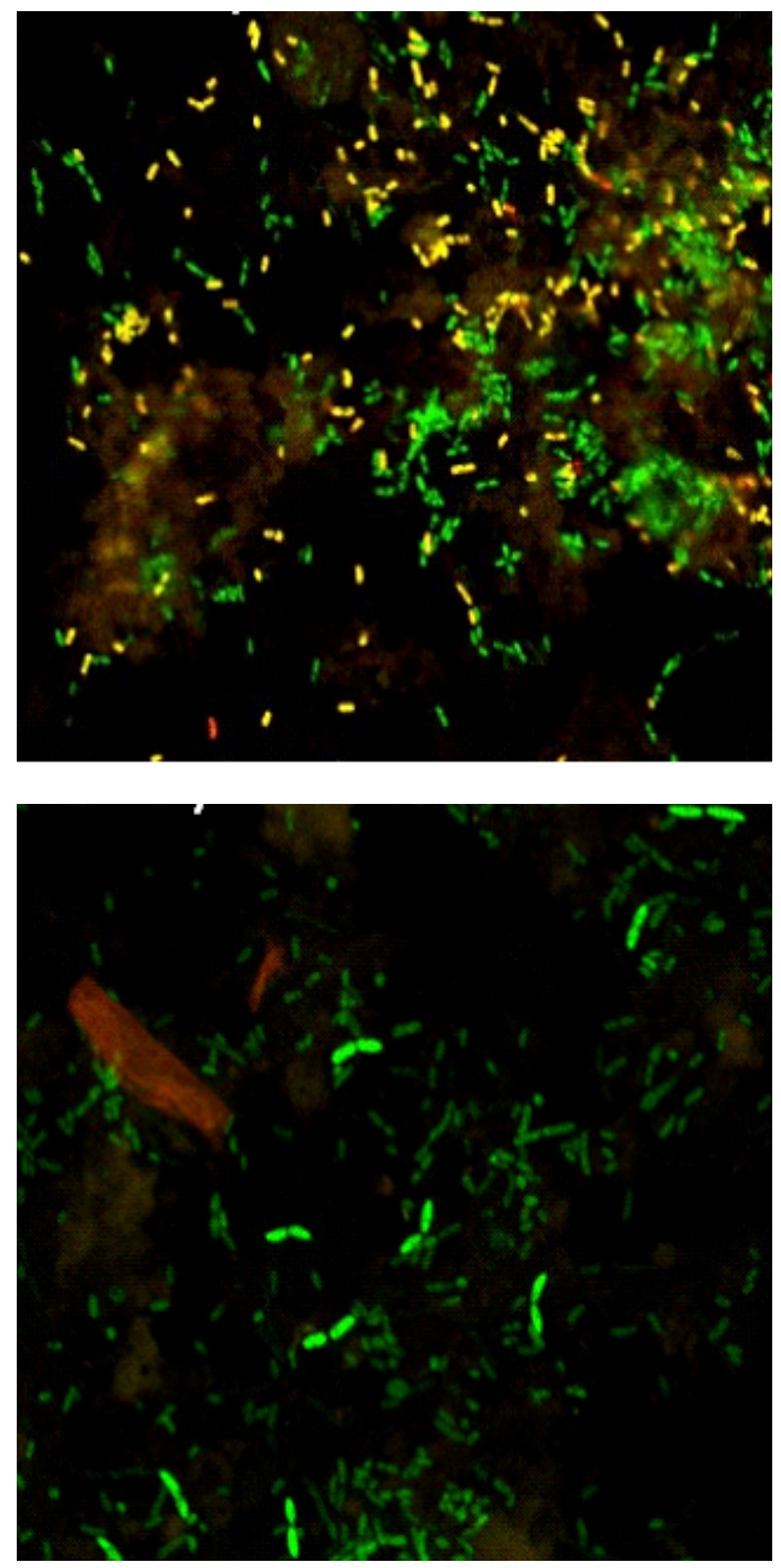

Fig. 1 FISH images of the early in vitro system with (top) and without (bottom) E. coli taken from day 0 samples. Both populations are intact. Red bacterial cells represent E. coli labeled by the Cy3-probe, while green bacterial cells represent all Eubacteria labeled by the FitC-probe. 


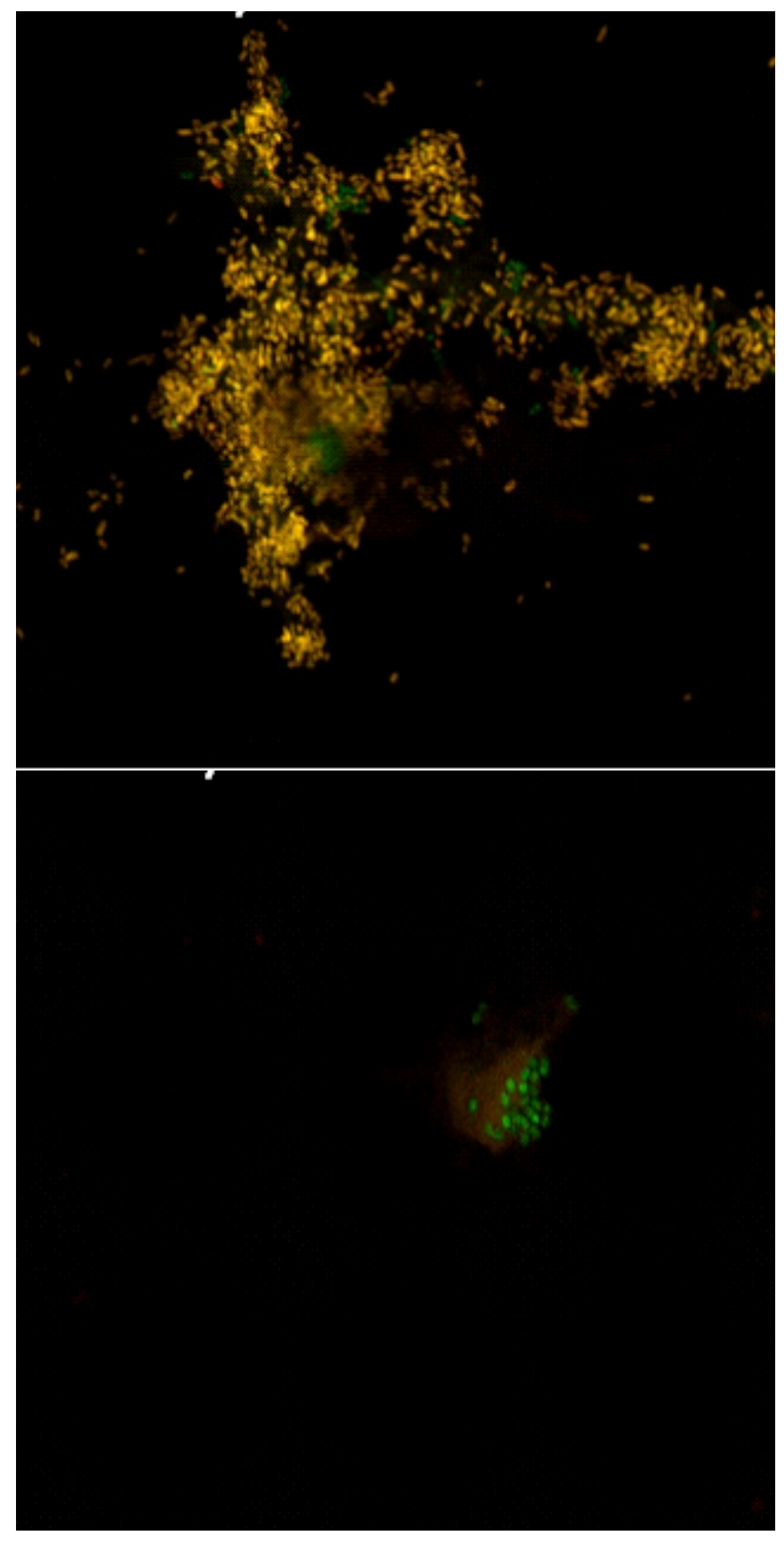

Fig. 2 FISH images of the early in vitro system with (top) and without (bottom) E. coli taken from day 3 samples. When $E$. coli is present, it grows out of proportion and takes over the system, and in both systems the rest of the population is mostly lost. Red bacterial cells represent E. coli labeled by the Cy3-probe, while green bacterial cells represent all Eubacteria labeled by the FitC-probe. 


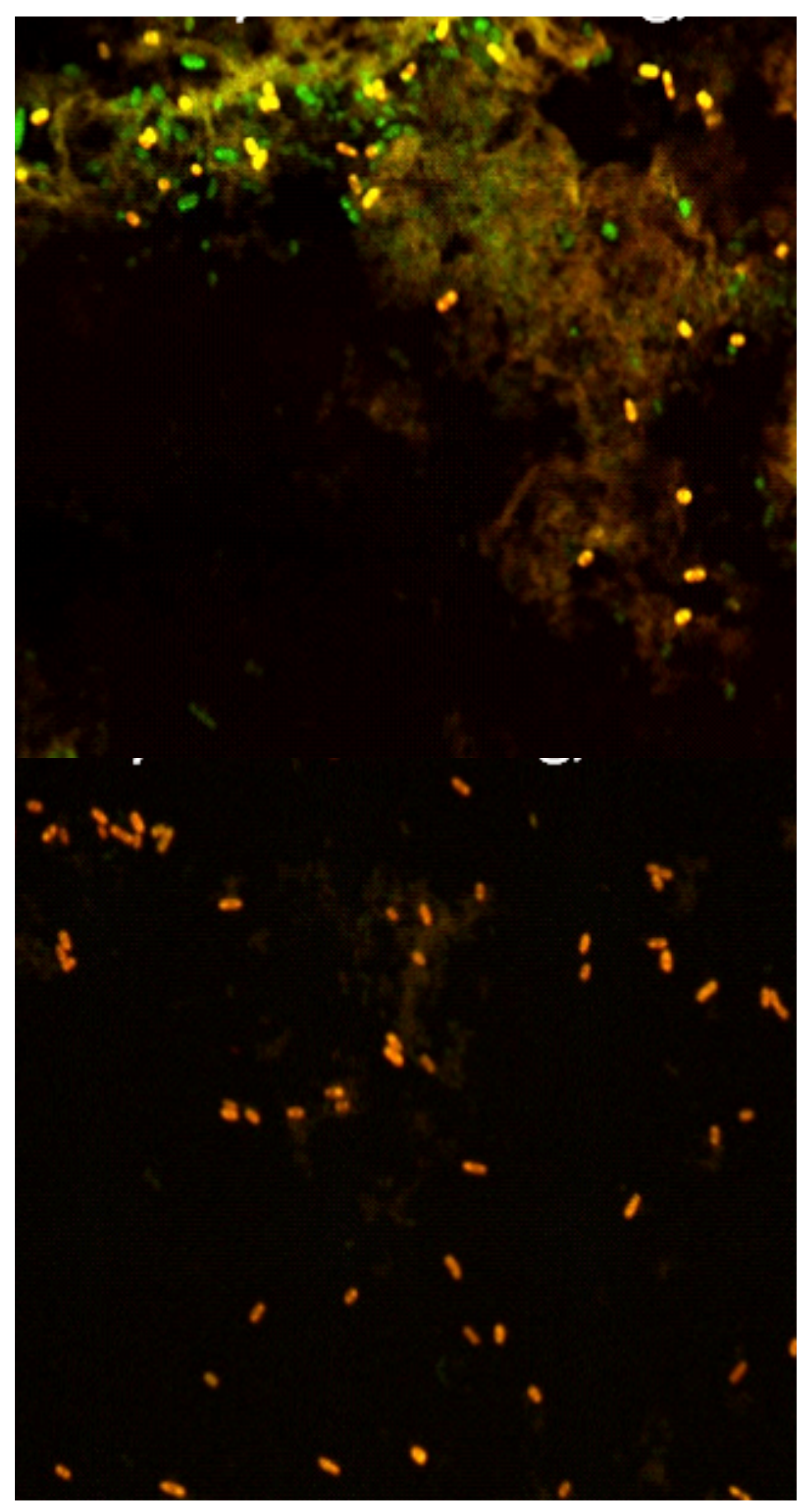

Fig. 3 FISH images of the in vitro system with mucin concentration increased to $500 \mathrm{ug} / \mathrm{ml}$ taken from day 5 (top) and day 6 (bottom) samples. While increasing the mucin concentration improved the longevity of the system, most of the population is still lost beyond day 5 . Red bacterial cells represent E. coli labeled by the Cy3-probe, while green bacterial cells represent all Eubacteria labeled by the FitC-probe. 

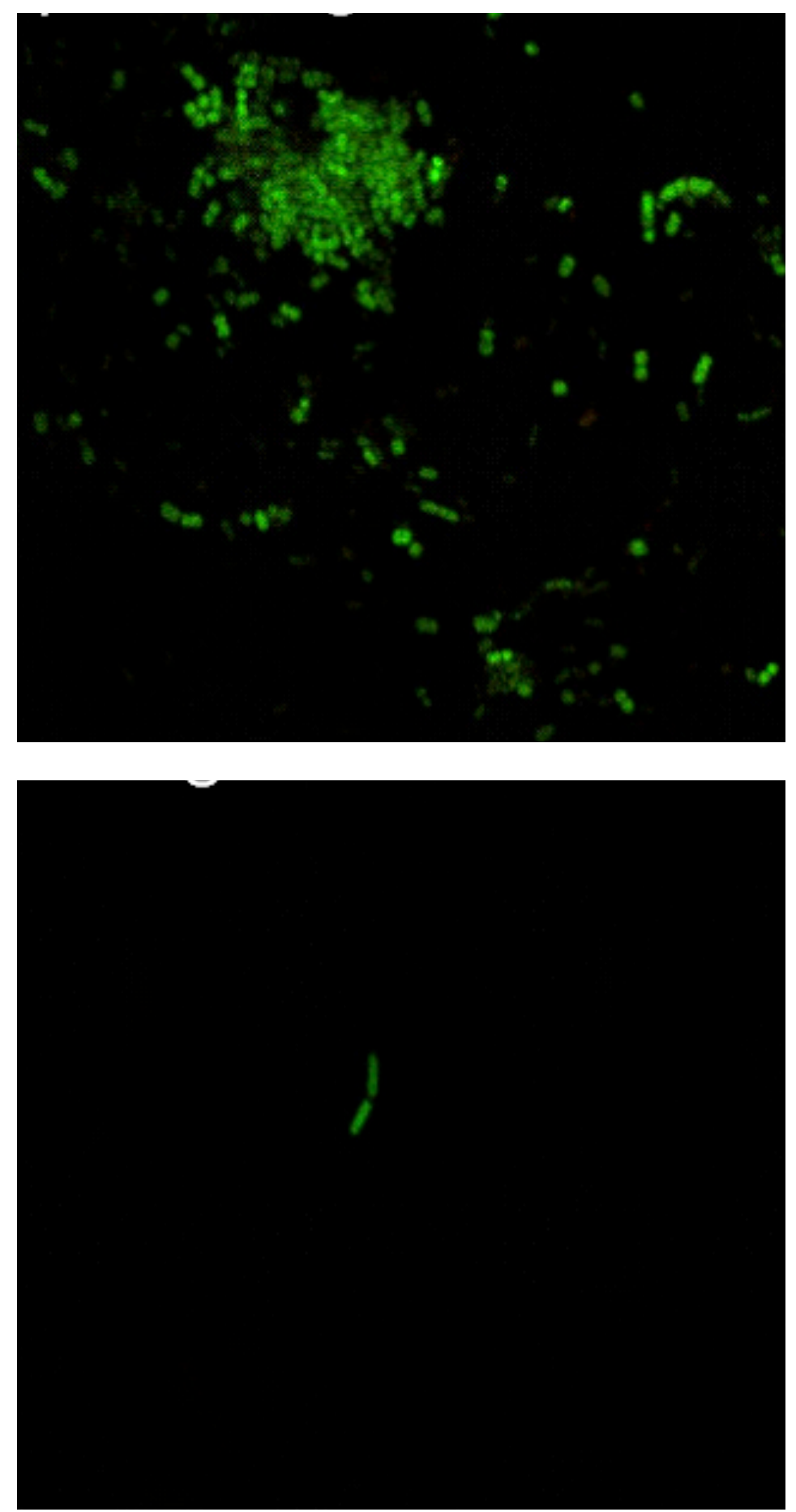

Fig. 4 FISH images of the in vitro system after adding $0.3 \%$ agarose without $E$. coli taken from day 6 samples (top) and before adding agarose taken from day 6 samples (bottom). Even without the E. coli present, agarose has improved the survivability of the population within the in vitro system. Red bacterial cells represent $E$. coli labeled by the Cy3-probe, while green bacterial cells represent all Eubacteria labeled by the FitC-probe. 


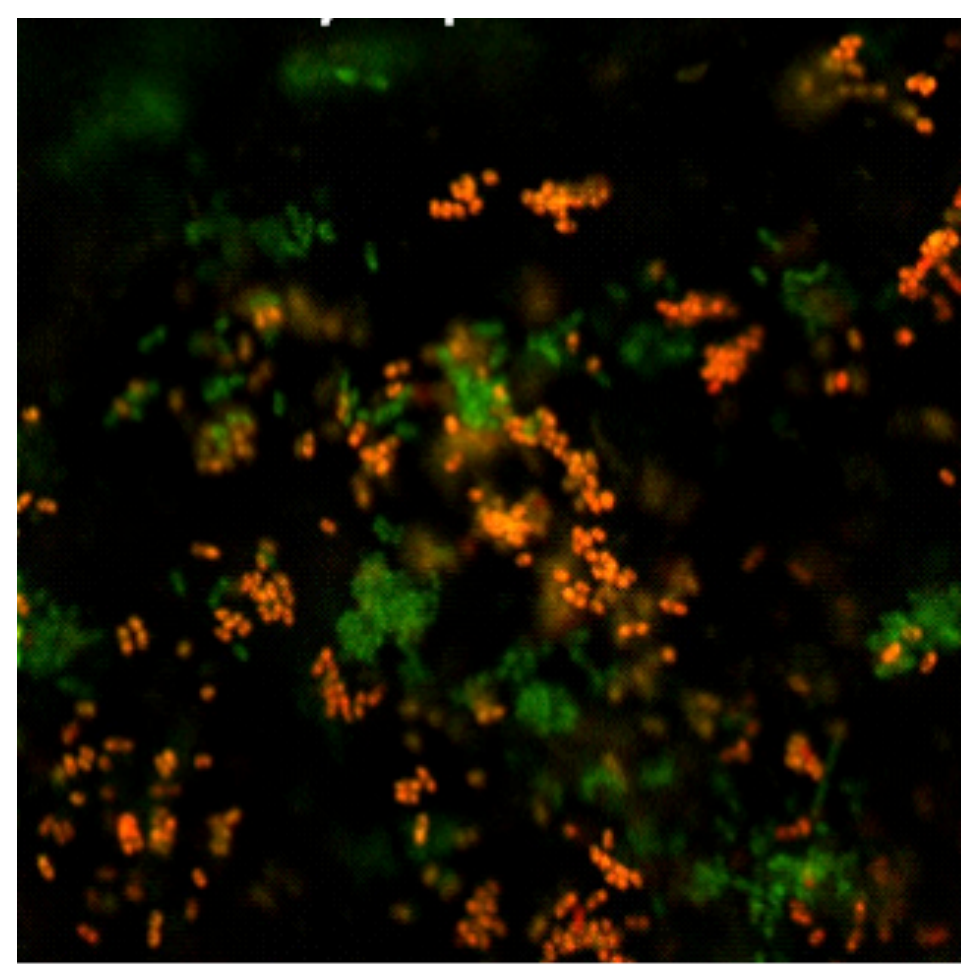

Fig. 5 FISH image taken from in vitro experiment in which mice were precolonized with $E$. coli for 3 days prior to collection into the in vitro system, taken from day 7 in vitro samples. The E. coli is no longer growing to take over the entire population, and the rest of the organisms are able to survive and form biofilm communities. Red bacterial cells represent $E$. coli labeled by the Cy3-probe, while green bacterial cells represent all Eubacteria labeled by the FitC-probe. 


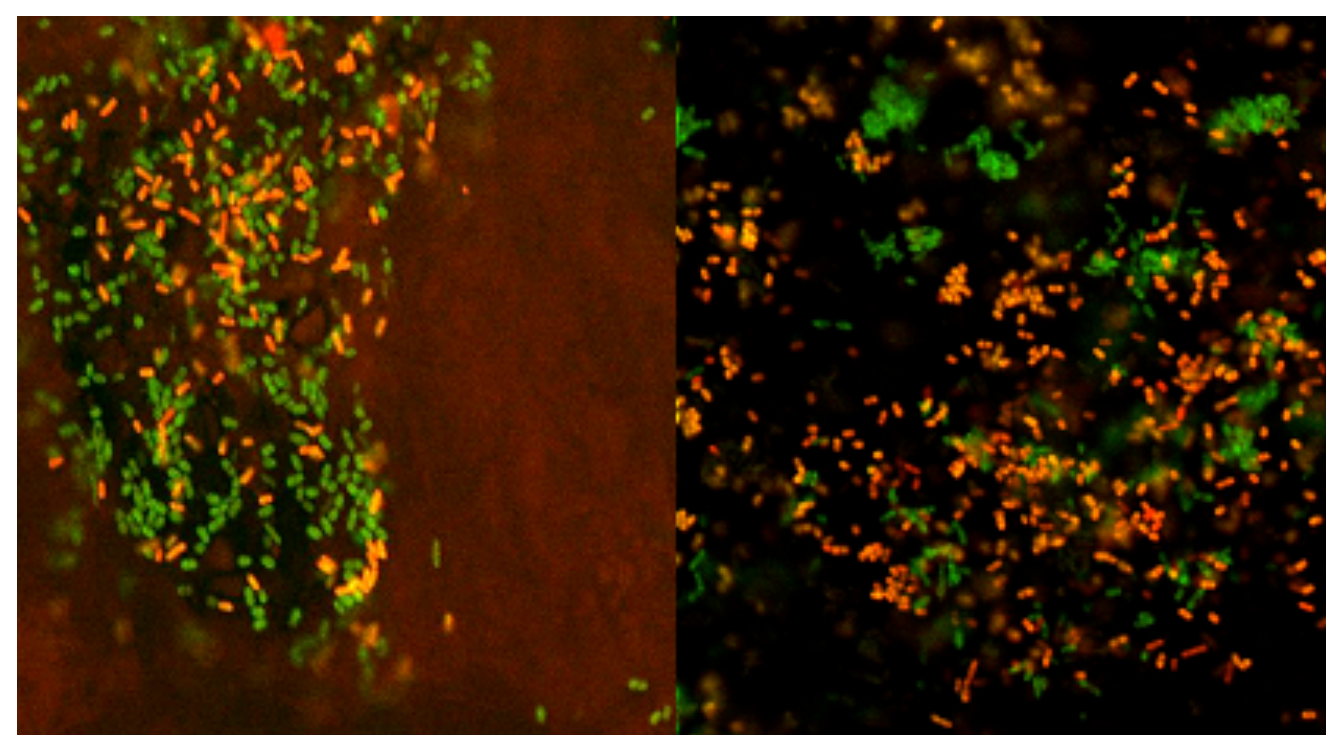

Fig. 6 Comparison of a FISH imaged biofilm of in vivo samples from a mouse colonized with Nissle 1917 for 10 days (left) and in vitro samples in which a mouse was precolonized with Nissle 1917 for 3 days prior to being collected into the in vitro system, taken from day 7 in vitro samples (right). 

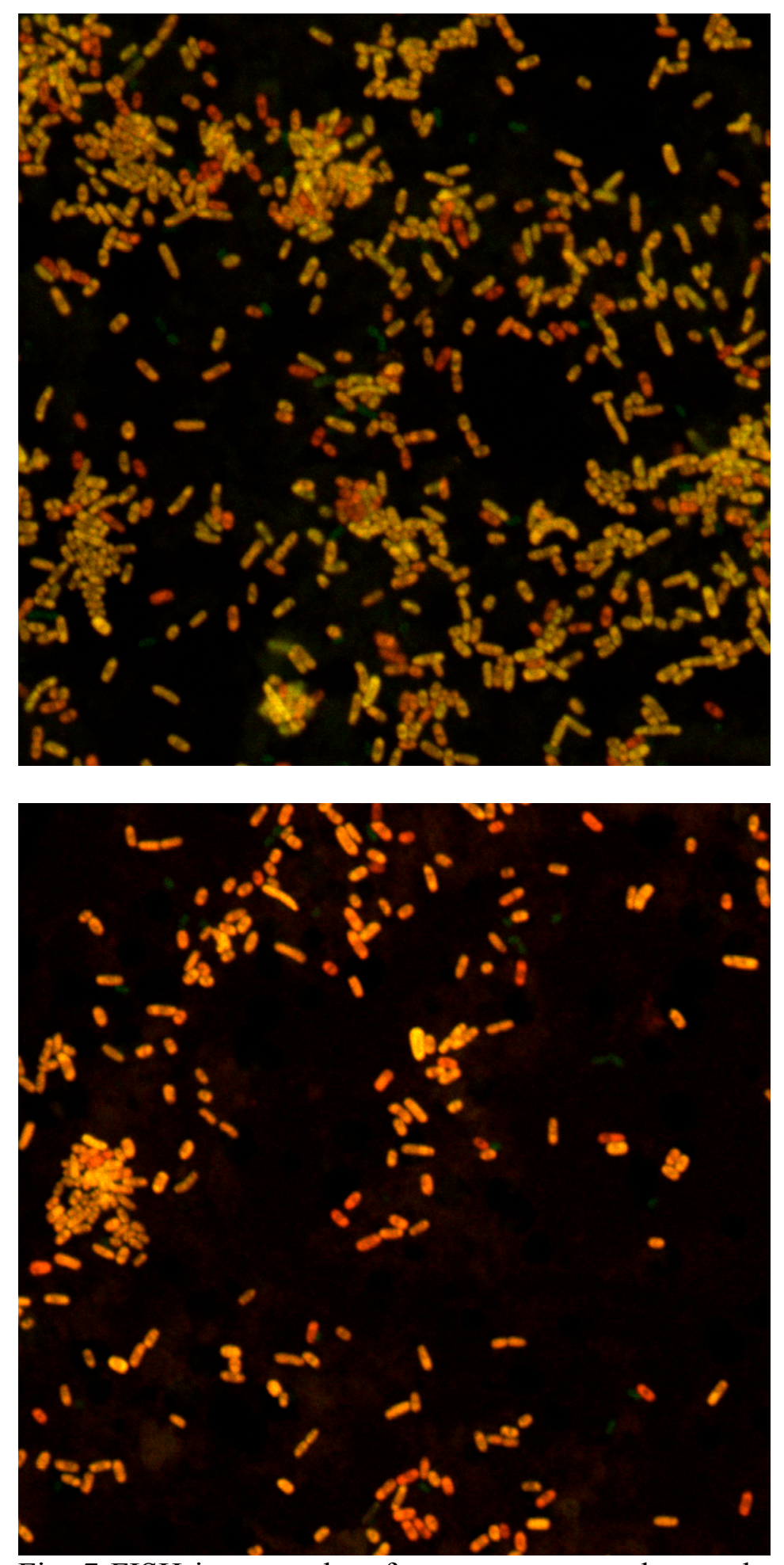

Fig. 7 FISH images taken from in vitro samples on day 7 in which either no mucin (above) or no Cleland's reagent (below) was added. These images show the importance of the mucin and Cleland's reagent in preserving the community within the in vitro system. Red bacterial cells represent $E$. coli labeled by the Cy3-probe, while green bacterial cells represent all Eubacteria labeled by the FitC-probe. 

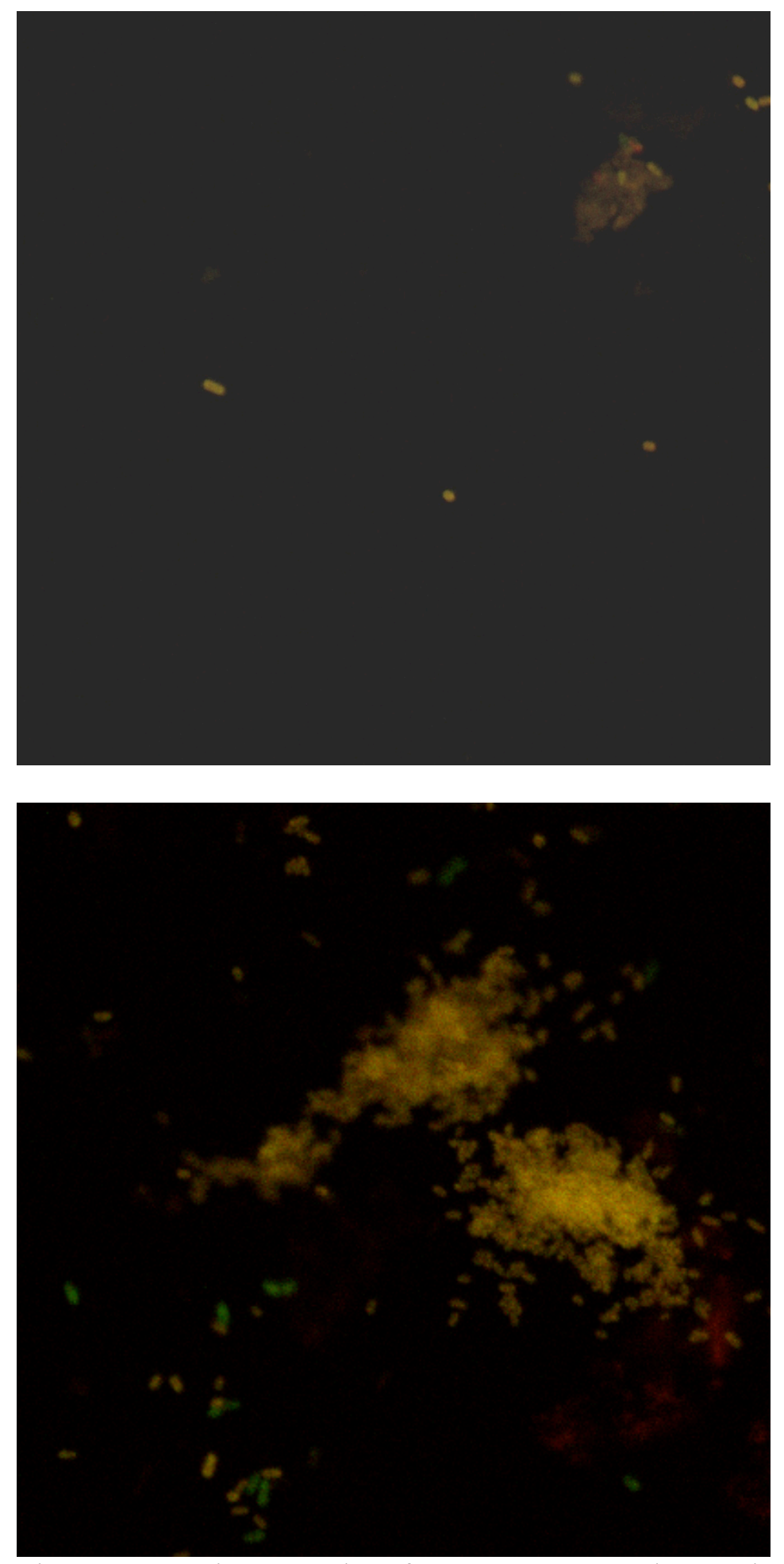

Fig. 87 FISH images taken from in vitro samples on day 7 in which either no mucus (above) or only $0.2 \mathrm{mg} / \mathrm{ml}$ mucus (below) was added. Decreasing the mucus concentration results in a loss of a majority of the population, with $E$. coli taking over as the majority of surviving cells. Red bacterial cells represent $E$. coli labeled by the Cy3-probe, while green bacterial cells represent all Eubacteria labeled by the FitCprobe. 


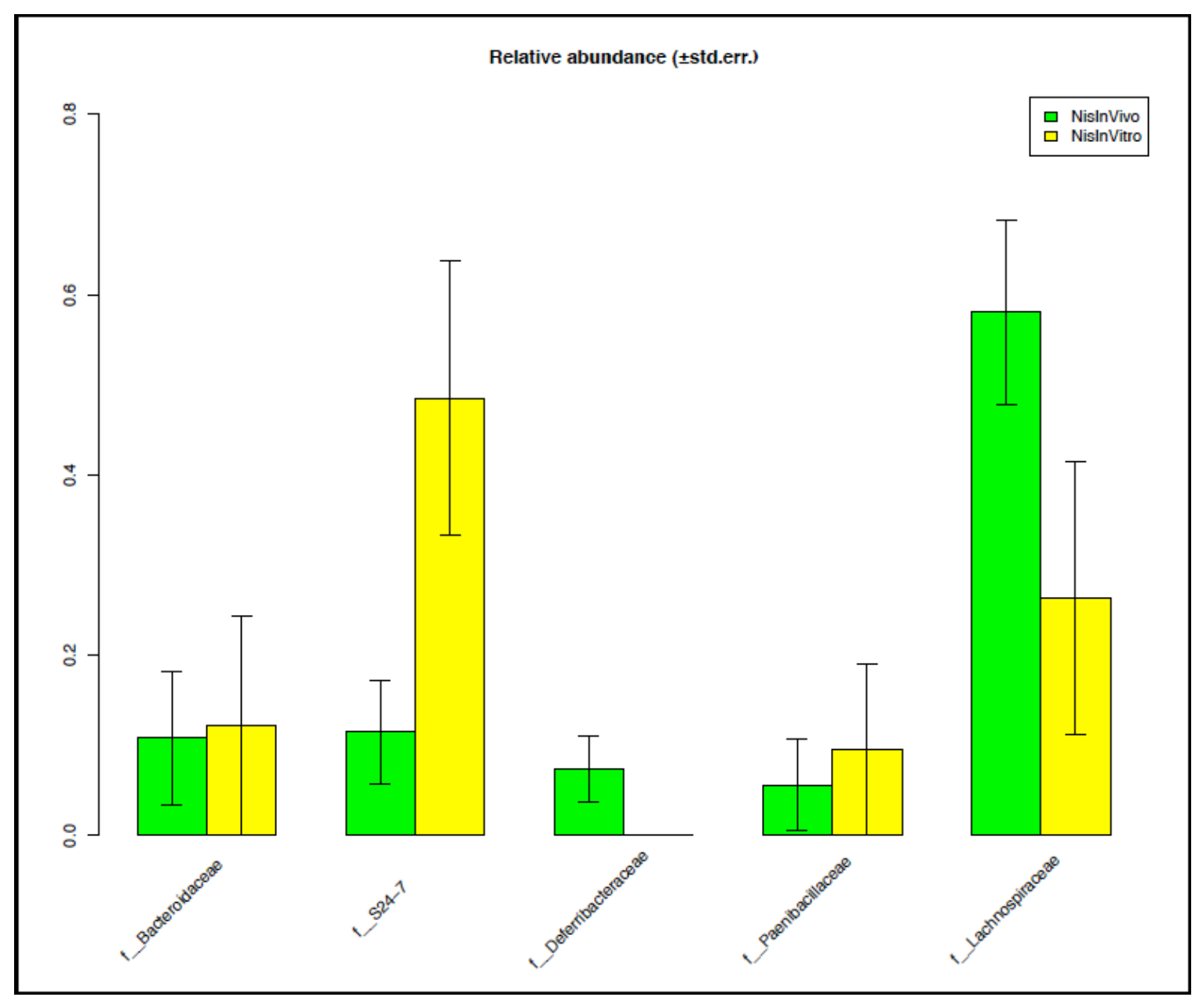

Fig. 9 Bar plot showing relative abundance of major families in mice colonized with Nissle 1917 for 10 days (green) and in vitro samples in which mice were precolonized with $E$. coli for 3 days prior to collection into the in vitro system, taken from day 7 in vitro samples. While there seems to be a difference in terms of s24-7 and Deferribacteracaea, the differences are not statistically relevant and both mice and in vitro samples have similar levels of representation from the same major families. Error bars indicate standard error of the mean. 


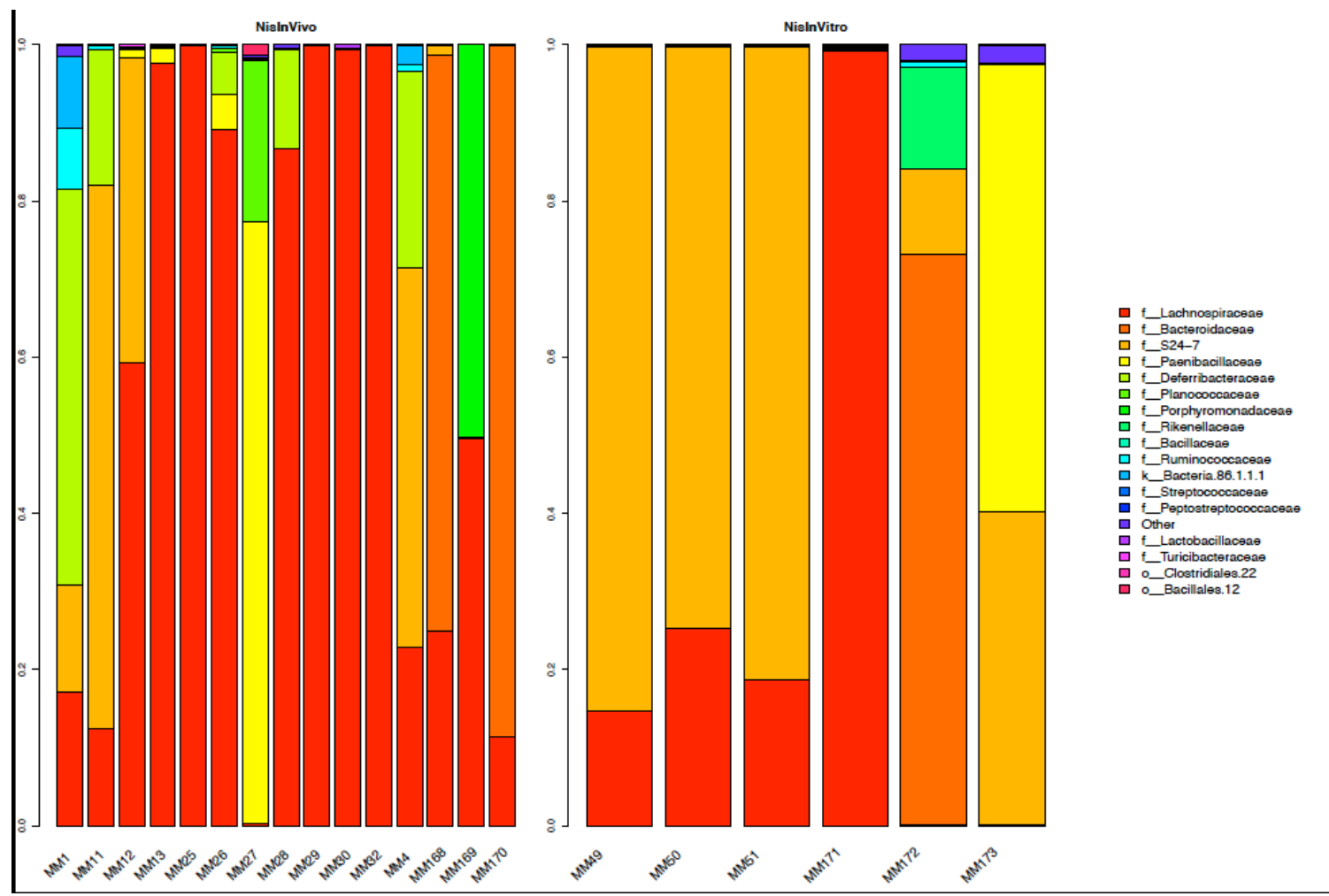

Fig. 10 Stacked bar plot showing relative abundance of Nissle 1917 in vivo (left) and in vitro (right) at the family level. The stacked bars are showing the same data as is seen in the relative abundance graphs, but separates the individual samples to better highlight the variation amongst hosts. 

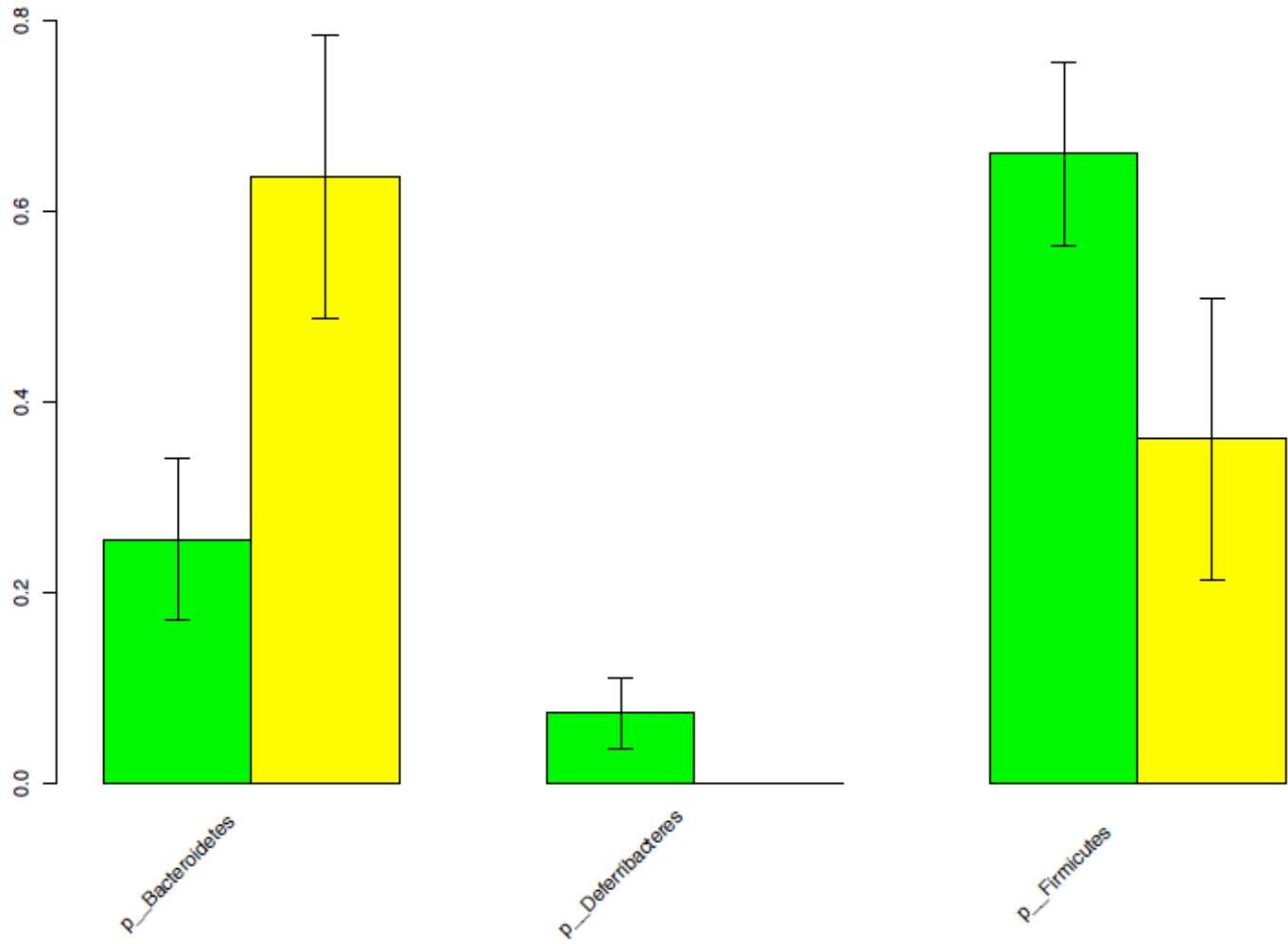

Fig. 11 Bar plot showing relative abundance of major phyla in mice colonized with Nissle 1917 for 10 days (green) and in vitro samples in which mice were precolonized with $E$. coli for 3 days prior to collection into the in vitro system, taken from day 7 in vitro samples. None of the differences seen are enough to be statistically significant $(\mathrm{P}>0.05)$. Error bars indicate standard error of the mean. 

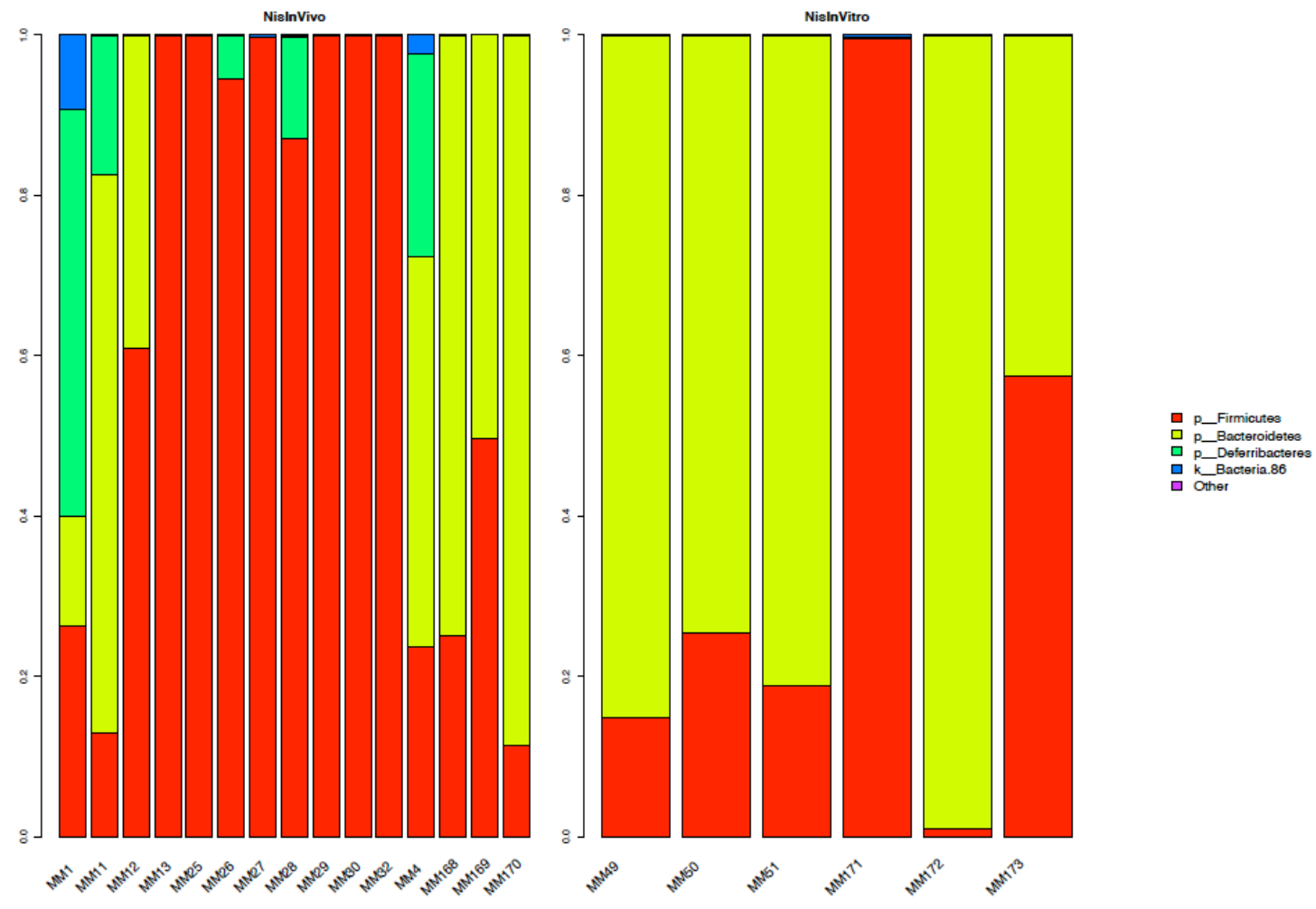

Fig. 12 Stacked bar plot showing relative abundance of Nissle 1917 in vivo (left) and in vitro (right) at the phylum level. The stacked bars are showing the same data as is seen in the relative abundance graphs, but separates the individual samples to better highlight the variation amongst hosts. 

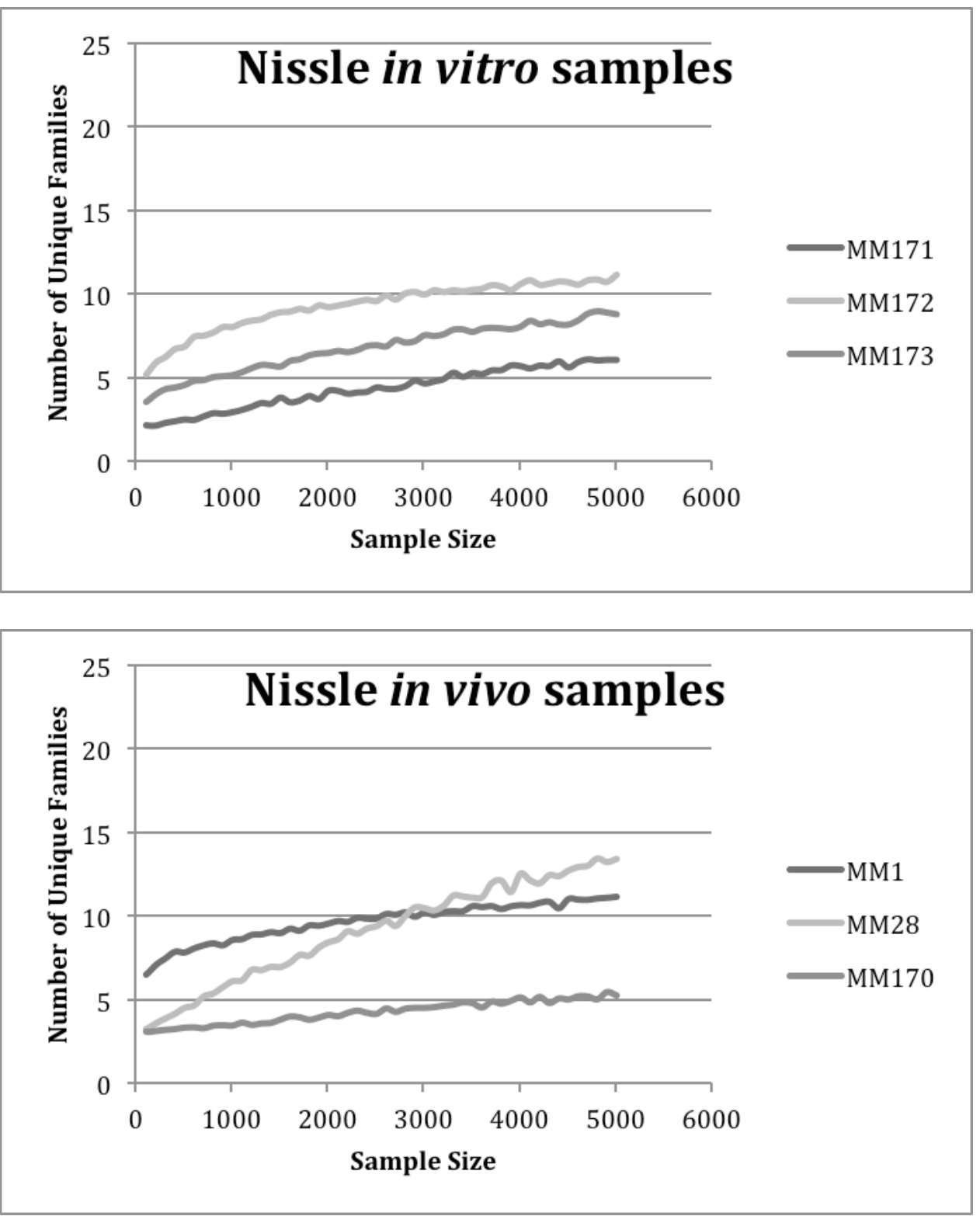

Fig. 13 Crude rarefaction curves of Nissle 1917 samples used to compare richness of diversity in vitro (top) and in vivo (bottom). 


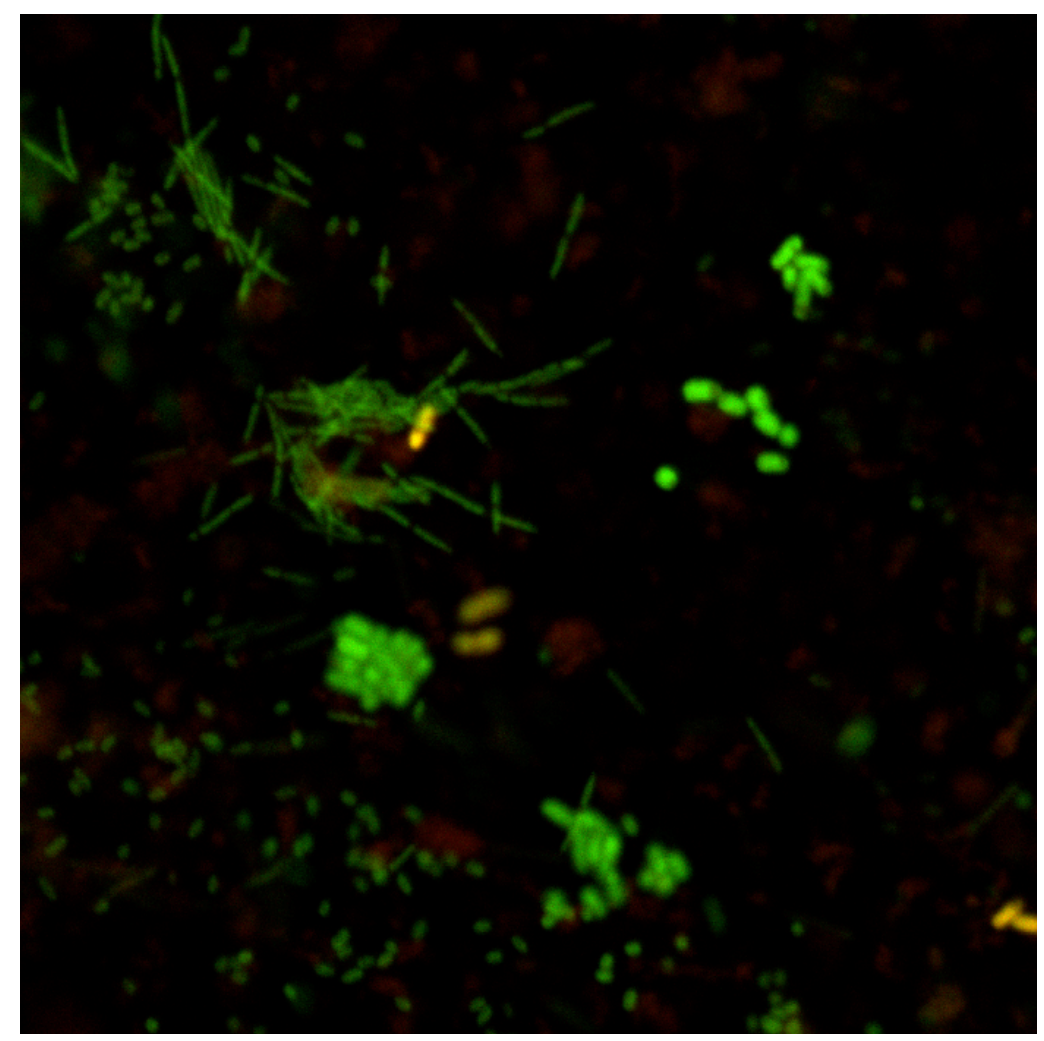

Fig. 14 FISH image of an in vitro sample in which the cecal mucus of an untreated "conventional" mouse was collected into the in vitro system, taken from day 7 in vitro sample. Diversity in the cell morphologies can be seen amongst the organisms present. Red bacterial cells represent E. coli labeled by the Cy3-probe, while green bacterial cells represent all Eubacteria labeled by the FitC-probe. 


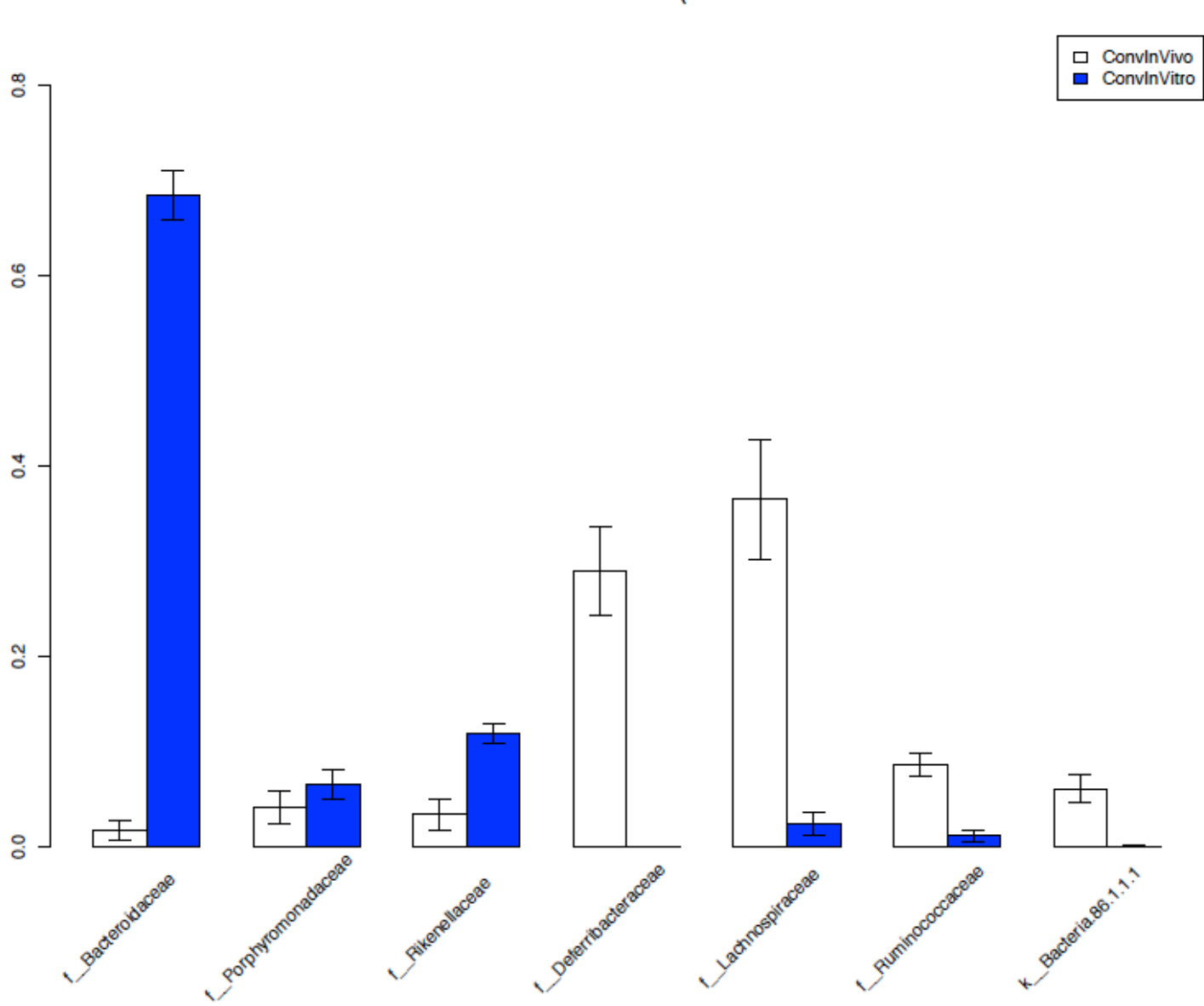

Fig. 15 Bar plot showing relative abundance of major families in untreated "conventional" mice (white) and in vitro samples in which untreated "conventional" mice were collected into the in vitro system (blue), taken from day 7 in vitro samples. Error bars indicate standard error of the mean. Differences between the in vitro and in vivo samples were seen in the Bacteroideaceae $(\mathrm{P}<0.0001)$, Deferribacteraceae $(\mathrm{P}<$ $0.001)$, and Lachnospiraceae $(\mathrm{P}<0.001)$. 


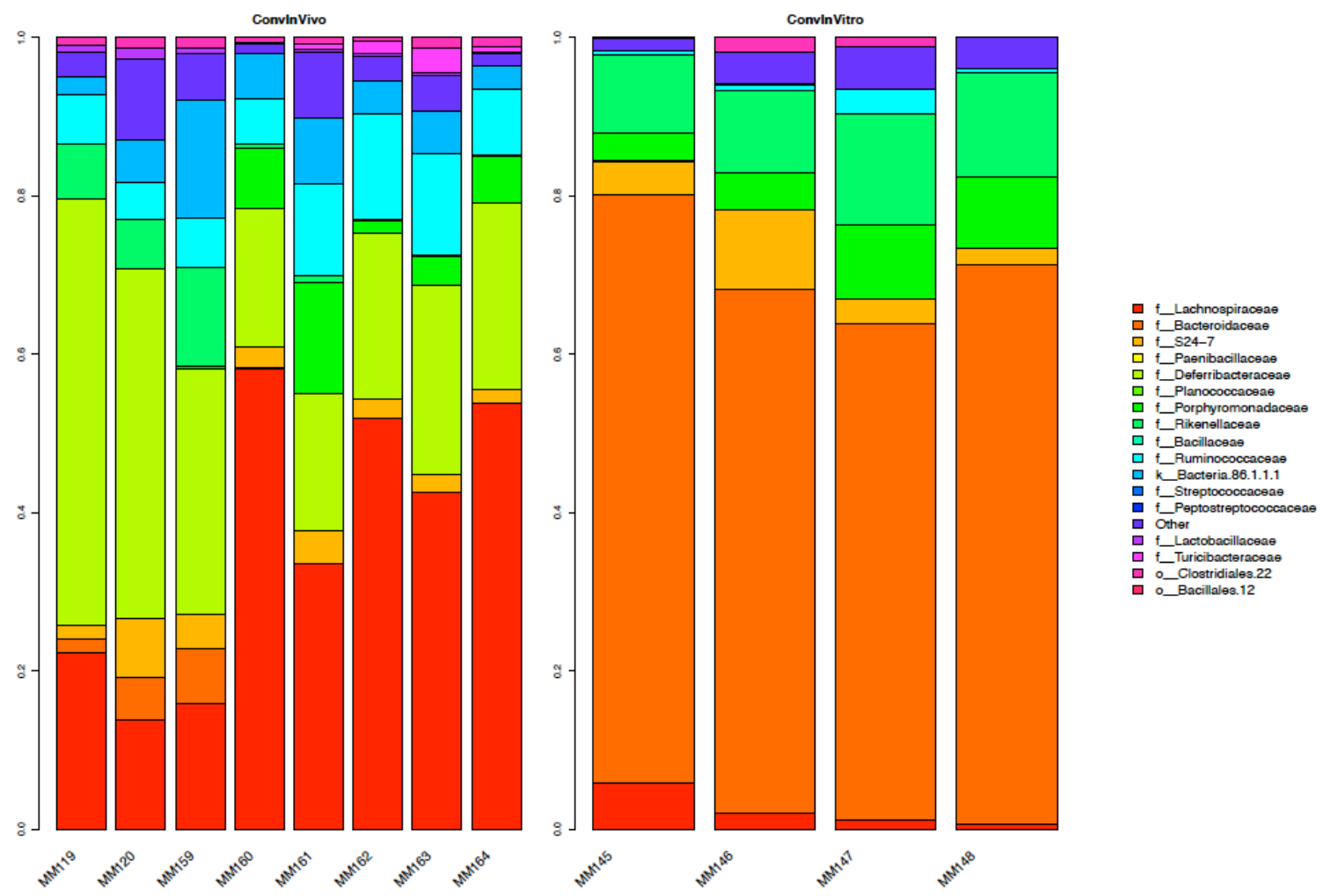

Fig. 16 Stacked bar plot showing relative abundance of conventional in vivo (left) and in vitro (right) at the family level. The stacked bars are showing the same data as is seen in the relative abundance graphs, but separates the individual samples to better highlight the variation amongst hosts. 

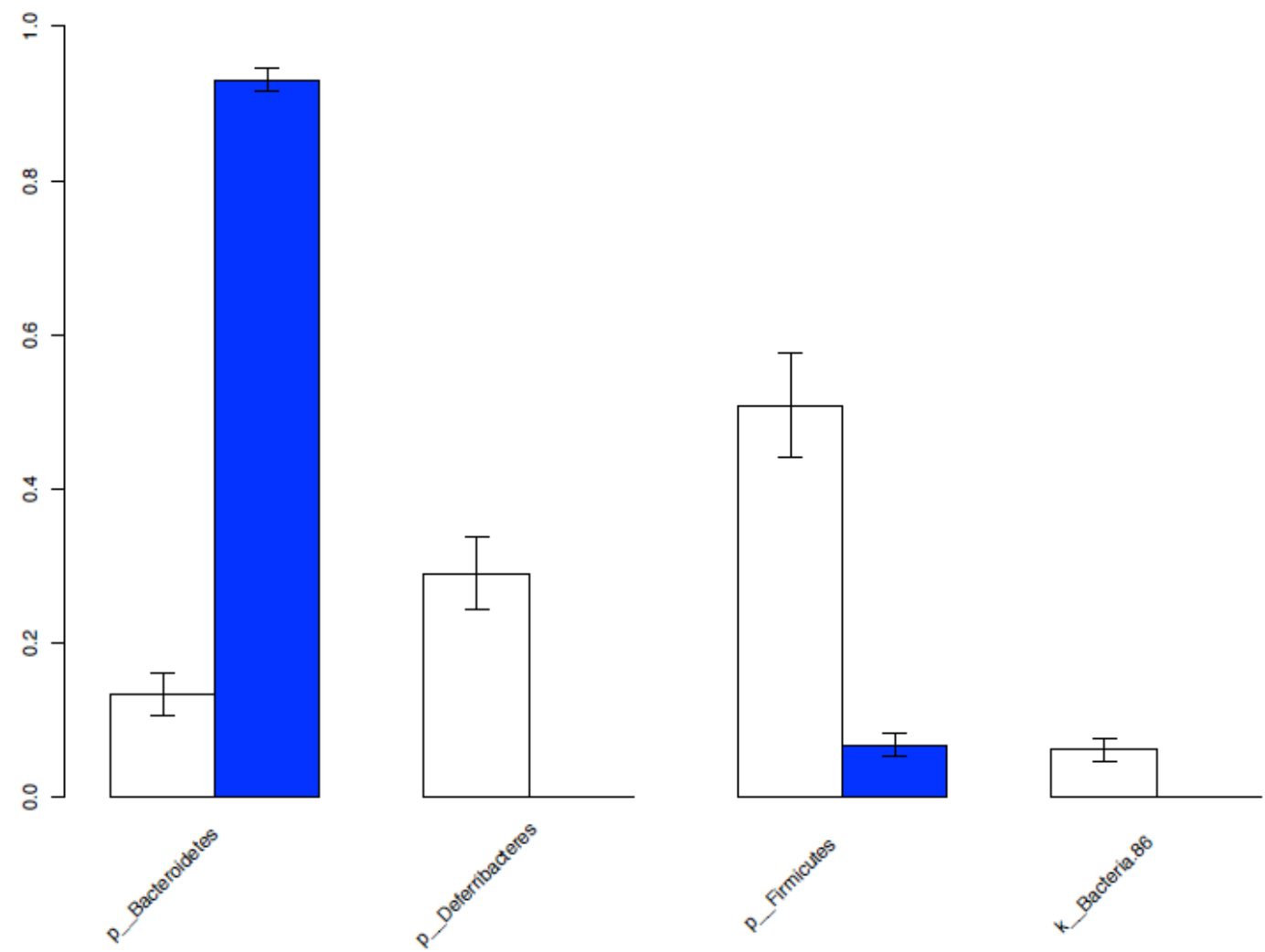

Fig. 17 Bar plot showing relative abundance of major phyla in untreated mice (white) and in vitro samples in which untreated mice collected into the in vitro system (blue), taken from day 7 in vitro samples. Error bars indicate standard error of the mean. At the phylum level, Bacteroidetes were more abundant relative to Firmicutes in the conventional in vitro samples compared to what was seen in the in vivo samples, and Deferribacteres had little representation in vitro. The differences seen between each phylum; Bacteroidetes, Deferribacteres, and Firmicutes, are statistically significant (P $<0.001$ for each). 

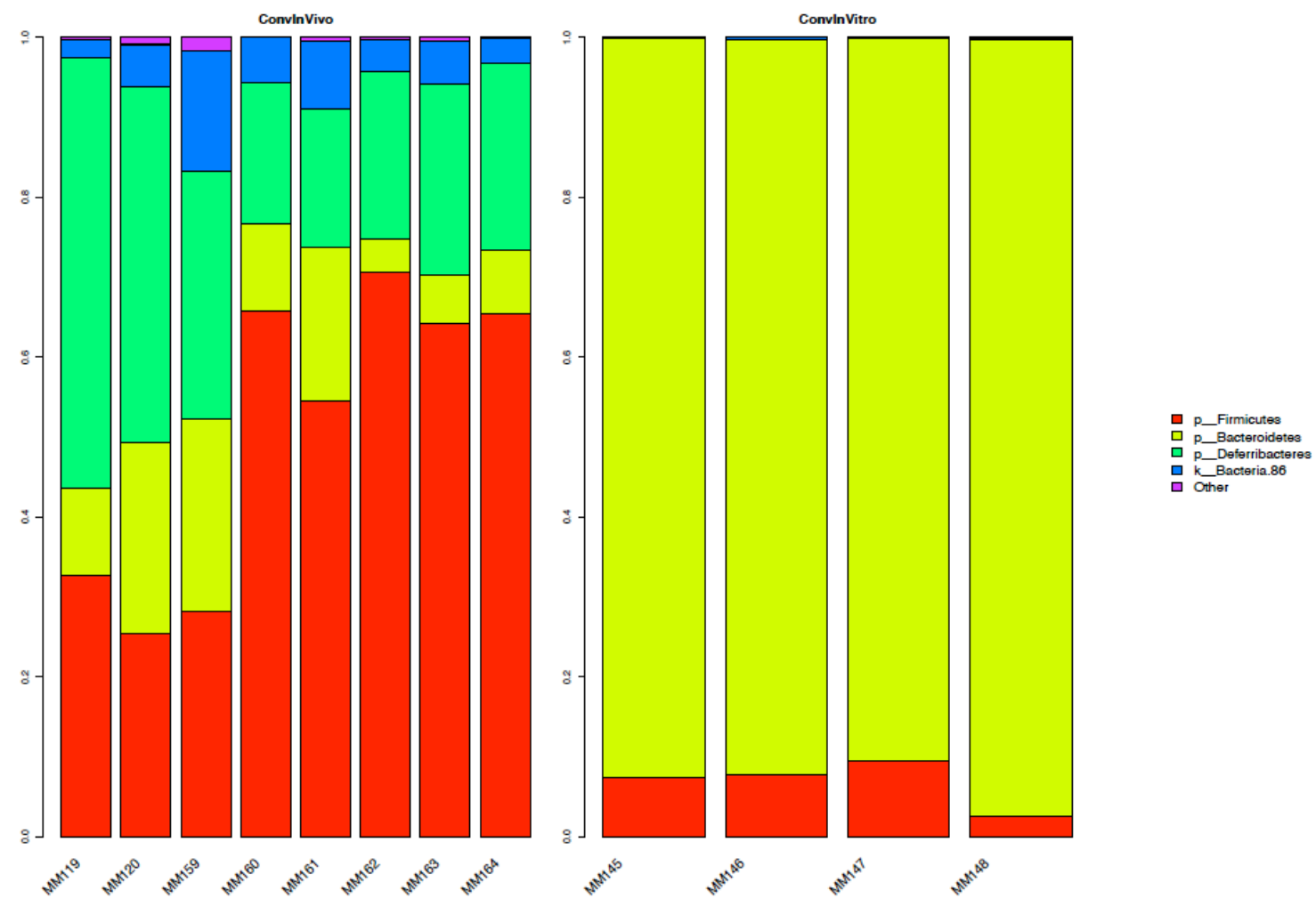

Fig. 18 Stacked bar plot showing relative abundance of conventional in vivo (left) and in vitro (right) at the phylum level. The stacked bars are showing the same data as is seen in the relative abundance graphs, but separates the individual samples to better highlight the variation amongst hosts. 

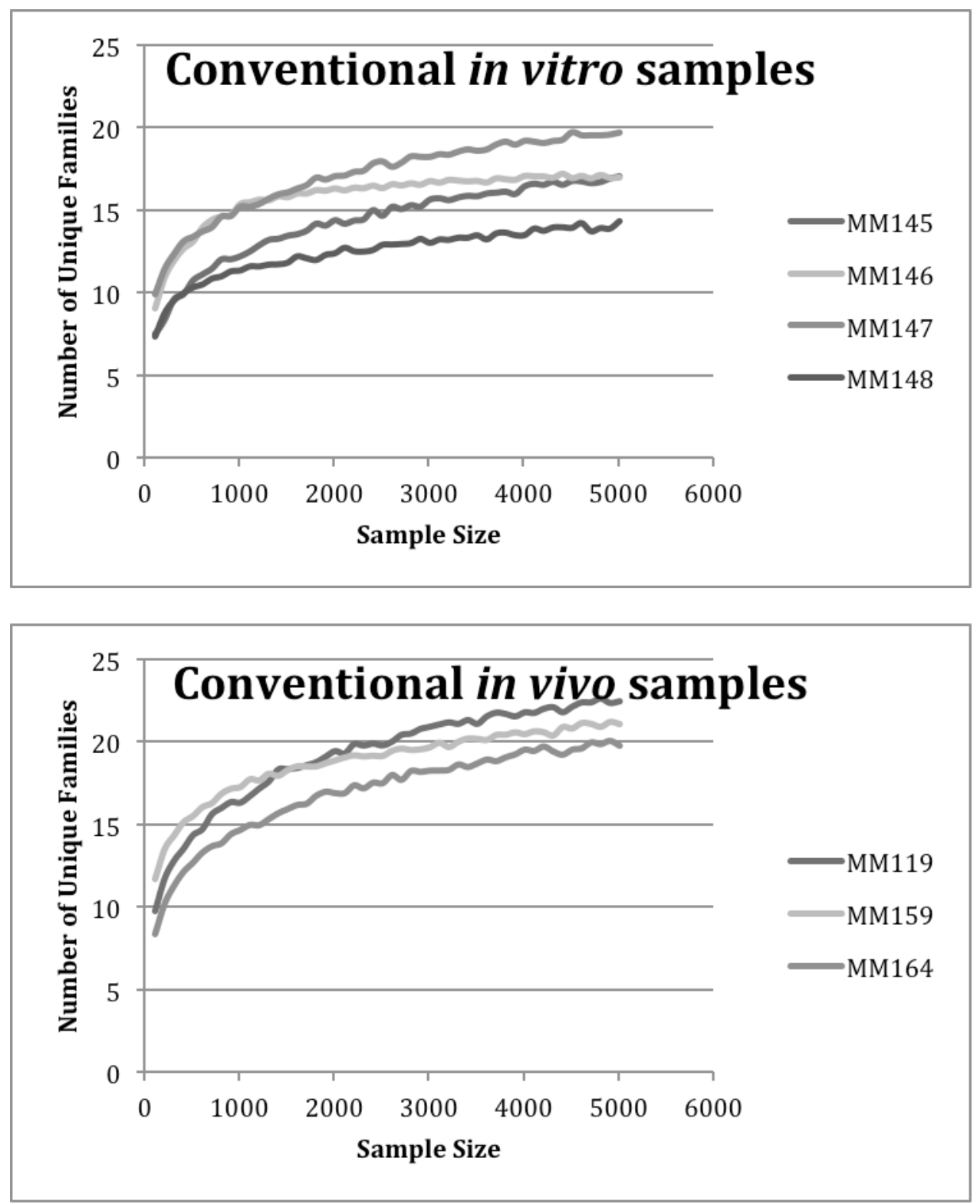

Fig. 19 Crude rarefaction curves of conventional samples used to compare richness of diversity in vitro (top) and in vivo (bottom). 

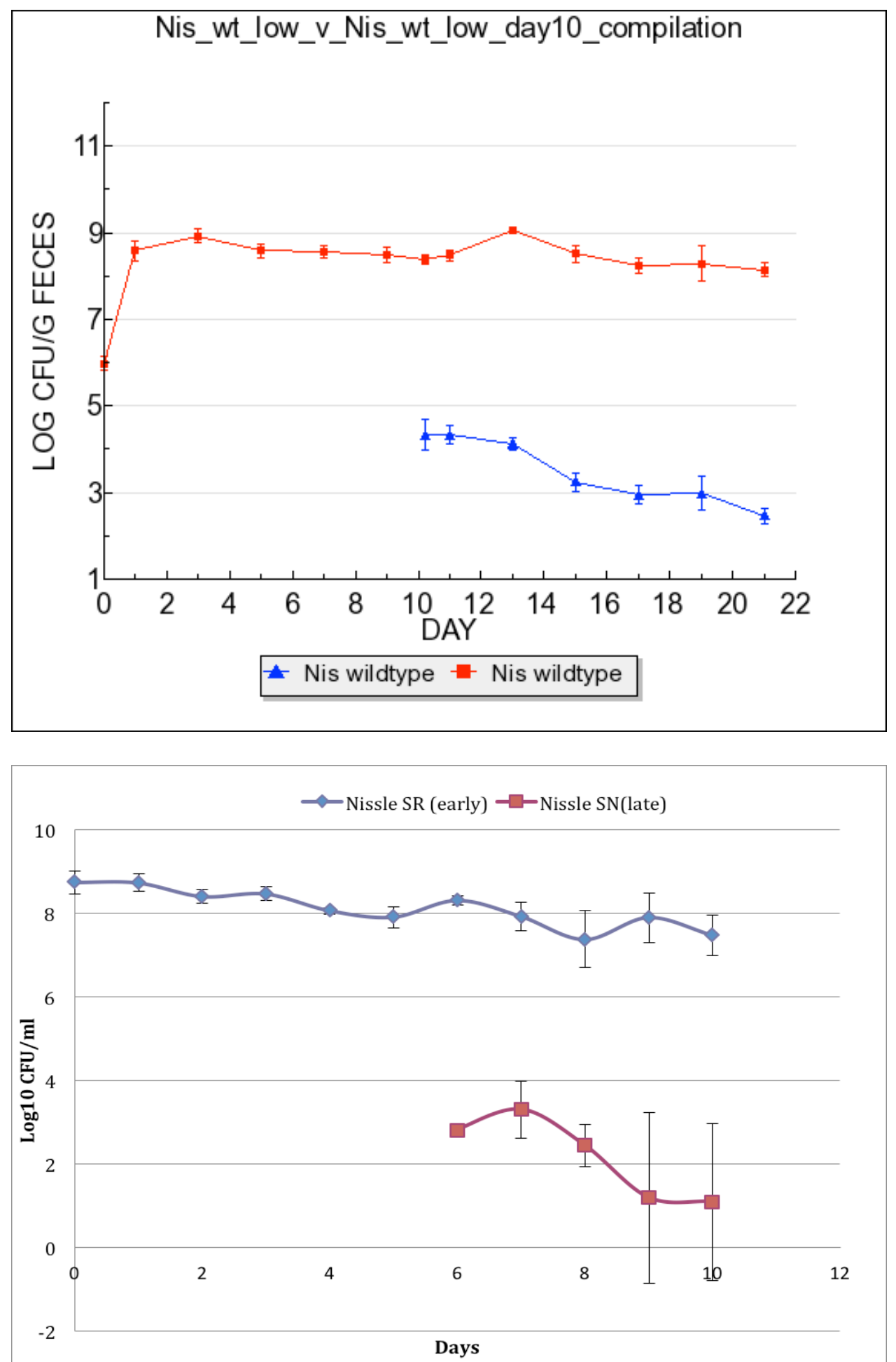

Fig. 20 Competition experiments of Nissle 1917 early vs Nissle 1917 late: in vivo (top) and in vitro (bottom). This shows that colonization resistance is seen in vitro just as it is seen in mice. 

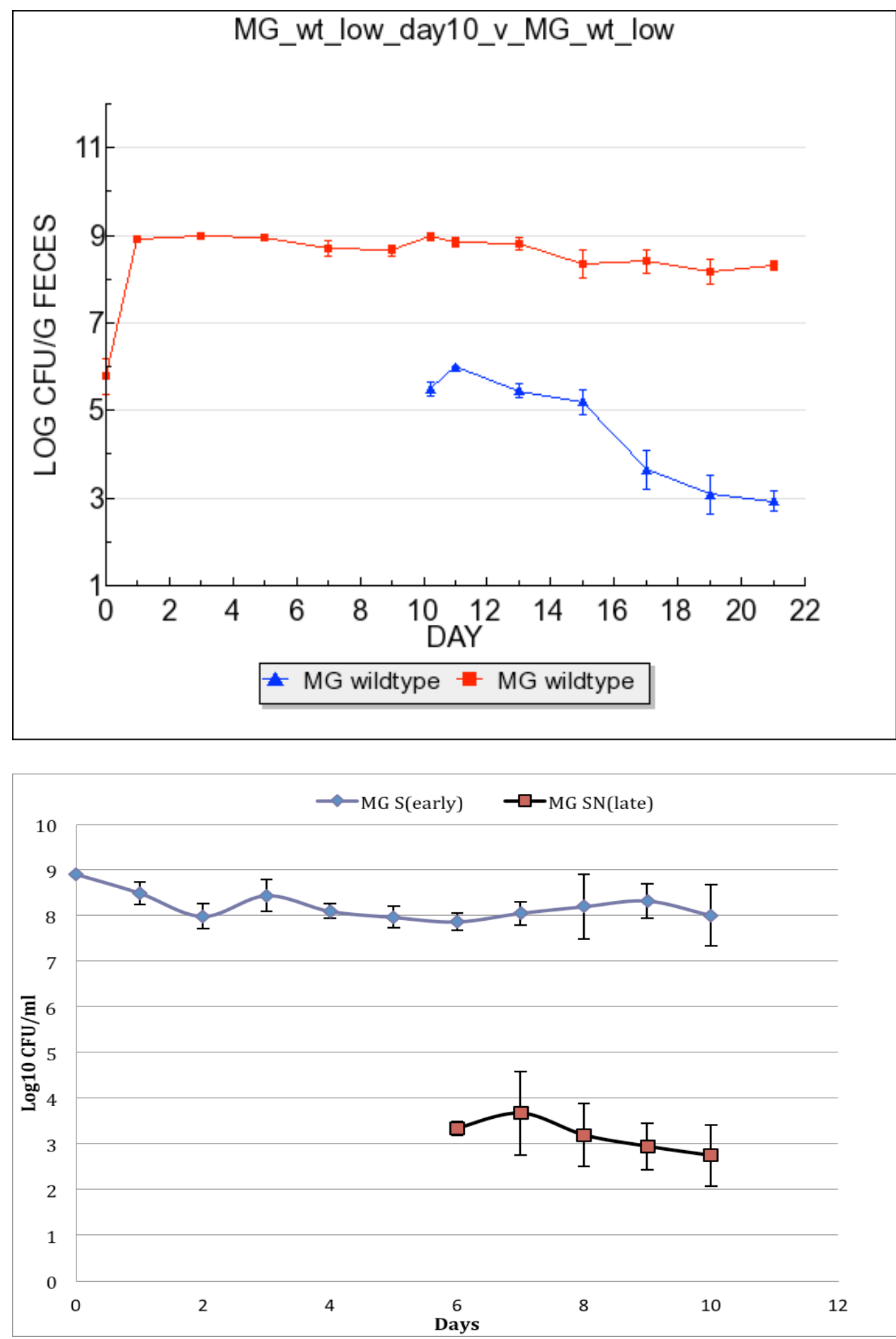

Fig. 21 Competition experiments of MG1655 early vs MG1655 late: in vivo (top) and in vitro (bottom). This shows that colonization resistance is seen in vitro just as it is seen in mice. 

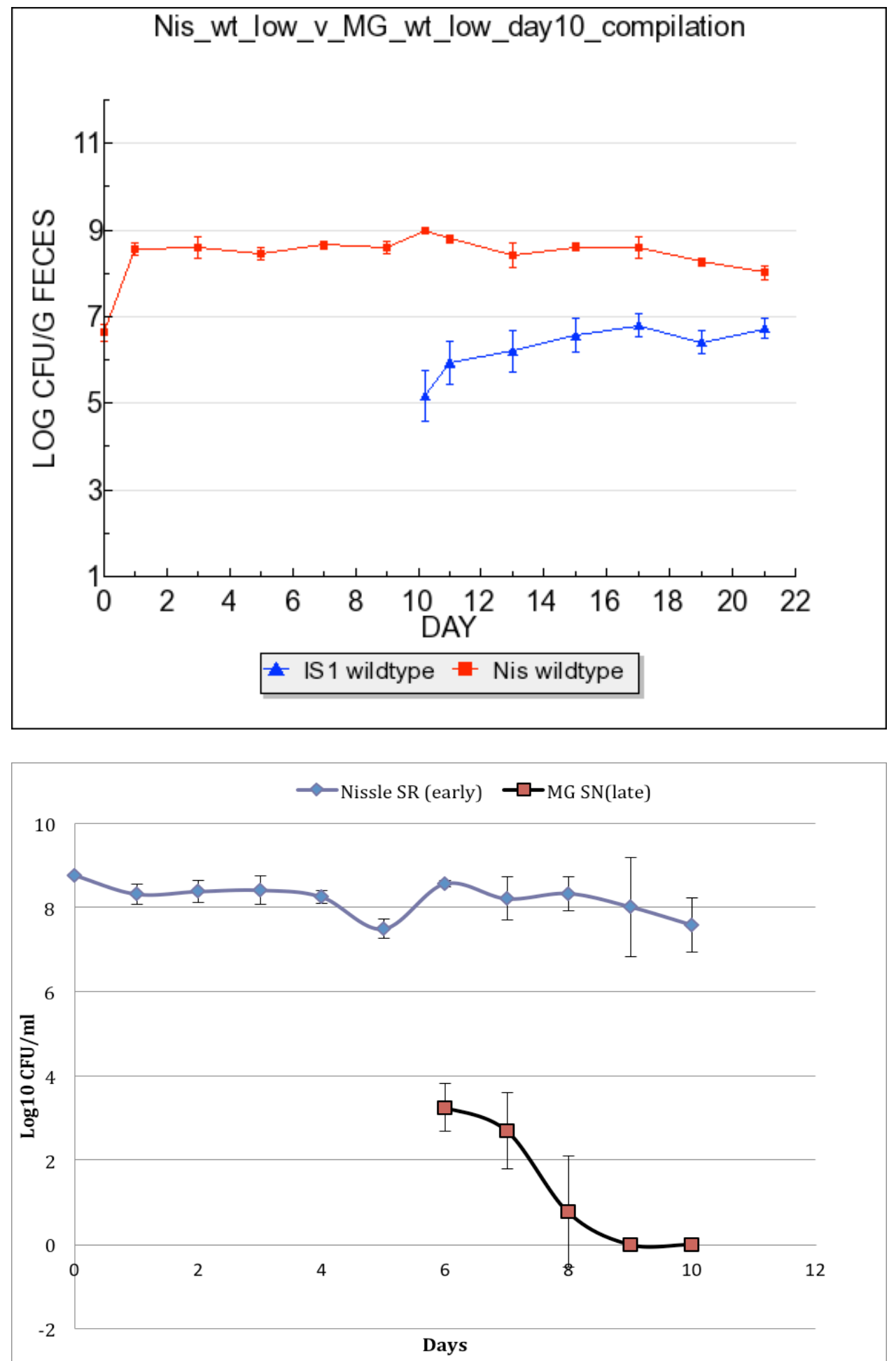

Fig. 22 Competition experiments of Nissle 1917 early vs MG1655 late: in vivo (top) and in vitro (bottom). This shows that not all competitions are mimicked perfectly in the in vitro system, possibly due to limitation of nutrients. 

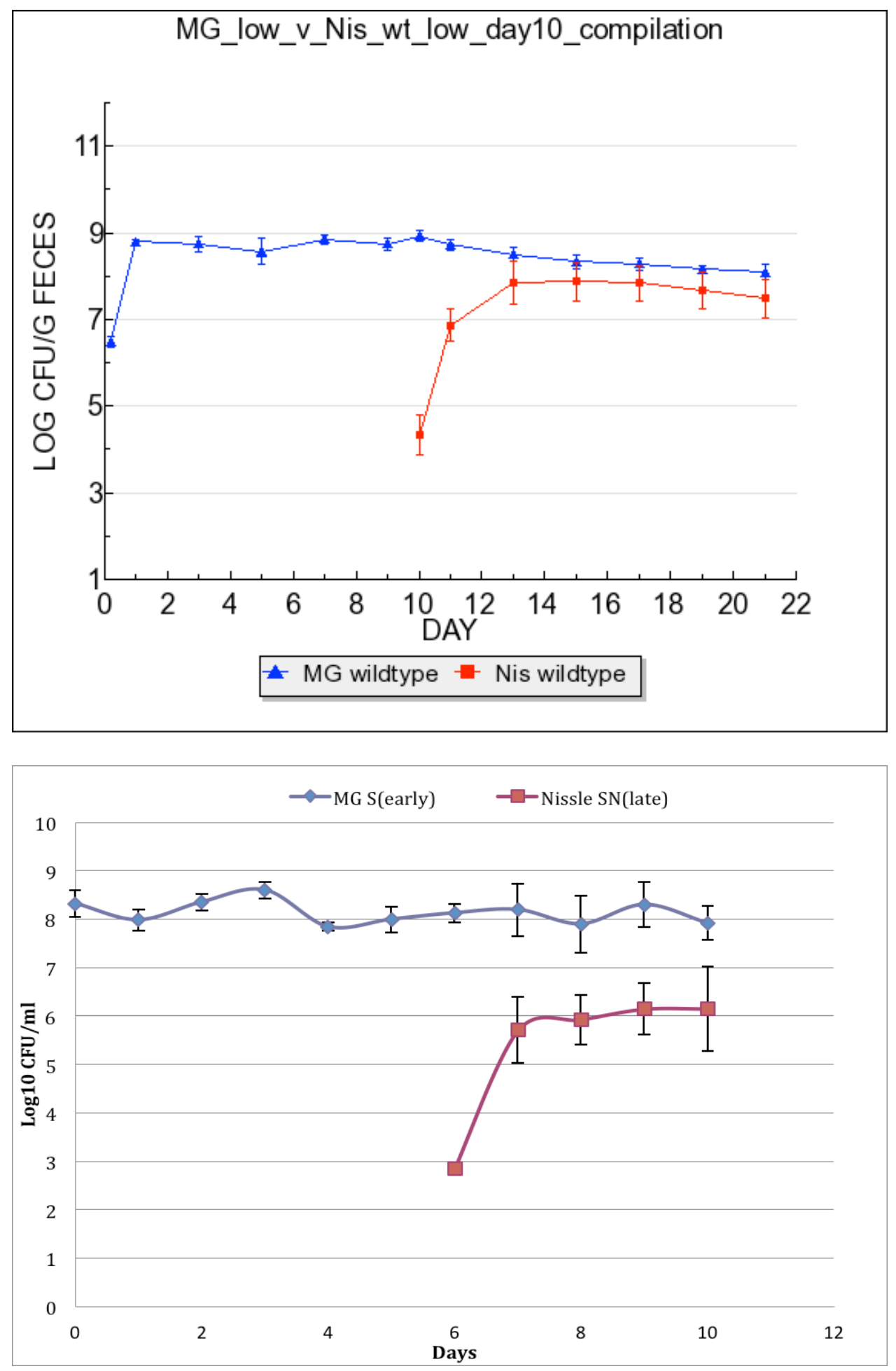

Fig. 23 Competition experiments of MG1655 early vs Nissle 1917 late: in vivo (top) and in vitro (bottom). This shows that competitions in which MG1655 is fed early and Nissle 1917 is fed or spiked in late are similar in mice and in vitro. 

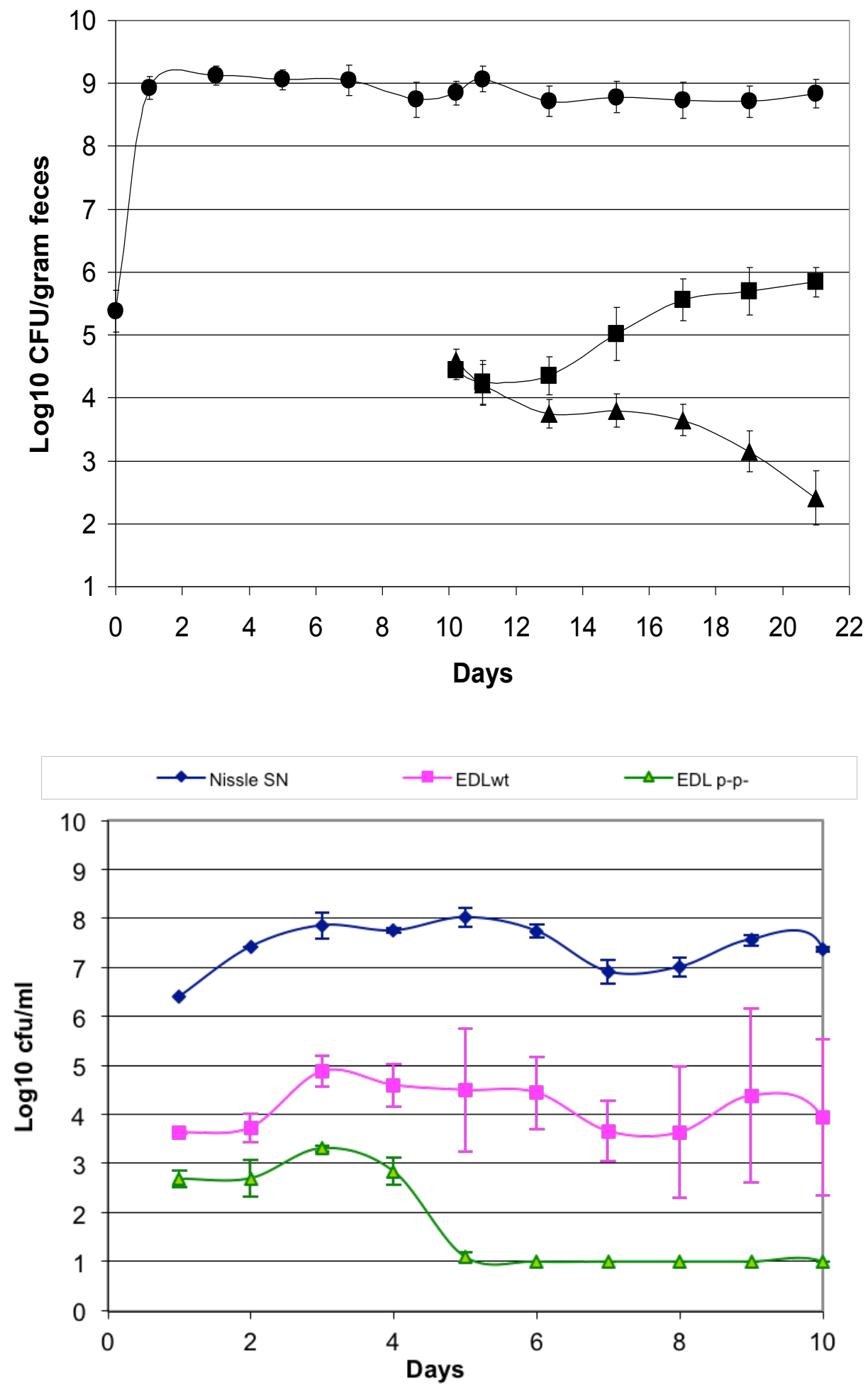

Fig. 24 Competition experiments of Nissle 1917 early vs EDL933 wildtype and EDL933 pckA-ppsA- late: in vivo (top) and in vitro (bottom). Another competition in which the in vitro system mimics what is seen in mice, as the EDL933 gluconeogenic mutant cannot compete and falls out of the system while the wildtype is maintained. 

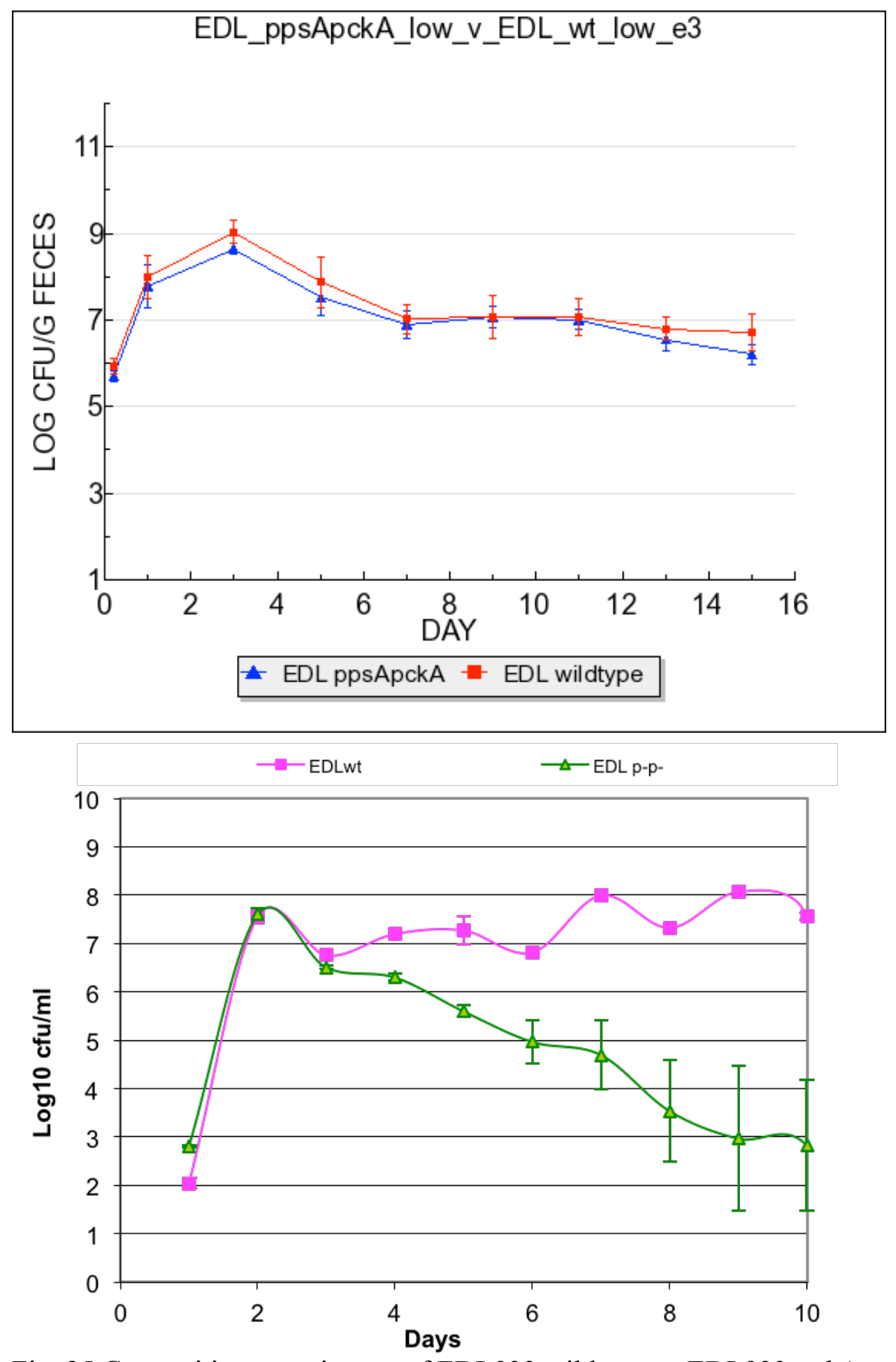

Fig. 25 Competition experiments of EDL933 wildtype vs EDL933 pckA-ppsA-: in vivo (top) and in vitro (bottom). This competition shows that the in vitro system is unable to mimic the mouse perfectly as EDL933 does not switch to gluconeogenic substrates in mice that were not pre-colonized with Nissle 1917, but does switch in the in vitro system. Again likely due to limitation of nutrients. 